\title{
Bibliografía potosina de estudios históricos
}

María Isabel Abella Armella

En cuestiones de política y de historiografía, los potosinos hemos sido como el atole: tardamos un buen tiempo en calentarnos pero también en enfriarnos.

Cuando se trató, en la década de 1820 , de forjar y promulgar una Constitución Política del Estado, fuimos detrás de Jalisco, Nuevo León, Zacatecas, Tamaulipas, Querétaro y otras entidades. Aunque una vez asumida la transformación del orden político colonial con las ideas republicanas, San Luis Potosí fue base y eje de organización de no pocas campañas y proyectos para la consolidación política del pacto federal, así como del movimiento ideológico precursor de la Revolución de 1910 -en la que la viabilidad histórica de dicho pacto fue ratificada.

La historiografía potosina, al menos la referente al periodo que cubre este trabajo, ha transitado, por otra parte, del retraso o la parquedad a la construcción pionera significada por las obras de Manuel Muro y Primo Feliciano Velázquez, de los libros o artículos que exaltan el hallazgo documental a la proliferación de otros de mayores alcances o con pretensiones analiticas, ya se trate de autores aficionados, profesionales, conservadores o liberales, o de la modernidad o arcaísmo de sus metodologias. En este proceso, la organización y valoración de las fuentes bibliográficas -como las de otro tipo- han jugado y seguirán jugando una destacada función.

San Luis Potosí cuenta con un importante acervo bibliográfico (véase la parte VIII de esta obra), fundado y enriquecido por el trabajo de investigadores pacientes y apasionados de la "historia matria", como Ramón Alcorta, José Francisco Pedraza, Joaquín Meade y Rafael Montejano y Aguiñaga, por quienes hemos descubierto las vetas de la bibliografia regional.

La presente obra es el resultado de una rigurosa selección de 323 fichas de las casi mil que integran nuestra investigación bibliográfica original, selección hecha con la finalidad de excluir todo lo relativo a fuentes históricas (leyes, licigios, informes, estatutos, memorias, discursos, etc.) para destacar la labor historiográfica que sobre la región se ha realizado.

Superando la clasificación o presentación tradicional, onomástica y cronológica de las obras, decidí situarlas y comentarlas por tema. Esto redundará en beneficio de los investigadores y de los lectores en general, pues la división de la bibliografía según los diversos y contrastantes procesos políticos, económicos, regionales y locales, ideológicos y culturales, que tuvieron su desarrollo en el estado -desde el surgimiento de la Independencia hasta los años de la posrevolución (1923)- permite una lectura más pro- 
funda y clara del proceso. Hay que aclarar a este respecto que, por contener indicios básicos de la identidad histórica regional, se incluyeron aquí algunas obras que desbordan nuestra cronología.

Una de las más importantes limitaciones de este trabajo, es que sólo se incluyen aquéllos estudios históricos que -como libros, folletos o artículos de revista publicados como sobretiros- se encuentran clasificados en las bibliotecas que pude consultar. A pesar de esto, los comentarios introductorios a cada parte de esta bibliografía, así como los que hacemos sobre cada una de las obras que la componen, son producto no sólo del trabajo de recopilación que nos ocupó varios meses, sino de las reflexiones, hallazgos, dudas y certidumbres a que nos ha conducido un proyecto de investigación regional que cumple ya varios años. Como dijera, pues, Paul Valéry: se puede ser ligero como un pájaro, pero no tanto como una pluma.

Esta bibliografia pudo elaborarse gracias a las facilidades que me brindaron los directores y el personal de las bibliotecas del Instituto Nacional de Antropologia e Historia, de El Colegio de México, y de la Nacional, en la capital de la República, y de la Casa de la Cultura, del Archivo Histórico del Estado y de la Universidad Autónoma de San Luis Potosí, en la capital potosina.

Agradezco, finalmente, la colaboración de Enrique Márquez, cuyos puntos de vista me permitieron estructurar mejor este trabajo y los comentarios y textos introductorios.

\section{Historia del estado}

En el amplio, rico y no siempre bien valorado conjunto de creadores de la historiografía potosina tradicional, seis son los nombres sobresalientes: Francisco Peña, Manuel Muro, Primo F. Velázquez, Nereo Rodríguez Barragán, Joaquín Meade y Rafael Montejano y Aguiñaga. A pesar de la vastísima bibliografía que corresponde a cada uno de ellos, sólo los tres primeros emprendieron y culminaron consistentemente la tarea de escribir obras generales sobre la historia de San Luis Potosí.

- Concentrado fundamentalmente en la época colonial, Peña llevó a su obra las preocupaciones, premisas o puntos de vista generados desde su ser eclesiástico, mientras que Muro, el historiador liberal por excelencia, distrajo a veces su militancia política para abarcar desde los tiempos prehispánicos hasta los años porfiristas.

Primo F. Velázquez, seglar y coronación intelectual del conservadurismo potosino decimonónico, siguiendo muy de cerca la cronología de Manuel Muro, pudo superarlo cuando llevó la relación de los acontecimientos locales hasta la década de 1930.

Como podrá apreciarse, hace faltà una historia general potosina más comprensiva del tiempo, más moderna en los métodos, y menos recelosa de recuperar el latido y significación de los procesos sociales. Hace falta, también, una historia potosina en la que se registre e interprete la presencia de los singulares y menudos procesos que se desarrollaron más allá de la ciudad de San Luis Potosi, pues en las obras de los autores mencionados frecuentemente la historia de la capital ha sido presentada como la historia general del estado.

Por otra parte, la investigación geográfica regional, a pesar de 
estar representada fundamentalmente por obras tradicionales $o$ escritas por aficionados, cuenta ya con el repertorio valioso que forman los trabajos del pionero Antonio Cabrera, del incansable Octaviano Cabrera Ipiña, del científico Henri Puig, de los educadores Alderete, Rivera, Almazán, García y Guardiola, y del que recientemente -con las técnicas más modernas- elaboró el Instituto Nacional de Estadística, Geografía e Informática.

\section{ObRas GenERALES}

BCC Muro, Manuel, Historia de San Luis Potosí, San Luis

M96h

1973

$1-3$

BCUASLP

$\mathrm{BP}$

972

M96h

1973

H-III

Potosí, Talleres Bolea de México, S.A., 1973, 3 vols.

Reproducción facsimilar de la primera edición de 1910 , que comprende, en su primer tomo, desde el establecimiento de las tribus indígenas en el estado, hasta finales de 1830; en el segundo, los acontecimientos locales que tuvieron lugar entre 1831 y 1848; y el tercero, desde la etapa inmediatamente posterior a la intervención norteamericana y la inva-

sión de los indios bárbaros del norte al territorio potosino hasta 1877, cuando ascendió como gobernador el general tuxtepecano Carlos Diez Gutiérrez.

Producto de una larga investigación de fuentes primarias, esta obra de Muro, dividida en 87 capitulos, constituye la expresión más acabada de la historiografía liberal potosina.

$\begin{array}{ll}\text { BCC } & \text { Penilla López, Salvador, Apuntes históricos de San } \\ \text { RAG } & \text { Luis Potosi, recopilados y formados por Salvador Pe- } \\ 972 & \text { nilla L. San Luis Potosí, Talleres Gráficos El Aguila, } \\ \text { P4a } & \text { 1942, 204 p. } \\ 1942 & \text { Basada sobre todo en fuentes de segunda mano } \\ \text { BCUASLP } & \text { (Historias de San Luis Potosi de Muro y de Peña), } \\ \text { BP } & \text { esta obra es una útil sintesis de la historia potosina, } \\ 972 & \text { que va de la época precolonial al siglo XIX. }\end{array}$

$\overline{\mathrm{BCC}}$

BP. 2.008

A26b

1969

617

BCOLMEX

972.42

P397e

Peña López, Francisco, Estudio histórico sobre San • Luis Potosi, introducción, transcripción, notas e indice de Rafael Montejano y Aguiñaga, San Luis Potosí, Academia de Historia Potosina, 1979, 299 p., láms., (Biblioteca de Historia Potosina, serie estudios 17).

Reedición anotada de la obra publicada en 1894. Esta obra -como comentan Alcorta y Pedraza en su Bibliografia - es fundamental para el estudio de la historia potosina. Su carácter general disculpa en cierta forma sus omisiones. Sobre historia precolonial, no expone absolutamente nada; además, las noticias sobre los tiempos independientes son bien pocas y de reducido interés; en cambio, la parte colonial es relativamente amplia sobresaliendo en ella lo referente a la fundación de la ciudad de San Luis Potosí, expuesta con abundancia de datos. Además, son amplias las noticias sobre fines del siglo XVI y la primera mitad del siglo xvir. Contiene también un apéndice de 36 páginas, donde se presentan catorce documentos que se refieren a la época antes mencionada. 
BCC

RAG

972

R7h9

1969

AHE

BP

972

R15h

1969

Rodríguez Barragán, Nereo, Historia de San Luis Potosi, San Luis Potosi, Sociedad Potosina de Estudios Históricos, 1969, 171 p.

Entre las historias generales de San Luis Potosí, la de Rodriguez Barragán es quizá la menos lograda porque -a pesar de su pretensión de tratar los largos y complejos procesos de la época precolonial hasta la contemporánea- es no sólo una obra demasiado breve sino un texto cuya estructura es caótica. Sin embargo, debido a que el autor lo fue también de muchos otros trabajos importantes sobre la historia regional, éste puede consultarse sobre todo para confirmar o ampliar algunas de las hipótesis y datos que se han manejado en aquéllos.

BCUASLP Velázquez, Primo Feliciano, Colección de documenBP

912

V38c

1897

I-IV tos para la historia de San Luis Potosi, San Luis Potosi, Imprenta del Editor, 1898, 4 vols.

Trabajo que reûne una abundante y. valiosa documentación catalogada y se basa en el estudio de las

BCOLMEX

CE

972.42

V $434 \mathrm{c}$ crónicas antiguas y en la investigación de archivos.

El primer volumen contiene documentos correspondientes al periodo $1582-1610$, y se refieren a la conquista del territorio potosino, descubrimiento y fundación de poblaciones, así como a su organización civil y política.

El segundo contiene documentos de interés para la historia eclesiástica antigua del periodo 1584-1848.

El tercero, que abarca del periodo virreinal (1550) hasta los linderos del siglo XIX (1779), comprende documentos sobre concesiones y reconocimientos de tierras, establecimiento de nuevas poblaciones y misiones, descubrimiento y población de minas, informes de misiones de custodia, etcétera.

El cuarto y último incluye documentos fechados entre 1612 y 1748 relativos a la Custodia del Río Verde, a las Misiones de Tampico, a la jurisdicción de la Villa de los Valles, a Matehuala y Rio Blanco.

\begin{tabular}{|c|c|}
\hline $\begin{array}{l}\text { BCC } \\
\text { BP } \\
972 \\
\text { V38h } \\
1982 \\
1-I V\end{array}$ & $\begin{array}{l}\text { Velázquez, Primo Feliciano, Historia de San Luis } \\
\text { Potosi, San Luis Potosi, Archivo Histórico del Estado } \\
\text { y Academia de Historia Potosina, } 1982,4 \text { vols., ils. } \\
\text { Reedición de la obra publicada en } 1946 \text { por la So- } \\
\text { ciedad Mexicana de Geografía y Estadística. Esta }\end{array}$ \\
\hline $1-4$ & $\begin{array}{l}\text { desde la época prehispánica hasta la contemporánea, } \\
\text { históricos de la región. Publicada muchos años des- } \\
\text { pués de la Historia de San Luis Potosí de Manuel }\end{array}$ \\
\hline \multicolumn{2}{|r|}{$\begin{array}{l}\text { Muro, este extenso trabajo comprende, en su primer tomo, desde } \\
\text { los aborígenes hasta la fundación de San Luis Potosí; en el se- } \\
\text { gundo, de los albores de la vida potosina (siglo XVI) a la última } \\
\text { década del siglo Xvirr; en el tercero, desde el surgimiento de la } \\
\text { insurrección de } 1810 \text { hasta la restauración de la República; y en } \\
\text { el cuarto y último, de la década de } 1870 \text { a la rebelión del general } \\
\text { Saturnino Cedillo en } 1938 \text {. }\end{array}$} \\
\hline
\end{tabular}




\begin{abstract}
BCC Velázquez, Primo Feliciano, Obras del Lic. D. Primo Feliciano Velázquez, México, Imp. de V. Agùeros V380 Editor, 1901, $454 \mathrm{p}$.

1901 Incluye una serie de estudios de primer orden para BNAL la historia de San Luis Potosí. El volumen está precẹ972.0081 dido por una biografía del autor, hecha por el editor, VEL.o. y contiene: Descubrimiento y conquista de San Luis Potosí; las Cabezas Chatas de Guadalcázar; discurso sobre la instrucción pública en San Luis Potosí; introducción a la historia eclesiástica potosina y bibliografía científica potosina.

BCC Velázquez, Primo Feliciano, San Luis Potosi, edición RAG y notas de Rafael Montejano y Aguiñaga, San Luis 972

V38s

1961

BCUASLP

BP*

972

V38s

1961

Potosí, Universidad Autónoma de San Luis Potosí, $1961,42 \mathrm{p}$.

Compilación de cinco artículos anónimos aparecidos en El Estandarte, periódico fundado y dirigido por Primo F: Velázquez entre septiembre y diciembre de 1890. Atribuidos a él mismo, estos artículos tratan temas fundamentales para la historia regional, referentes a los cronistas, documentos antiguos, etnografía, estadistica, etcétera.
\end{abstract}

\title{
DESCRIPCIONES GEOGRAFICAS
}

AHE Alderete, Jesús R. y Vicente Rivera, Geografía del BP

913

Alg

1969

BNAL

917.242

ALD.g. Estado de San Luis Potosi, Geografía escolar, 13 ed. adicionada y reformada, México, Editorial Tizoc, 1969, 118 p., ils.

Escrito con fines pedagógicos, éste que hace varias las de enseñanza media, es un esbozo general contemporảneo de la geografia física y humana de San Luis Potosí.

BCC Almazán Cadena, Antonio, Síntesis Geográfica del Estado de San Luis Potosi, San Luis Potosí, 2a. ed., 913

A65s

1985 Ediciones del Ateneo Nacional de Investigaciones Geográficas, sección S.L.P., 1985, 306 p., ils. y mapas.

El autor hace una breve reseña histórica del estado de San Luis Potosí en su primer capítulo, y dedica los restantes a los temas siguientes: denominación y situación geográfica, extensión y división política, evolución geológica y rocas, geomorfología, clima, suelos e hidrologia. Al final de la obra, se agregan algunas consideraciones sobre los problemas ecológicos que han surgido con la vida moderna en la región.

BCC Bassols Batalla, Angel, et al., Las Huastecas en el desa$\mathrm{BP}$

918

B26h

1977 rrollo regional de México, México, Trillas, 1977, 436 p.

Primer intento de análisis de la vida económica y social de la vasta región de las Huastecas (que comprende a los estados de San Luis Potosi, Veracruz, Tamaulipas, Hidalgo, Puebla y Querétaro), a partir de la utilización del concepto región desde la perspectiva geograficoecológica. A pesar de este útil esfuerzo de sistematización, la obra presenta serias deficiencias en la interpretación de los procesos históricos regionales. 


$\begin{array}{ll}\text { BCC } & \text { Cabrera, Antonio, Apuntes históricos, geográficos y } \\ \text { BP } & \text { administrativos sobre el estado de San Luis Potosi, } \\ 913 & \text { formados y arreglados por Antonio Cabrera, San } \\ \text { C1a } & \text { Luis Potosí, Tip. de Cabrera e hijos, 1890, 72 p. } \\ 1890 & \text { Cabrera aporta en este breve trabajo relevantes } \\ \text { BINAH } & \text { cifras sobre población, actividades productivas, } \\ \text { L.G.O. } & \text { demarcaciones politicas, valores de la propiedad e } \\ \text { F1336 } & \text { instrucción pública, así como los referentes a los } \\ \text { C32 } & \end{array}$

\begin{abstract}
BCC Cabrera Ipiña, Octaviano, San Luis Potosí y su terri-
RAG

910

c1s

1962 torio, ensayo geográfico, s.l., s.e., 1962, 302 p., ils.

BNAL

917.242

CAB.s.

Las primeras 92 páginas de esta obra contienen un panorama general de la geologia, orografía, climas, hidrología, botánica, zoología y antropología del esperspectiva de la geografía física. Incluye también algunos datos históricos sobre fundación, y propone una regionalización geográfica municipal a partir de la existencia de cuatro grandes agregados: estepa, cuenca de Rioverde, sierra y Huasteca.
\end{abstract}

$\begin{array}{ll}\text { BCC } & \text { Cabrera Ipiña, Octaviano, San Luis Potosi, 4a. ed., } \\ \text { BP } & \text { San Luis Potosí, Talleres Linotipográficos Atlas, } \\ 913 & 1969,3362 \text { p., láms., fotos, planos. } \\ \text { C1s } & \text { Basada en fuentes de segunda mano y dividida en } \\ 1969 & 16 \text { capítulos, esta obra pretende ser un bosquejo glo- } \\ \text { BNAL } & \text { bal, aunque somero, del estado de San Luis Potosí } \\ 917.242 & \text { desde la perspectiva geoantropológica e histórica. } \\ \text { CAB.s. } & \text { Los temas que trata son: 1. Estructura del terreno, } 2 . \\ 1969 & \text { El hom } \\ \text { El hombre, 3. El relieve del suelo, 4. Actividades, 5. La gente, 6. } \\ \text { Agua, 7. Valles y planicies, 8. Los municipios, 9. La Huasteca, } \\ \text { 10. La Sierra Madre, 11. La cuenca del Rio Verde, 12. Algo sobre } \\ \text { la flora, 13. El tunal grande, 14. Esquema climático, 15. La xero- } \\ \text { zona y 16. Disquisiciones sobre la fauna. }\end{array}$

BCC García, Bruno A., Cartilla elemental de geografía del 913 estado de San Luis Potosi, San Luis Potosí, TipograG21c - fía de Bruno A. García, 1883, 190 p.

1883 Recopilación bastante útil relativa a la geografía y estadística demográfica. Contiene datos generales sobre el estado y de los partidos y municipios que por la época lo integraban.

BCC Guardiola, Bartolo, El estado de San Luis Potosi, carRAG

912

G9e

1913 tilla explicativa del mapa editado por esta casa, San Luis Potosí, Manuel Sancho Editor, 1913, 15 p. elementales y comunes sobre la geografía potosina.

BINAH

L.G.O.

F1336

M1528a

Macias Valadez, Francisco, Apuntes geográficos y estadísticos sobre el estado de San Luis Potosi, en la Rezález Obregón). pública de los Estados Unidos Mexicanos, San Luis Potosí, México, s.e., 1878, 138 p. (Colección Luis Gon-

Obra geograficohistórica, que es ya casi un clásico de la biblio- 
grafía potosina. Contiene noticias generales, extensión y límites del estado, en su primera parte; noticias estadísticas de cada partido y municipio, y de las congregaciones, haciendas y ranchos del estado en la segunda parte.

$\begin{array}{ll}\text { BCC } & \text { Puig, Henri, Vegetation de la Huasteca, Mexique. } \\ \text { BP } & \text { Etude phytogeographique et ecologique, México, } \\ 918 & \text { MAEFM, 1976, 531 p., ils., } 3 \text { mapas. (Etudes Mesoa- } \\ \text { P9v } & \text { méricaines v. V.) }\end{array}$

Aplicando un concepto de región de estrictos contenidos ecológicos, Puig ofrece en esta obra, además de un análisis riguroso del espacio huasteco, algunas sugerencias importantes en torno a la relación de los procesos históricos y sociales con las transformaciones ecológicas ocurridas en la región entre las épocas prehispánica y colonial.

BCC Secretaria de Agricultura y Fomento, División territoRAG rial de los Estados Unidos Mexicanos, corresponSAF 21722 diente al censo de 1910. Estado de San Luis Potosi, 1918 México, Oficina Impresora de Hacienda, 1918, 48 p. Contiene noticias estadísticas demográficas (por edades, instrucción, estado civil, cultos y nacionalidad). Incluye una lista alfabética de las localidades del estado, y ofrece datos sobre la geografía, la economía y el territorio potosinos.

BCC Secretaría de Programación y Presupuesto, INEGI, Ex. Sintesis geográfica del estado de San Luis Potosí, Mé${ }_{913}^{B P}$ xico, INEGI, 1985, 2 vols, ils., Anexo cartográfico.

1985 Contiene la más reciente información geográfica I-II sobre el estado de San Luis Potosí, principalmente del medio físico. La información que ofrece se basa en la cartografía existente y en la verificación que con trabajo de campo realizó la Secretaría de Programación y Presupuesto a través de su Instituto Nacional de Estadística, Geografía e Informática. Se divide en los siguientes capítulos: 1 . División municipal y principales localidades, 2. Vias de comunicación, 3. Climatologia, 4. Geología, 5. Hidrología, 6. Regiones fisiográficas, y apéndices. El anexo cartográfico contiene trece mapas relativos a la topografía, climas, hidrologia, suelos, usos agrícola, forestal, pecuario, regionalización geográfica y frontera agrícola.

BCC Sustaita, José, San Luis Potosi, sinópsis histórica, geoRAG gráfica y estadistica del estado, San Luis Potosí, Tip.

910.2

1907 de la Escuela Industrial Militar, 1907, 133 p.

Se trata de una obra menor que, sin embargo, da cuenta de diversas actividades económicas y de gobier-

AHE

BP

910.2

S19s

1907

\section{Historia de los municipios}

Como hemos afirmado, las historias generales de San Luis Potosí han registrado preferentemente los acontecimientos desarrollados en la capital del estado. A pesar de esto, la historia de la 
ciudad de San Luis Potosí todavia está en muchos aspectos por escribirse. Las obras precursoras de Julio Betancourt, Antonio Cabrera, Rafael del Castillo y Manuel Muro, que describen su organización urbana, sus actividades sociales y económicas, así como la sugerente recreación o recuperación de sus costumbres, hechas en los libros de Montejano, Medellín y Vera, aunque nos son útiles o atrapan por la pasión con que fueron escritos, permiten constatar que mucho es lo que queda todavía por hacerse.

El estado de San Luis Potosi, por otra parte, comprende tres espacios regionales característicos: el del altiplano, el del centro y el de la Huasteca. La historia potosina, la de la economia, la de la cultura o la política, resulta incomprensible -en su dinámica y motivos profundos- sin el reconocimiento de ese espectro territorial que la historiografia aficionada o profesional no ha atendido con suficiencia.

Sobre la historia de los municipios del altiplano, destacan sobre todo las obras dedicadas al Real de Catorce, y, en general, a aquéllos que como éste tuvieron como eje de su desarrollo la actividad minera (Charcas, Matehuala) o la explotación de las salinas que la complementaban.

Sobre la historia de la región central, sobresalen las obras dedicadas a los municipios de Cárdenas y Rioverde -muy importantes durante el siglo XIX-y, por su notable elaboración artística, la que Rafael Montejano y Aguiñaga dedicó al Valle del Maíz, aunque la que Dominique Chemin escribió a propósito de la vida de Lagunillas puede ser en muchos sentidos apreciada.

Finalmente, la región huasteca ha sido pretexto de libros importantes como el de Antonio J. Cabrera, escrito al despuntar el porfiriato, y los que Joaquín Meade y Peter Mandeville dedicaron a Valles.

A pesar de la existencia de no pocas obras sobre historia local, la historiografía potosina todavía experimenta un cada vez más evidente vacio en este sentido: las excepciones notables siguen siendo los libros magistrales de Antonio J. Cabrera (La Huasteca Potosina, ligeros apuntes sobre este pais...) y de Rafael Montejano y Aguiñaga (El Valle del Maí...).

\title{
CaPital
}

\begin{abstract}
$\mathrm{BCC} \quad$ Betancourt y Moreno, Julio, Rasgos biográficos de los $\mathrm{BP}$ descendientes de don José Antonio Betancourt y doña 92.2-48 Agustina de la Rosa Ferrer, vecinos de la ciudad de 1910 San Luis Potosi, San Luis Potosí, Ranulfo BetanII court impresor, La Económica, Matehuala, 1905 y 1910, 2 vols., ils.

Esta es la única historia de familia que se conoce relativa a las familias originarias o avecindadas en San Luis Potosí; en ella se encuentran numerosos e interesantes datos referentes a la historia de San Luis en general.
\end{abstract}

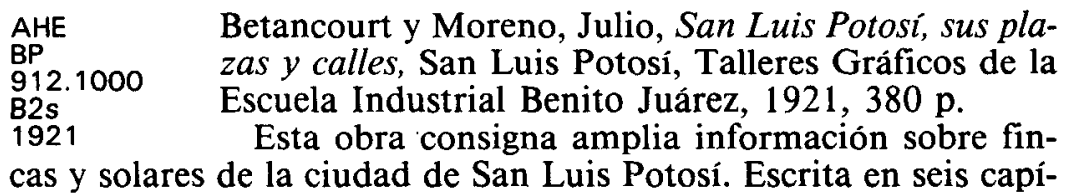


tulos, siguiendo el criterio cronológico (1576-1869), es una obra trunca, ya que no toca la época que abarca desde los tiempos de ? caída del emperador Maximiliano hasta los inicios de la década de 1920.

$\begin{array}{lc}\text { BCC } & \text { Cabrera, Antonio J., Apuntes históricos, geográficos y } \\ \text { RAG } & \text { administrativos referentes a la ciudad de San Luis Po- } \\ 912.9 & \text { tosi, San Luis Potosi, Tip. de A. Cabrera e hijos, } \\ \text { C1a } & 1891,119 \text { p. } \\ 1891 & \text { Información histórica que se remonta a la funda- } \\ \text { BINAH } & \text { ción de la ciudad de San Luis Potosí; datos sobre su } \\ \text { XXVIII-7-23 } & \text { aspecto físico, situación geográfica y astronómica, al- } \\ 1899 & \text { tura, división política y administrativa, forma de gobierno, demo- } \\ \text { tura, } & \\ \text { grafía, valor fiscal de fíncas rústicas y urbanas. También se incluye } \\ \text { una descripción de los principales edificios de la ciudad y su fun- } \\ \text { dación, de los medios de transporte, etc. Es una importante fuente } \\ \text { de consulta para entender la historia y las diversas manifestacio- } \\ \text { nes de la ciudad natal del autor, quien anualmente emprendia la } \\ \text { elaboración de una obra de esta naturaleza y sobre este mismo } \\ \text { tema a manera de guías actualizadas. }\end{array}$

BCUASLP Castillo, Rafael del, Guia del viagero en San Luis Poto+912.2 si, San Luis Potosí, Tip. de Velez hijos, 1891, 146 p. $\mathrm{C} 26 \mathrm{~g}$ 1891

Incluye noticias históricas y estadísticas de las principales poblaciones del estado, su origen, derecho de consumo, directorios administrativo, de profesionistas, comercial e industrial. Proporciona también información sobre los consulados y sus titulares, el correo y telégrafo federal, líneas telefónicas, ferrocarril, expreso nacional mexicano, inhumaciones, tranvías, coches de sitio, etcétera. $\begin{array}{ll}\text { BCC } & \text { Meade, Joaquin, San Luis Potosi, guia de la ciudad y } \\ \text { RAG } & \text { del estado. Guide to the city and the state, 2a. ed., } \\ 910.2 & \text { s.1., Talleres Gráficos Laguna, 1946, 141 p., ils. } \\ \text { M3s } & \text { A pesar de las limitaciones que tiene para los in- } \\ 1946 & \text { vestigadores toda guia, ésta de Joaquín Meade, su- } \\ \text { BNAL } & \text { cinta y rigurosa, contiene valiosos datos sobre la his- } \\ 917.242 & \text { toria de la ciudad, de sus edificios, establecimientos } \\ \text { MEA.s. } & \\ \text { comerciales, industriales y recreativos. }\end{array}$

BCC Medellin Espinoza, Ignacio, Leyendas potosinas, $\mathrm{Pu}-$ RAG blicación patrocinada por el C. Hipólito Cedillo, pre863 sidente municipal del partido de la capital del Estado 1934 de San Luis Potosí en el año de MCMXXXIV, San BCuAslp Luis Potosí, México, Talleres Linotipográficos del +398.23 Periódico Acción, 1934, 23 p.

M331 Recreación de tipo periodístico de las más famosas 1934 leyendas potosinas (La llorona, Juan del Jarro, El Callejón de las Manitas, etc.) cuyo asiento histórico fue la ciudad capital. 
AHE

BP

863

M13d

1,978

$-\mathrm{BCC}$
$\mathrm{BP}$
912.2
$\mathrm{M} 8 \mathrm{~g}$
1978

BCUASLP

$+912.2$

$\mathrm{MBg}$

1978

res de la capital.

personajes, apariciones y tesoros escondidos, este libro es una exhibición afortunada del talento literario del Lic. Montejano, quien, de paso, nos hace una amena descripción de la atmósfera social de la capital potosina del siglo XIX.

Montejano y Aguiñaga, Rafael, Guia de la ciudad de San Luis Potosí, 5a. ed., San Luis Potosí, Academia de Historia Potosina, 1978, 167 p.

Guía que ofrece, en su introducción, noticias sobre la geografia, la historia, el arte y la cultura de la ciudad de San Luis. También comprende una breve bibliografía "para el turista", siete intinerarios para recorrer la ciudad, y un índice de artistas y luga-

$\mathrm{BCC}$

972.008

A26b

1969

41

Montejano y Aguiñaga, Rafael, Tres planos antiguos de la ciudad de San Luis Potosi, San Luis Potosi, Academia de Historia Potosina, 1976, 28 p.

Estudio y presentación de los planos (inéditos y desconocidos) más antiguos de la ciudad de San Luis Potosí. Entre ellos, destaca el plano que levantó Miguel Espinoza de los Monteros en 1758, el más antiguo que se ha descubierto hasta ahora.

\begin{abstract}
$\mathrm{BCC}$
BP

912.1

M96m

1903

BNAL

972.42

MUR.m.

Muro, Manuel, Miscelanea potosina, biografias, articulos históricos y de costumbres, tradiciones y leyendas, San Luis Potosí, Tipografía de la Escuela Industrial Militar, 1903, $256 \mathrm{p}$.

Integrada con biografias, artículos varios, históricos y de costumbres, fiestas religiosas y populares, $y$ leyendas, esta Miscelanea de Muro permite identificar no sólo los procesos culturales de la ciudad de San Luis Potosí sino a quienes -a finales del siglo pasado- fueron actores sociales dominantes.
\end{abstract}

\section{BCC \\ RAG \\ 863 \\ V42t \\ 1941}

BCOLMEX

917.242

V473t

BCUASLP

BP*

914.5

A47s

1969

grafia, clima, agricultura y ganaderia, minería, industria, artesanía, vías de comunicación y transportes del municipio de Charcas.

$\mathrm{BCC}$

Vera, Agustín, Tradiciones potosinas, San Luis Potosí, A. Macías Editor, 1941, 120 p.

El propósito del autor de este breve libro fue el de reunir los relatos más interesantes de hechos legendarios, transmitidos de generación en generación entre los habitantes de la ciudad. También aparece una relación de sucesos históricos locales.

\section{REGION DEL ALTIPLANO}

Aguilera, Manuel, Sintesis histórica de Charcas, S.L.P, San Luis Potosí, S.L.P., s.e., 1969, 11 p.

Folleto que se refiere brevemente a la fundación, proceso histórico, situación, extensión, limites, oro-

Cabrera, Antonio J., El estado de San Luis Potosi, Volúmen Segundo. Obra que contiene multitud de datos $e$ informes referentes al partido de Santa Maria 
del Rio del mismo estado, Prol. del profesor de instrucción pública, escritor y periodista Bartolo GuarBCC diola, San Luis Potosí, Imprenta, libreria y encuaderRAG 913.1 C1e 1905 II nación de A. Cabrera, 1905, 146 .

Cabrera recopila y ordena numerosos datos de carácter histórico, geográfico y estadístico relativos al antiguo partido de Santa Maria del Río, desglosados muchos de ellos de otras publicaciones o bien, directamente obtenidos de observaciones propias, informes de particulares y autoridades.

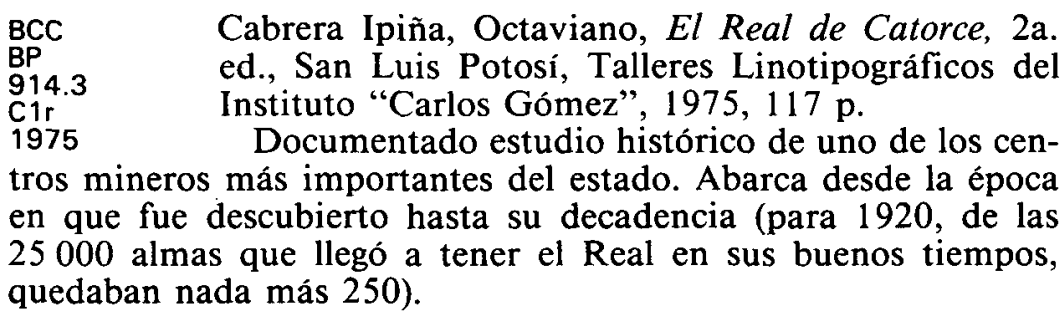

AHE Cázares Loera, Samuel, Rasgos históricos de MateBP $\quad$ huala (en el $4^{\circ}$ centenario de su fundación), México, 914.1 D. F., Talleres Tipográficos del Servicio de Trans1950 porte Eléctrico del D.F., 1950, 13 p.

El autor comienza haciendo una digresión histórica en torno a la fecha de fundación de la ciudad de Matehuala, y continúa ofreciendo algunos datos sobre su geografía, riqueza mineral, demografia, economía y de sus prohombres.

BCC Montejano y Aguiñaga, Rafael, Charcas, S.L.P., su BP historia, Fr. Luis de Palacio, su convento-parroquia, 972.008 San Luis Potosí, Academia de Historia Potosina, $1974,158 \mathrm{p}$. mimera población fundada en el altiplano potosino y foco de evangelización del norte de México. Acuciosa y documentada descripción del convento franciscano, de sus obras de arte y de sus moradores.

AHE Montejano y Aguinaga, Rafael, El Real de Minas de la Purisima Concepción de los Catorce, S.L.P., 2a. A3b ed., México, Academia de Historia Potosina, 1981, 1969264 p., ils.

214 Documentada historia del célebre mineral, famoso por sus riquezas, sus innovaciones técnicas y su parroquia, que fue y es centro de nutridas y constantes romerías. La primera edición de esta obra se hizo en 1975.

BCC

RAG

913.4

M8v

1964

BCUASLP

$\mathrm{BP}$

913.4

Montejano y Aguiñaga, Rafael, El Valle de Santa Isabel del Armadillo, S.L.P, San Luis Potosí, Imprenta Evolución, 1964, 296 p.

Historia de la célebre población y municipio de Armadillo, tan antiguo como la capital del estado, famoso porque en ella se abrió la primera imṕrenta potosina en el ocaso de la dominación española, per- 
M8v

1964

BCC

RAG

915.1

R7a

1947

teneciente a Alejo Infante y su hijo José Tomas, finísimo grabador potosino.

del Boletín de la S. M. de G. y E.

Rodríguez Barragán, Nereo, Apuntes para la historia y la geografía de la ciudad de Salinas en el estado de San Luis Potosí, México, Sociedad Mexicana de Geografía y Estadística, 1947, 433-492 p., ils. Sobretiro

Relación anecdótica y amena de datos históricos, geográficos, económicos y políticos sobre Salinas, que durante la época colonial y aun después fue un importante centro salinero.

$\mathrm{BCC} \quad$ Wallace, Lucy H., Real de Catorce, México. The in$\mathrm{BP}$ 914.3 W16r

1965 La autora es una periodista norteamericana, fotócredible city, Mission, Texas, Amigo Enterprises publishers, 1965, $116 \mathrm{p}$. grafa, quien ha publicado artículos y fotografias en periódicos y revistas de varios países. La presente obra es una buena muestra de fotografías del Real. Contiene también textos referentes a la historia política, económica y social del lugar.

\section{REGION CENTRAL}

BCC Cabrera Ipiña de Corsi, Matilde, Refutación genealó$\mathrm{BP}$

916.2

C1r gica del libro "El Valle del Maiz, S.L.P.", México, s.e., $1970,55 \mathrm{p}$.

1970

AHE

BP

916.2

$\mathrm{C} 3 \mathrm{r}$

1970

Con motivo de la publicación de la obra El Valle del Maíz, S.L.P. de Rafael Montejano y Aguiñaga, la autora solicitó a la Academia Mexicana de Genealogía y Heráldica que llevara a cabo un estudio de su obra Cuatro Grandes Dinastias Mexicanas en los Descendientes de los Hermanos Fernández de Lima Barragán, por considerar que la de Montejano, la impugna, además de que considera que incurre en imprecisiones. En la Refutación... se presentan los dictámenes que rindió la comisión nombrada por la Academia para satisfacer la solicitud de la autora.

$\begin{array}{ll}\text { BCC } & \text { Chemin, Dominique, Lagunillas, reseña histórica, } \\ \text { BP } & \text { San Luis Potosí, Academia de Historia Potosina, } \\ 972.008 & 1984,14 \text { p., Biblioteca de Historia Potosina, serie } \\ \text { A26b } & \text { cuadernos, 82. } \\ 1969 & \text { Descripción histórica que comprende desde me- } \\ 82 & \text { diados del siglo XVI, con el paso de los franciscanos } \\ \text { AHE } & \text { por el municipio, hasta la segunda mitad del siglo } \\ \text { BP } & \text { XVIII, que registra un movimiento demográfico y cul- } \\ \text { O08 } & \text { tural que -aunado al despojo de tierras y engrandeci- } \\ \text { A3b } & \text { miento de las haciendas en el XIX- provocarian } \\ \text { 486 } & \text { miento de las }\end{array}$

$\mathrm{BCC}$

$\mathrm{BP}$

917.6

E86h

1933

BCC

RAG

917.6
Escalante, Albino E., Historia de la fundación de San Ciro de Albercas, estado de San Luis Potosi, San Luis Potosi, México, s.e., 1933, 20 p., una lámina.

Documentada y breve historia de la Villa de San , Ciro, desde la época del poblamiento de tribus gua'chichiles y chichimecas hasta la década de 1850 , cuando en la Villa (y, concretamente, en la Hacienda 
bulo del autor.

de Amoladeras) se fundaron las Colonias Militares

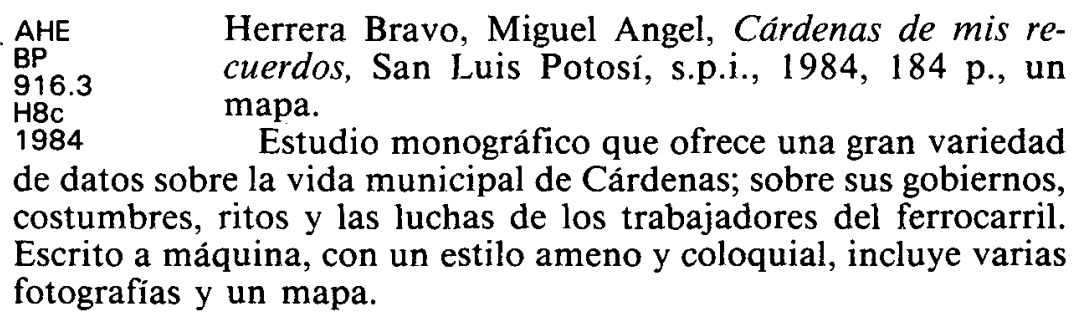

BCC Herrera Bravo, Miguel Angel, Monografía del muni916.3 $\mathrm{H} 45 \mathrm{~m}$ 1967

BCUASLP $\mathrm{BP}^{*}$

916.3

H45m

1967

AHE

BP

916.4

M13a

1968

cipio de Cárdenas, S.L.P., San Luis Potosí, s.p.i., 1967, 28 p.

Donde se trata de la historia, geografía, administración municipal 1965-1967. Breve relación de datos históricos, geográficos y culturales de Cárdenas. Incluye una lista de gobernantes locales (1899-1967).

$1968 \quad H$ Historia del municipio de Alaquines, de su descubrimiento, fundación y del proceso de aculturación a través de los siglos XVI al XX.

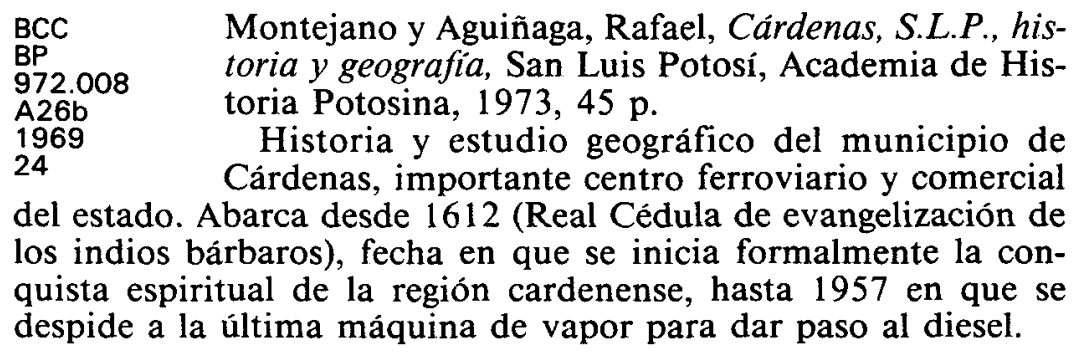

BCUASLP Montejano y Aguiñaga, Rafael, Rio Verde, $350^{\circ}$ ani917.2 $\mathrm{MBr}$ 1967 Discurso suficientemente fundado sobre el descu-

Montejano y Aguiñaga, Rafael, Alaquines y su Señor del Santo Entierro, San Luis Potosí, Imprenta Evolución, 1968, $27 \mathrm{p}$. brimiento, pacificación y colonización de la zona media potosina y de la evangelización de la paramería norte, y del establecimiento de la Custodia de Santa Catarina del Rioverde y de sus prohombres (siglos XVI y XVII).

BCC

RAG

916.2

M8v

1967

BCUASLP

BP

916.2

M8v

1967
Montejano y Aguiñaga, Rafael, El Valle del Maiz, S.L.P., San Luis Potosí, Imprenta Evolución, 19.67, $372 \mathrm{p}$.

De entre la vastísima bibliografía producida por el investigador Montejano, esta obra destaca no sólo por la consistencia de sus informaciones, sino por su factura literaria de alta calidad. Comprende una larga y profunda descripción de los acontecimientos 
locales, desde los tiempos de la fundación del antiguo Valle del Maíz hasta la década de 1960 , así como información sobre la genealogía de los Barragán, que fue el clan dominante de la región.
BCC Rodríguez Barragán, Nereo, Historia y geografía del 917.9 municipio de Rayón, San Luis Potosí, Sociedad Poto- R7h
1975
BCUASLP
$\mathrm{BP}^{*}$
917.9
R7h
1972 sina de Estudios Históricos, 1975, 37 p.
Breve descripción histórica, geográfica y demográ- fica del municipio que antiguamente se llamó Nuevo Gamotes. Se refiere también el autor a la zona arqueo- lógica rayonense, y hace semblanza de los persona- jes locales más destacados.

$\overline{\mathrm{BCC}}$

$\mathrm{BP}$

917.2

V42e

1985 riográfica del autor, en la que reconstruye "episodios elocuentes y significativos" de la vida diaria de Rioverde: el campo, el comercio, los inmigrantes, la vida socioeconómica, etcétera.

Verástegui nació en la capital potosina por accidente porque pasó la mayor parte de su vida en Rioverde.y él mismo se consideraba rioverdense.

\begin{tabular}{|c|c|}
\hline $\begin{array}{l}\mathrm{BCC} \\
\mathrm{BP} \\
972.008 \\
\mathrm{~A} 26 \mathrm{~b} \\
1969 \\
51,55 \\
58,62 \\
74\end{array}$ & $\begin{array}{l}\text { Verástegui González O., Eugenio, Rio Verde, S.L.P, } \\
\text { San Luis Potosí, Academia de Historia Potosina, } \\
1979 \text {, (Biblioteca de Historia Potosina, serie cuader- } \\
\text { nos, } 51,55,58,62 \text { y } 74 \text { ). } \\
\text { Pequeña historia del municipio de Rioverde, desde } \\
\text { sus origenes prehispánicos, pasando por las Misiones } \\
\text { irreinal, hasta la década de } 1850 \text {. }\end{array}$ \\
\hline $\begin{array}{l}B C C \\
B P \\
916.5 \\
V 52 m \\
1078\end{array}$ & $\begin{array}{l}\text { Villegas Galván, José Alfredo, Monografia del muni- } \\
\text { cipio de Cerritos, S.L.P., s.p.i., 1978, } 75 \mathrm{p} \text {. } \\
\text { Esta es una especie de "historia universal" del mu- } \\
\text { nicipio de Cerritos, situado en un fértil valle de la }\end{array}$ \\
\hline & $\begin{array}{l}\text { éf } \\
\text { and } \\
\text { s. }\end{array}$ \\
\hline
\end{tabular}

\section{REGION DE LA HUASTECA}

$\mathrm{BCC}$

RAG

918

A69h

1953

Verástegui González Obregón, Eugenio, Estampas provincianas, pról. de Rafael Montejano y Aguiñaga, San Luis Potosi, Ed. Universitaria Potosina, 1985, 247 p. Edición póstuma que complementa la obra histoto crítico o informaciones de primera mano, desarrolla como tema central uno de los procesos menos conocidos sobre la historia de las Huastecas: las iniciativas (en los siglos XIX y XX) para la formación de un estado Huasteco a partir de segregaciones territoriales de los estados que componen la región de las Huastecas (Veracruz, Tamaulipas, San Luis Potosí, Querétaro, Hidalgo, Puebla). 


\begin{abstract}
BCC Cabrera, Antonio J., La Huasteca potosina, ligeros 918 C1h 1876 apuntes sobre este pais, San Luis Potosí, Tipografía del Comercio, 1876, $180 \mathrm{p}$.

Libro producto de la visita oficial que el autor hizo BNAL $R$ a la región hacia 1873 , tres años antes de su publicalas estructuras económicas y sociales y, de una manera especial, la cuestión étnica. El autor plantea profunda y amenamente la circunstancia en que se encontraba la región poco antes del porfiriato.
\end{abstract}

$\begin{array}{ll}\text { BCC } & \text { García Pacheco, Sixto, Monografia de Tamazun- } \\ \text { RAG } & \text { chale, 2a. ed., Tamazunchale, Librería México, } \\ 918.16 & 1968,33 \text { p., ils. } \\ \text { G21m } & \text { Esta obra, basada fundamentalmente en fuentes de } \\ 1968 & \text { segunda mano, parte de la época independiente y } \\ \text { BCUASLP } & \text { concluye en la contemporánea. Son particularmente } \\ \text { BP*A } & \text { interesantes los relatos que el autor incluye sobre la } \\ 918.16 & \text { rebelión indigena de 1879, que se inició en la cabe- } \\ \text { G21m } & \text { cera municipal y que luego logró extenderse a otros } \\ 1968 & \end{array}$

BCC Mandeville, Peter B., La jurisdicción de la Villa de BP 972.008 Santiago de los Valles 1700-1800, San Luis Potosí, $\mathrm{A} 26 \mathrm{~b}$ 1969 503 Academia de Historia Potosina, 1976, 122 p., 1 h. pleg. (Biblioteca de Historia Potosina, serie documentos 3).

Este trabajo de topografía histórica, en cuya confección fueron recuperadas las obras más importantes sobre la región en el periodo preindependiente, asi como documentos de archivos tan importantes como el de Indias, es de gran utilidad para los investigadores no familiarizados con la organización socioeconómica y demográfica del espacio norte y central de la Huasteca potosina.

\begin{tabular}{lc} 
BCC & Meade, Joaquín, Breves datos históricos de Coxcatlán, \\
$\mathrm{BP}$ & S.L.P., Ciudad Valles, Imprenta Robledo, 1964, 14 p. \\
918.5 & El autor hace énfasis en los acontecimientos histó- \\
$\mathrm{M} 3 \mathrm{~b}$ & ricos del municipio, del siglo XVII y los anteriores; \\
1964 & contiene escasas noticias referentes a los siglos XIX \\
BCUASLP & y XX. \\
$\mathrm{BP}^{*}$ & \\
918.5 & \\
$\mathrm{M} 3 \mathrm{~b}$ & \\
1964 & Meade, Joaquín, Historia de Valles; monografía de la \\
\hline $\mathrm{BCC}$ & Huasteca potosina, San Luis Potosi, Sociedad Poto- \\
$\mathrm{BP}$ & sina de Estudios Históricos, 1970, 319 p. \\
918.1 & Meade sacrificó aquí el análisis en beneficio de la \\
$\mathrm{M} 3 \mathrm{~h}$ & \\
1970 & \\
reconstrucción anecdótica que, hay que decirlo, está sustentada en \\
fuentes de primera mano. \\
El aspecto más atendido por el autor es la experiencia de quie- \\
nes tuvieron la responsabilidad o el privilegio del gobierno en la \\
Huasteca potosina desde el siglo XVI hasta finales de la década de \\
1960.
\end{tabular} 
BP

972.013

M3h

la época colonial, siglo XVI. 450 aniversario de la funda-

1983 ción de Ciudad Valles, S.L.P. 1533-1983, México, Academia Potosina de Ciencias y Artes, 1983, 218 p., ils.

Se nos presenta, al principio de esta obra, un panorama geográfico general de la zona, sus límites, ciudades y pueblos destacados. En los siete capítulos que la componen se estudian: los grupos indígenas (chichimecas y huastecos) que habia en San Luis Potosí a la llegada de los españoles; la conquista, los colonizadores y las primeras fundaciones en la Huasteca; los aspectos económicos (encomiendas, mercedes, haciendas); hechos históricos destacados; aspectos políticos (autoridades y alcaldes mayores); la evangelización en la región; y, aspectos socio-culturales (la educación y las primeras edificaciones españolas en la Huasteca). Se incluye al final un apéndice que contiene listas de encomenderos, encomiendas, mercedes de tierras y haciendas importantes.

BCC Montejano y Aguiñaga, Rafael, La parroquia de Tan-

RAG

918.2

M8p

1954

BCUASLP

$+1918.2$

M8p

1954 canhuitz; datos para su historia, San Luis Potosí, Universidad Autónoma de San Luis Potosí, 1954, 37 p.

Historia del municipio de Tancanhuitz, hoy Ciudad Santos, y de su parroquia (San Miguel Arcángel de Tancanhuitz) que es una de las más antiguas de la diócesis potosina.

Este que fue el primer trabajo de Montejano sobre el municipio, se remonta al año de 1522 (expedición de Francisco de Garay por el río Pánuco), y centra la atención en la experiencia evangelizadora, además de proporcionar útiles datos geográficos y demográficos que cubren hasta la década de 1950.

\begin{tabular}{|c|c|}
\hline $\begin{array}{l}\text { BCC } \\
\text { RAG } \\
918.2 \\
\text { M8t } \\
1965\end{array}$ & $\begin{array}{l}\text { Montejano y Aguiñaga, Rafael, Tancanhuitz, lugar } \\
\text { de la flor amarilla, San Luis Potosí, Academia de } \\
\text { Historia Potosina, } 1965,72 \text { p., láms. } \\
\text { Monografía de Tancanhuitz, uno de los munici- }\end{array}$ \\
\hline $\begin{array}{l}\text { BCUASLP } \\
\text { BP } \\
918.2 \\
\text { M8t } \\
1965\end{array}$ & $\begin{array}{l}\text { pios huastecos más importantes. Montejano se re- } \\
\text { fiere a la historia, geografía y población del “lugar de } \\
\text { la flor amarilla", desde la conquista hasta la época } \\
\text { contemporánea. }\end{array}$ \\
\hline $\begin{array}{l}\text { BCC } \\
\text { BP } \\
398.2 \\
P 811 \\
1979\end{array}$ & $\begin{array}{l}\text { Priego Pardiñaz, Carlos, Leyendas y anécdotas de la } \\
\text { Huasteca, pról. de Rafael Montejano y Aguiñaga. Ta- } \\
\text { mazunchale, s.e., 1984, } 153 \text { p. } \\
\text { Selección de } 18 \text { leyendas sobre la vida social y po- }\end{array}$ \\
\hline \multicolumn{2}{|c|}{$\begin{array}{l}\text { lítica de la región huasteca. El autor, maestro rural, las ha resca- } \\
\text { tado -gracias al íntimo contacto que tuvo con el pueblo y los nú- } \\
\text { cleos aborígenes (nahuatlacos o huastecos)- de lo más abrupto de } \\
\text { la sierra, mediante la transmisión oral. }\end{array}$} \\
\hline $\begin{array}{l}\text { BCC } \\
\text { BP y } \\
\text { RAG } \\
972.1 .1 \\
\text { R7t } \\
1932\end{array}$ & $\begin{array}{l}\text { Rodríguez, Blas E., Tampico, datos para la histor } \\
\text { de la Huasteca, México, Editorial Cultura, } 193 \\
95 \text { p., ils. } \\
\text { Esta es una importante colección de document } \\
\text { sobre la historia precolonial y colonial de Tampico }\end{array}$ \\
\hline $\begin{array}{l}\mathrm{AHE} \\
3 \mathrm{P} \\
272\end{array}$ & $\begin{array}{l}\text { Ico (siglo XVI } \\
\text { olfo (1823). }\end{array}$ \\
\hline
\end{tabular}

1932 


\section{Historia politica}

La bibliografía sobre la historia política potosina de los pocos más de cien años que nos ocupan, presenta innumerables vacios y sugiere también temas de investigación para llenarlos. Ni la Independencia ni el proceso posterior de la crisis del estado nacional han merecido la atención de los historiadores académicos: sobre el periodo 1810-1876 destacan, por cierto, los trabajos elaborados por un buen número de historiadores aficionados (Rodríguez Barragán, Penilla, Mancilla, Pedraza, Ramírez Arriaga y otros). El movimiento revolucionario de 1910 , en cambio, ha venido despertando el creciente interés de los profesionales (Rojas, Falcón), aunque la historia revolucionaria no podrá interpretarse de un modo convincente si antes no se emprende una investigación amplia y acuciosa sobre la vida política porfiriana en territorio potosino.

Finalmente, a pesar de las enormes limitaciones que presenta la bibliografía política sobre San Luis Potosí, son dignas de mención las obras que Sánchez Unzueta, Galaviz de Capdevielle y otros autores han dedicado a los movimientos sociales que se desarrollaron al promediar el siglo XIX, tema siempre soslayado por los historiadores tradicionales.

\section{ORIGENES Y PRIMER TRECHO DE LA INDEPENDENCIA}

BCC Herrera, Luis, Relación de la revolución en San Luis RAG 031 Potosi... Lego de San Juan de Dios, la noche del 10 al 972. 03111 de noviembre de 1810, Relación inédita, paleogra1944 fiada y anotada por Nereo Rodríguez Barragán, MéBNAL xico, Vargas Rea, 1944, 39 p.

972.008

Edición del manuscrito que perteneció al historiaBAH.7. dor oaxaqueño don Carlos María de Bustamante, y que se guarda en la Biblioteca del Museo Nacional.

Rodríguez Barragán, en sus notas, hace biografias breves de los principales personajes de la Independencia en San Luis Potosí, y añade noticias sobre la fundación de pueblos y otros datos de interés que encontró en el Archivo General de la Nación. Presenta también una introducción al texto del documento en la que narra los inicios de la revolución de Independencia en San Luis.

$\begin{array}{ll}\text { BCC } & \text { López de Santa Anna, Antonio, Plan de San Luis, } \\ \text { RAG } & \text { 1823, San Luis Potosí, editó Nereo Rodríguez Barra- } \\ 972.044 & \text { gán, } 1955,6 \text { p. } \\ \text { S2p } & \text { Edición facsimilar del Plan que se firmó en la capi- } \\ 1955 & \text { tal de San Luis Potosí el } 5 \text { de junio de 1823, bajo } \\ \text { BCC } & \text { el patrocinio político de Antonio López de Santa } \\ \text { BP } & \\ 972.440 & \text { Anna. }\end{array}$

L81p

1955

$\overline{\mathrm{BCC}}$

RAG

972.008

A26b

1969

601

Montejano y Aguiñaga, Rafael, El clero y la Independencia en San Luis Potosi, San Luis Potosí, Academia de Historia Potosina, 1971, 100 p.

Documentada reseña biográfica de los religiosos y sacerdotes de uno y otro bando que tomaron parte en el movimiento de insurgencia nacional. 


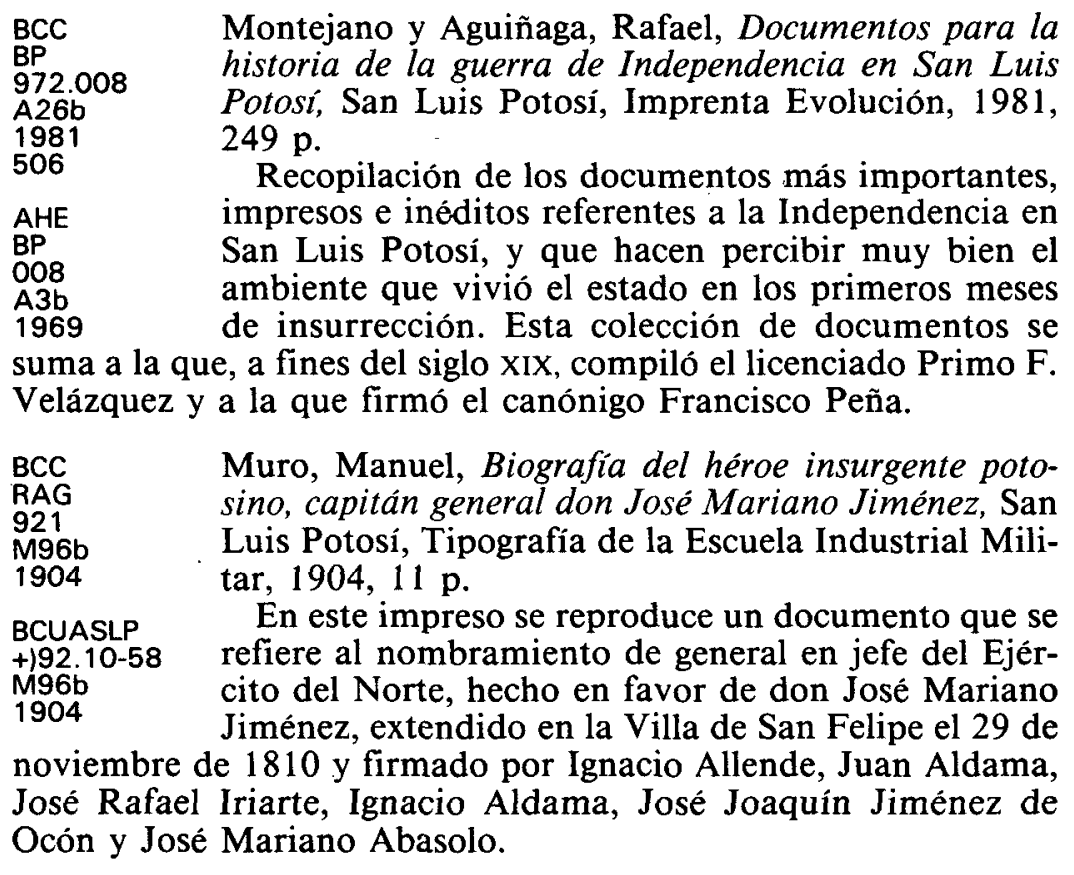

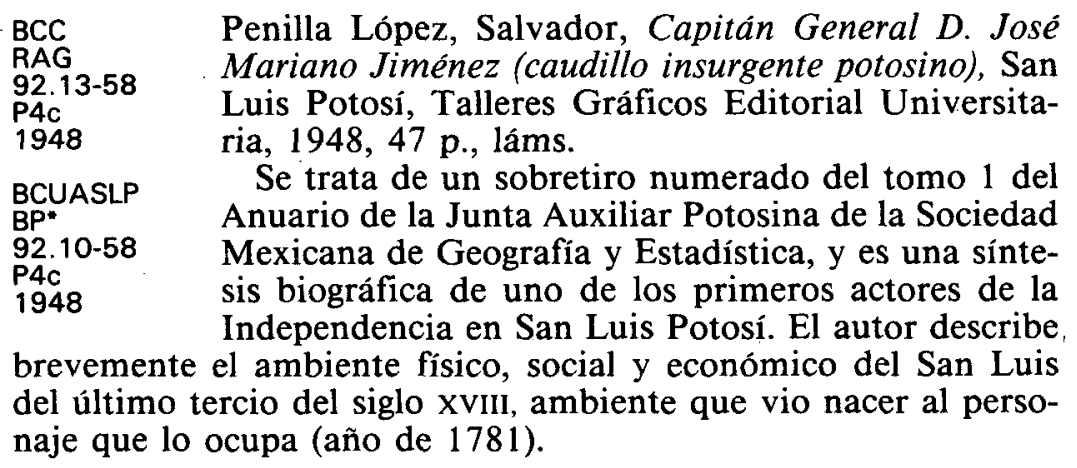

BCC Rodriguez Barragán, Nereo, Expedición del General

RAG Mina a través de la provincia de San Luis Potosi, San

972.033 Luis Potosí, Talleres Gráficos Editorial Universita-

1948 ria, 1948, 31-72 p.

AHE También sobretiro numerado del tomo $1 \mathrm{del}$

BP Anuario de la Junta Auxiliar Potosina de la S. M. de

972.033 G. y E., reconstruye brevemente el itinerario de

$\begin{array}{ll}\text { R18e } & \text { Francisco Javier Mina por el oriente potosino; hace }\end{array}$ especial énfasis en la región de Ciudad del Maíz.

BCC Rodríguez Barragán, Nereo, Historia de la guerra de

Independencia en la provincia de San Luis Potosí,

R7h San Luis Potosi, Sociedad Potosina de Estudios His-

1976 tóricos, 1976,86 p., ils.

BNAL Peculiar narración de lo que fue el movimiento de 972.4203 independencia en San Luis Potosi. Se incluyen ilusROD.h traciones que muestran las Cajas Reales a fines del siglo XVIII, del Palacio de Gobierno del Estado, del Convento de 
San Francisco, que fue prisión de los primeros insurgentes potosinos, y de otros sitios y personajes relacionados con la Independencia en San Luis. En la segunda parte, se leen largas notas del autor sobre el texto principal, un retrato del general Mina, del general Octaviano D'Almivar así como datos sobre las intendencias en la provincia potosina, y sobre el ejército de Nueva España hacia 1810 .

\section{INICIACION Y CRISIS DE LA VIDA CONSTITUCIONAL}

$\mathrm{BCC}$

RAG

342.2

1826

Congreso Constituyente del Estado de San Luis Potosí, Constitución Politica del Estado Libre de San Luis Potosí, México, Imprenta del Aguila, 1826, 95 p.

Texto completo y original de la Constitución que fue firmada el 17 de octubre de 1826 por José Ildefonso Díaz de León, gobernador del estado, por José Ignacio de Gárate, secretario, y por Francisco Antonio de los Reyes, Ignacio Soria, y Manuel Ortiz de Zárate, presidente y secretarios del Congreso, respectivamente.

BCC Díaz de León, Rafael, Biografía del primer gobernaRAG dor de San Luis Potosi, San Luis Potosi, Talleres 92.4-51 Gráficos Escuela Industrial, 1927, 6 p.

1927 Biografía brevísima del licenciado Ildefonso Díaz de León, en la que se omiten datos importantes referentes a su trayectoria política, en el momento crucial de la constitución de San Luis Potosí como estado soberano. BCC Gorriño y. Arduengo, Manuel María de, Ensayo de

341

G76e

1825 una Constitución Política que ofrece a todos los habitantes del Estado Libre de la Luisiana Potosina, o sea el ciudadano D.M.M.G.A., México, Oficina de don Mariano Ontiveros, $1825,72 \mathrm{p}$.

El autor desempeñaba el cargo de diputado en la Legislatura local en la época de la redacción de esta importante obra. Consta de un "Proemio" que es una exposición de motivos abundante en consideraciones históricas y filosóficas; del "Ensayo de Constitución" o proyecto; y de unas "Conclusiones", en dos páginas.

BCC Mancilla Rivera, Luis, El sentido social de la primera RAG 972.057 legislación constitucional potosina (1827-1828); estuM2s dio histórico-jurídico, 2a. ed., San Luis Potosí, Talle1951

BCUASLP +1972 .

570

M2s

1951 res Gráficos de la Editorial Universitaria, 1951, 23 p.

Este es un estudio histórico-jurídico, que se sitúa en la acción gubernamental de Ildefonso Diaz de León quien, por cierto, decretó la abolición de la esclavitud en San Luis Potosí. La primera edición se hizo en 1948, y es un sobretiro del Anuario de la Junta Auxiliar Potosina de la Sociedad Mexicana de Geografía y Estadistica. 
misma, San Luis Potosi, Academia de Historia Potosina, 1975, 70 (59) p.

AHE

BP

A3b

1969

15

Se trata de una documentada presentación del estucional en el estado. cenario político y constitucional potosino, luego de la consumación de la Independencia. El autor, prolijo en detalles, reconstruye muy bien el cuadro mínimo de actores y hacedores del primer orden consti-

BCC Ramírez Arriaga, Manuel, La conspiración potosina RAG contra la Constitución centralista del año 1836, Mé972.052 xico, Artes Gráficas del Estado, 1946, 65-88 p., So1946 bretiro del tomo LXII, núm. 1 del Boletín de la Sociedad Mexicana de Geografía y Estadística.

Narración del movimiento político iniciado por la Junta Departamental de San Luis Potosí en 1841 que tuvo por objeto promover la reforma de la Constitución centralista (las Siete Leyes), durante la presidencia del general Anastasio Bustamante.

$\begin{array}{ll}\text { AHE } & \text { Echenique Portillo, Gabriel y Nereo Rodríguez B., } \\ \text { BP } & \text { Diputados potosinos al Congreso Constituyente de } \\ \text { 328.3 } & 1824 \text {, San Luis Potosi, Imprenta "Evolución", 1975, } \\ \text { E3d } & 42 \mathrm{p} \text {. } \\ 1975 & \text { Relación biográfica mínima de los artífices de la } \\ \text { BINAH } & \text { primera iniciativa constitucional potosina. } \\ \text { FTS } & \end{array}$

Rodríguez Barragán, Nereo, Esclavos..., San Luis Potosí, s. e., 1927.

Artículo publicado en el periódico Acción de San Luis Potosí a propósito del primer centenario de la abolición de la esclavitud. Se incluye el decreto firmado por el vicegobernador del estado, José $B P$

972.570

R7e 1927

BCC
$\mathrm{BP}^{*}$
$92.2-24$
$\mathrm{R} 7 \mathrm{~g}$
1977
Eulogio de Esnaurrízar y algunos apuntes sobre la esclavitud en el mundo, en el pais y en San Luis Potosí.

Rodríguez Barragán, Nereo, El general de división Miguel Francisco Barragán y su célebre Exposición. Contestación de la H. Legislatura de San Luis Potosi, San Luis Potosí, ed. mimeografiada, 1977, 19 p.

Biografía del general Barragán que nació en el Valle del Maíz, S.L.P. En 1830 fue nombrado comandante militar en Jalisco y alli lanzó su "Exposición" pretendiendo unificar a los partidos que existian en el país, en cuya tarea fracasó. En 1836 fue presidente de la república.

BCUASLP Rodríguez Barragán, Nereo, Lic. José Ildefonso Diaz fundador del Colegio Guadalupano Josefino, San Luis Potosí, Sociedad Potosina de Estudios Históricos, 1972, $32 \mathrm{p}$. cargo por Vicente Romero, antiguo legislador potosino. La primera edición se hizo en 1965. 
$\mathrm{BCC}$

$\mathrm{BP*}$

917.6

G16d

1971

Galaviz de Capdevielle, María Elena, Descripción y pacificación de la Sierra Gorda, México, s.e., 1971, $149 \mathrm{p}$.

Sobretiro de la Historia Novohispana, se refiere a los alzamientos campesinos y a la pacificación de la Sierra Gorda, desde el siglo XVI hasta principios del Xx. La autora se basa fundamentalmente en el informe de don Gerónimo de Labra (protector de los indios chichimecas - jonaces) fechado en 1740, que constituye la más completa descripción de los límites, parajes, habitantes y misiones de esa región a principios del siglo xvIII, y que incluye un relato sobre una rebelión indígena sucedida en 1703. También le fueron útiles para el trabajo, las crónicas de religiosos y otras fuentes bibliográficas. Se incluyeron así mismo tres mapas de la zona en importantes momentos de su historia.

$\begin{array}{ll}\text { BCC } & \text { Galaviz de Capdevielle, María Elena, Eleuterio Qui- } \\ \text { BP } & \text { roz y la rebelión de 1847 en Xichú, San Luis Potosí, } \\ 972.008 & \text { Academia de Historia Potosina, 1979, 25 p. (Biblio- } \\ \text { A26b } & \text { teca de Historia Potosina, serie cuadernos 69). } \\ 1969 & \text { Basada en documentos del Archivo Histórico de la } \\ 69 & \text { Defensa Nacional y en otros, la autora de este folleto } \\ \text { AHE } & \text { presenta una descripción sucinta de los aconteci- } \\ \text { BP } & \text { mientos que tuvieron lugar entre 1847 y 1850 en la } \\ \text { O08 } & \text { A3b } \\ \text { A369 } & \text { Sierra Gorda, región natural situada en los límites de } \\ 469 & \text { los estados de Guanajuato, Querétaro y San Luis Po- } \\ & \text { tosí. }\end{array}$

$\mathrm{BCC}$

$\mathrm{BP}$

972.008

$\mathrm{A} 26 \mathrm{~b}$

1969

53

Montejano y Aguiñaga, Rafael, Origen y progreso de la revolución de Sierra Gorda 1847-1849, Edición e introducción de R. Montejano y Aguiñaga, San Luis Potosí, Academia de Historia Potosina, 1977, 18 p.

Reproducción anotada de un testimonio anónimo sobre la insurgencia campesina de la Sierra Gorda (1847-1850).

BCC Muro, Manuel, El asesinato del Gobernador del EsRAG tado D. Julián de los Reyes. Reminiscencias, San Luis M96a Potosí, Tipografía de la Escuela Industrial Militar, $1908 \quad 1908,89 \mathrm{p}$.

Biografía de quien fuera gobernador del estado (1848-1853), y cuyo asesinato se atribuye al Directorio de Rioverde, compuesto por quienes eran en 1853 sus más acervos enemigos, después de haber sido hacia 1848 sus más fervientes partidarios.

BCC
BP
972.00
A26b
1969
78

AHE
BP
008
A3b
1969
478

Sánchez Unzueta, Horacio, Un motín de campesinos en la hacienda de Bocas, S.L.P., 1847-1853, San Luis Potosí, Academia de Historia Potosina, 1982, 11 p.

El movimiento agrario que es objeto de este ameno relato, surgió paralelamente a los levantamientos campesinos que se dieron al oriente del estado (Sierra Gorda) y a la crisis política que acarreó la disputa por el poder protagonizada por los representantes de los grandes intereses mineros y agrícolas de San Luis Potosí. Basado en fuentes primarias, éste 
es el primer trabajo que se escribió sobre el movimiento que tuvo su desarrollo durante seis años, y que trascendió hasta 1864.

\section{EL ASCENSO LIBERAL}

$\mathrm{BCC} \quad$ Arriaga, Ponciano, Los millones de la Mesilla, en $\mathrm{BP}$ parte descubiertos por uno de los pro-hombres del gobierno actual de México, prólogo y notas de Nereo Rodriguez Barragán, San Luis Potosí, Talleres Gráfi-

AHE

$\mathrm{BP}$

972.06

A $1 \mathrm{~m}$

1975 cos de la Editorial Universitaria Potosina, 1975, 34 p., láms.

Rodríguez Barragán hace en esta obra un prólogo explicativo de lo que significó para el país el Tratado de la Mesilla en 1853; expone algunos datos biográficos de los principales personajes que intervinieron en él, de Ponciano Arriaga y de Melchor Ocampo, autor y comentarista, respectivamente, del folleto "Los Millones de la Mesilla", firmado en Brownsville el 1o. de marzo de 1855.

BCC
BParajas, Pedro, Protesta del Illmo. Sr. Obispo de San
252
1858
Luis Potosi contra la Ley de 25 de junio de 1856, San
Luis Potosí, Imprenta de Dávalos, 1858, 34 p.
vino la venta de los bienes raíces del clero. En ella se expone el
desarrollo de la relación de la Iglesia con el gobierno, "y lo que
ella ha hecho por este", y se niega obediencia en la diócesis poto-
sina a la disposición legal de referencia.

AHE Bazant, Jan, Antonio Haro y Tamariz y sus aventuras BP políticas, 1811-1869, México, El Colegio de México, 92.8-68 1985, 200 p., láms.

1985 Biografía de uno de los personajes más pintorescos del escenario político mexicano del siglo XIX. Haro militó primero en el partido liberal, para después seguir la causa conservadora; fue jefe político de la capital de San Luis Potosí en 1855, desde donde lanzó con Anastasio Parrodi el antisantanista Plan de San Luis.

Para elaborar esta excelente obra, el autor consultó ocho archivos nacionales y del extranjero.

AHE Constitución Politica del Estado Libre y Soberano de BP San Luis Potosi, 1857, San Luis Potosi, s.p.i., 1857, 342.2 $37 \mathrm{p}$.

Texto original y completo de la Constitución que suscribieron J. Noreña, Domingo Dena, Gregorio Vázquez y Martín Gascón, en la Sala de Comisiones del H. Congreso del Estado, el 11 de septiembre de 1857.

BCC Proyecto de Constitución del Estado que se presentó

al $H$. Congreso por su comisión respectiva, en sesión de 11 de septiembre de 1857, y se imprime a virtud de haber acordado su publicación el mismo H. cuerpo,

San Luis Potosí, Imprenta del Gobierno, 1857, 37 p.

Edición original del Proyecto que fue firmado en la sala de Comisiones del $\mathrm{H}$. Congreso del Estado, el 11 de septiembre de 1857 
por J. Noreña, Domingo Dena, Gregorio Vázquez y Martín Gascón.

\begin{tabular}{|c|c|}
\hline $\begin{array}{l}\text { BCC } \\
\text { RAG } \\
972.0652 \\
\text { R19C } \\
1955\end{array}$ & $\begin{array}{l}\text { Ramírez Arriaga, Manuel, La contribución potosina } \\
\text { al Plan de Ayutla, San Luis Potosí, Universidad Au- } \\
\text { tónoma de San Luis Potosi, 1955, } 39 \mathrm{p} \text {. } \\
\text { El tema central del folleto es la autoria del Plan: }\end{array}$ \\
\hline $\begin{array}{l}\text { BCUASLP } \\
\text { BP* } \\
972.670 \\
\text { R19c } \\
1955\end{array}$ & $\begin{array}{l}\text { cuestiona que sea Ignacio Comonfort el autor y ana- } \\
\text { liza la participación de algunos representantes del } \\
\text { Partido Liberal (Ocampo, Juárez, Arriaga, Ruiz, } \\
\text { Prieto) en la elaboración del mismo. Por lo tanto, la } \\
\text { contribución local a que el autor se refiere, fue la de }\end{array}$ \\
\hline
\end{tabular}

\begin{tabular}{ll} 
BCC & Ramírez Arriaga, Manuel, Don Ponciano Arriaga y el \\
BP & Plan del Hospicio, México, s.e., 1946, 43 p. \\
$92.1-82$ & Sobretiro del tomo LXI, núm. 2 del Boletin de la \\
R19d & Sociedad Mexicana de Geografia y Estadística en el \\
1946 & que se analiza la actuación de Arriaga como ministro \\
BCC & de Justicia frente al Plan del Hospicio por el cual se \\
RAG & proclamó, en Guadalajara, la revolución contra el ré- \\
$92.1-82$ & gimen de Arista (20 de octubre de 1852), y, en gene- \\
R19d & ral, contra las instituciones liberales. Suscrito por \\
1946 & \multicolumn{2}{c}{. } \\
varios canónigos, prebendados y sacerdotes, el Plan llamaba de \\
nuevo a Santa Anna o al establecimiento de un segundo imperio.
\end{tabular}

\section{LA INTERVENCION FRANCESA}

BCC Bustamante, Juan, El Estado de San Luis Potosi, sus RAG

972.072

B97e 1884 servicios prestados en la guerra de la intervención extranjera. Ligeros apuntes, México, Imprenta y Litografía de Irineo Paz, 1884, 20 p.

Narración de los hechos de armas que ocurrieron en territorio potosino durante la época en que, siendo gobernador el autor de estos apuntes, el estado de San Luis Potosi contribuyó notablemente a la causa republicana.

\begin{tabular}{ll} 
BCC & Pedraza, José Francisco, Juárez en San Luis Potosi, \\
BP & 1863-1867, San Luis Potosí, Gobierno Constitucional \\
972.081 & del Estado, 1972, 88 p., láms. \\
P33j & Amena reconstrucción del escenario histórico local \\
1972 & durante la estancia del presidente Juárez que, hu- \\
BCUASLP & yendo de México -por el embate intervencionista e \\
BP & \\
972.081 & imperial-, iba hacia Paso del Norte. \\
P3j. & \\
1972 & \\
\hline BCC & Rodríguez Barragán, Nereo, Don Juan Bustamante, \\
RAG & gobernador liberal de San Luis Potosi, San Luis Po- \\
$92.2-97$ & tosi, en Tiempo de Cuadrante, Talleres Gráficos de \\
R7d \\
1956 & la Editorial Universitaria, 1956, 31 p., una il. \\
AHE & Pequeña biografia de uno de los personajes impor- \\
BP & tantes en la historia militar del siglo XIX a nivel na- \\
92.97 & cional. Potosino, nacido en Villa del Valle de San \\
R7d & Francisco, hoy Villa de Reyes, S.L.P., en 1818, sus \\
1956 & Fran
\end{tabular}


méritos militares le permitieron que Juárez lo nombrara gobernador del estado en 1867.

BCUASLP Rodríguez Barragán, Nereo, Juárez y la princesa BP* Salm Salm, San Luis Potosí, s.e., 1962, núm. 1960.

92.10-9 Breve noticia sobre el último intento de negocia1962

$1-4$ ción para evitar el fusilamiento del derrotado Maximiliano de Habsburgo, intento hecho por la princesa Salm Salm ante el presidente Juárez en la capital de San Luis Potosí. Existen dos ediciones anteriores a ésta: una de 1955 y la otra de 1958.

\section{VIDA POLITICA PORFIRIANA}

BCC A la grata memoria del señor ingeniero D. Blas Es92.5-86 1907 contria, ministro de Fomento, muerto el dia 4 de enero de 1906, San Luis Potosí, Tipografía de la Escuela Industrial Militar, 1907, 74 p., 1 h. pleg.

El organizador de este libro homenaje fue el señor Marcelino López Zamarrón, exsecretario particular del ingeniero Blas Escontria, que antes de ocupar la cartera de Fomento fue gobernador del estado. Se incluyen textos del licenciado Primo Feliciano Velázquez, del señor Alberto López Hermosa y de otros allegados o admiradores del exgobernante.

BCC Galindo y Villa, Jesús, Bosquejo biográfico del señor RAG ingeniero don Blas Escontria, México, Imprenta y G16b $\quad$ Fototipia de la Secretaría de Fomento, 1906, 29 p.

1906 Esta es una detallada biografía de quien ocupó la gubernatura del estado entre 1898 y 1905 . Se incluyen datos relevantes sobre la vida política y económica potosina de la época.

AHE Márquez Jaramillo, Enrique, La casa de los señores $\mathrm{BP}$ santos (un cacicazgo en la Huasteca potosina, 18761910), México, El Colegio de México, 1979, 67 (4) 28(20) p.

Tesis para optar por el grado de Maestro en Cien-

$\mathrm{BCC}$

$\mathrm{BP}$

918

M13c

1979 cia Política, aborda el problema de las estructuras de poder y de los procesos sociales y políticos de esa región durante el siglo XIX. Hipótesis notable de esta obra: la Revolución mexicana tuvo como actores protagónicos a un grupo de rancheros acomodados del oriente potosino y no a las masas campesinas.

BCC

RAG

92.9-77

M3s

1936

BCUASLP

+) 92.9-77

M3s

1956

Meade, Joaquin, Semblanza de Don José Encarnación Ipiña, San Luis Potosí, Impresos del Centro, 1956, 43 p.

Homenaje a uno de los más importantes hacendados y hombres políticos de San Luis Potosí, la semblanza registra acontecimientos importantes como la estancia de Benito Juárez en San Luis Potosí durante la guerra de los Tres Años y la propuesta del propio Ipiña -ante el Congreso estatal en 1911-de fraccionar las grandes propiedades para beneficio de los labriegos potosinos. Ipiña fue el último gobernador porfirista de San Luis Potosí. 


\begin{abstract}
$\mathrm{BCC}$
$\mathrm{BP}$

92.5-86

M96r

1910

Muro, Manuel, Reseña de las fiestas y obsequios tributados al señor ingeniero $D$. José $M$. Espinosa $y$ Cuevas con motivo de su exaltación al poder para un nuevo periodo gubernativo, San Luis Potosí, Imp.

BCUASLP

$+)$ 92.5-86 M96r

Moderna, 1910,65 p.

Crónica de las fiestas que con motivo de la reelec1910

ción del ingeniero José María Espinosa y Cuevas como gobernador del estado (10. de diciembre de 1910) se organizaron en la capital. Contiene útiles listas de comerciantes, banqueros y miembros de los clubes políticos del estado.

BCC Rodríguez Barragán, Nereo, El Canónigo Mauricio ZP Zavala apóstol del agrarismo en el Valle del Maiz. 3a. 92.26-26 ed. corregida y aumentada, pról. de Roberto Llanas 1972

F., San Luis Potosí, Talleres Gráficos de la Editorial Universitaria Potosina, 1972, 33 p.

Esbozo biográfico y relación de acciones políticas de quien, entre 1879 y 1883 , promovió la insurgencia indigena contra caciques y terratenientes de las regiones huasteca y de Ciudad del Maíz. Las dos ediciones anteriores se hicieron en 1958 y 1960.

BCuAslp Sustaita, Alberto y M. González Pérez, Homenage al Ex. Sr. General Carlos Diez Gutiérrez, gobernador del es92.451 tado de San Luis Potosi, San Luis Potosí, Lit. Escuela $\mathrm{S} 9 \mathrm{~h}$

1897 Industrial Militar, $1897,48 \mathrm{p}$.

Contiene una amplia biografía política del general que, oriundo del Valle del Maíz, gobernó al estado durante 18 años (1876-1880 y 1884-1898) y una descripción interesante de algunas edificaciones civiles y de las actividades oficiales de la época.
\end{abstract}

\title{
Surgimiento y DESARRollo de LA REvolucion
}

BCC Acosta, Miguel M., Pedro Antonio de los Santos, sol-

RAG

92.19-2

A26p

1944

BCUASLP

+ ) $92.19-2$

1944

durante el siglo XIX. dado y mártir de la Revolución de México, San Luis Potosí, s.e., 1944, 33 p.

El autor de esta semblanza fue compañero de armas de De los Santos, uno de los revolucionarios potosinos más destacados cuya familia ejerció una prolongada hegemonia política y social en la Huasteca

$\mathrm{BCC}$

RAG

972.008

A26b

1969

2

Alcocer Andalon, Alberto, El general y profesor Al-

$\mathrm{BCC}$

$\mathrm{BP}$

972.008

A26b

1969

2 berto Carrera Torres, San Luis Potosí, S.L.P., Academia de Historia Potosina, 1969, 20 p., láms. (Biblioteca de Historia Potosina, serie cuadernos 2).

Esta es una de las biografías más completas sobre el general Carrera que, originario de Tamaulipas, actuó durante la Revolución conjuntamente con los hermanos Cedillo. El autor incluye tres facsímiles de documentos sobre algunos momentos claves de la vida del personaje.

$\mathrm{BCC} \quad$ Alcocer Andalon, Alberto, Librado Rivera, ilustre $\mathrm{BP}$ precursor de la Revolución mexicana, San Luis Po- 
972.008

A26b

1969

22

AHE

BP

008

$\mathrm{A3b}$

1969

$\mathrm{H} 22$

BCUASLP

$+972.924$

B24h

1946

|-||

tosí, Academia de Historia Potosina, 1973, 17 p., láms. (Biblioteca de Historia Potosina, serie cuadernos 22.)

Síntesis biográfica de uno de los más notables integrantes del Club Liberal "Ponciano Arriaga" que, de la capital potosina, lanzó una convocatoria nacional para la formación del Partido Liberal Mexicano en 1901.

Barragán Rodríguez, Juan, Historia del ejército y de la Revolución Constitucionalista, México, Talleres de la Editorial Stylo, 1946, 2 t.

En los 54 capitulos que integran los dos tomos de esta obra, el autor, quien fuera jefe del Estado Mayor de Venustiano Carranza, presenta su testimonio sobre el derrotero de la Revolución de 1910, desde sus orígenes hasta el ascenso carrancista a la Presidencia de la República. Barragán, miembro de un clan con una larga tradición de poder en San Luis Potosí, refiere también diversos hechos políticos y acciones de guerra que acontecieron en este estado, como la batalla del Ebano.

BCC Bustamante, Luis F., De El Ebano a Torreón (colecRAG 972.0915 B97d 1915 ción de reportazgos de guerra), Monterrey, Tip. "El Constitucional", 1915, 129 p.

Se refiere básicamente a la defensa constitucionalista de la plaza del Ebano, en la región oriental potosina. Los combates duraron del 21 de marzo al 31 de mayo de 1915 , habiendo sido la victoria de los carrancistas, quienes obligaron a levantar el sitio a las fuerzas villistas contrincantes. La batalla del Ebano fue la más importante de las libradas en San Luis Potosí durante la Revolución.

\footnotetext{
BCC Bustamante, Luis F.. Perfiles y bocetos revolucionaRAG rios, México, Tip. "El Constitucional", 1917, 183 p., 920 ils. y fotos.

1917

Contiene los apuntes biográficos de: Corl. Juan BCUASLP Barragán, Gral. Adolfo Huerta Vargas, Gral. Samuel BP de los Santos, Gral. Francisco A. Espinosa, Gral. Ma920

B97p

1917 nuel Lárraga, Corl. Ramón M. Santoscoy, Lic. Manuel Rivas, Corl. Juan Sarabia, Tte. Corl. Fernando Vázquez, Rafael Nieto, Lic. Manuel Aguirre Berlanga, Corl. Federico Chapoy, Corl. Félix González, Tte. Corl. Luis G. Quezada, Gral. Dr. Rafael Cepeda, notables luchadores constitucionalistas del estado y otras regiones del país.
} BCC Bustamante, Luis F., Quién es el Corl. Juan Barra-

92.2-24

1917 gán, Jefe del Estado Mayor del Primer Jefe, San Luis Potosi, Talleres de "El Constitucional" 1917, 52 p.

Biografía de quien fuera originario de Rioverde (1890), nieto del Gral. Miguel Barragán (presidente de la República en 1836), miembro del club organizador del Partido Democrático al lado de Pedro Antonio Santos, Gutiérrez Crespo y otros; maderista, y jefe de Estado Mayor del primer jefe de la Revolución. 


\begin{abstract}
$\mathrm{BCC}$
$\mathrm{BP}$

92.29-21

D5 $1 \mathrm{~h}$

1932

BCUASLP

+1 92.19-21

D51h

1932

Díaz de León, Rafael, Homenaje a Juan Sarabia, San Luis Potosi, Talleres Tipográficos de la Escuela Industrial Militar, 1932, 44 p.

Rendido durante la época cedillista y, concretamente, durante el gobierno del Corl. Ildefonso Turrubiates, este homenaje fue organizado por un comité conmemorativo de ciudadanos potosinos. El homenaje al que fue destacado escritor antiporfirista

y precursor de la Revolución mexicana fue celebrado a propósito del XII aniversario luctuoso de quien también ejerció la poesía. Sarabia, originario de la capital potosina (1881) colaboró notablemente en El Diario del Hogar y El Hijo del Ahuizote; al fallecer (1920) ostentaba el rango de senador de la República por San Luis Potosí.
\end{abstract}

$\begin{array}{ll}\text { BCC } & \text { Falcón, Romana, Revolución y caciquismo; San Luis } \\ \text { BP } & \text { Potosi, 1910-1938, México, El Colegio de México } \\ 972.09 & \text { (Centro de Estudios Históricos), 1984, 306 p., ils. } \\ \text { F16r } & \text { Este es uno de los estudios más ambiciosos sobre } \\ 1984 & \text { el derrotero político y social del cedillismo, experien- } \\ \text { BCOLMEX } & \text { cia de poder social regional consolidada por el Gral. } \\ 972.42 & \text { Saturnino Cedillo. Basada en fuentes de primera } \\ \text { F182r } & \text { mano (archivos norteamericanos e ingleses), es una detallada re- } \\ \text { mano } & \\ \text { construcción histórica desde la perspectiva de la consolidación del } \\ \text { poder central de la posrevolución. }\end{array}$

BCUASLP Gavira, Gabriel, Su actuación politico militar revolu$+92.7-27$ G27g 1933 cionaria, 2a. ed., México, s.e., 1933.

El Gral. Gavira fue gobernador y comandante militar de San Luis Potosí, entre el 19 de julio y el 10. de octubre de 1915, cuando entregó el mando militar y el gobierno al Gral. Vicente Dávila. Entre los rasgos sobresalientes de su actuación, se encuentran: la prohibición para fabricar bebidas alcohólicas en el estado; la confiscación de propiedades y fincas de los Cientificos y del clero, la devolución al municipio de la Villa de Reyes de los ejidos de que habia sido despojado por la hacienda de Gogorrón.

$\mathrm{BCC}$

$\mathrm{BP}$

972.008

A26b

1969

618

Gómez Gutiérrez, Octaviano, Antonio Diaz Soto y Gama, San Luis Potosi, Academia de Historia Potosina, 1978, 88 p., ils. (Biblioteca de Historia Potosina, serie estudios 18 ).

Esbozo biográfico, en parte basado en fuentes de primera mano, de uno de los liberales potosinos precursores del movimiento revolucionario de 1910 , y que va de 1878 a 1967.

$\begin{array}{ll}\text { BCC } & \text { González Castillo, Eusebio, Graciano Sánchez, San } \\ \text { BP } & \text { Luis Potosi, Gobierno Constitucional del Estado, } \\ 920 & 1978,40 \text { p. (Potosinos Eméritos 5). } \\ 1978 & \text { Basada en fuentes de primera y segunda mano, } \\ 5 & \text { esta es una biografía de quien es considerado como } \\ \text { AHE } & \text { maestro del agrarismo nacional y como potosino } \\ \text { BP } & \text { emérito. } \\ 920 & \text { Graciano Sánchez, el revolucionario, se une a las } \\ \text { G7p } & \text { filas de Pancho Villa, participa en la batalla del } \\ 5 & \end{array}$


Ebano y en el combate de Agua Prieta; posteriormente es secretario de la Confederación Campesina Mexicana y luego de la CNC.

Otros generales revolucionarios como Vicente Dávila, Federico Chapoy y Marcial Cavazos, que gobernaron. a San Luis Potosí en la época constitucionalista.

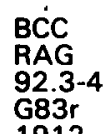

Grimaldo, Isaac, Rasgos biográficos del Dr. Rafael Cepeda, Gobernador constitucional del estado de San Luis Potosi, San Luis Potosi, Tipografía de "El Heraldo"; 1912, 9 p.

El autor se constituyó, a partir de este trabajo, en el biógrafo oficial de los gobernantes en turno. El Dr. Cepeda se hizo cargo del gobierno al triunfar el alzamiento maderista; desde 1910 habia sido nombrado, por la Junta Revolucionaria, gobernador interino y comandante militar, pero su periodo como gobernador constitucional corresponde al cuatrienio de 26 de septiembre de 1911 a 25 de septiembre de 1915. $\begin{array}{ll}\text { BCC } & \text { Grimaldo, Isaac, Vida del ciudadano divisionario Sä- } \\ \text { RAG } & \text { turnino Cedillo, San Luis Potosí, Imprenta "Fénix", } \\ 92.3-34 & \text { 1935, I-1X, 30 p. } \\ \text { G83v } & \text { Esta biografía fue publicada en 1935, cuando el } \\ 1935 & \text { Gral. Cedillo se encontraba en la cumbre de su poder } \\ \text { BCUASLP } & \begin{array}{l}\text { político. Grimaldo hace un recorrido discontinuo e } \\ +192.3-34\end{array} \\ \begin{array}{l}\text { G83v } \\ 1935\end{array} & \begin{array}{l}\text { incompleto de la vida de quien fue uno de los caci- } \\ \text { ques regionales más importantes del México posre- }\end{array} \\ \text { volucionario. }\end{array}$

$\begin{array}{ll}\text { AHE } & \text { Madero, Francisco I., Plan de San Luis: facsimil del } \\ \text { BP } & \text { original mecanográfico, con correcciones de puño y le- } \\ 972.0912 & \text { tra de Francisco I. Madero, Introd. de Luis González, } \\ \text { M11. } & \text { México, Seçretaria de Gobernación, Comité de Pu- } \\ 1980 & \text { blicaciones, 1980, 14 p. }\end{array}$

Edición con la que el gobierno de la República rindió homenaje al Plan de San Luis. Contiene una presentación firmada por el. Prof. Enrique Olivares Santana, secretario de gobernación, en octubre de 1980; la introducción escrita por Luis González ("El Plan de San Luis Potosí en un bosque de planes"); el facsímil del original mecanográfico de Francisco I. Madero y una reproducción de la primera edición del Plan, impresa en San Antonio, Texas, por don Fausto Nieto.

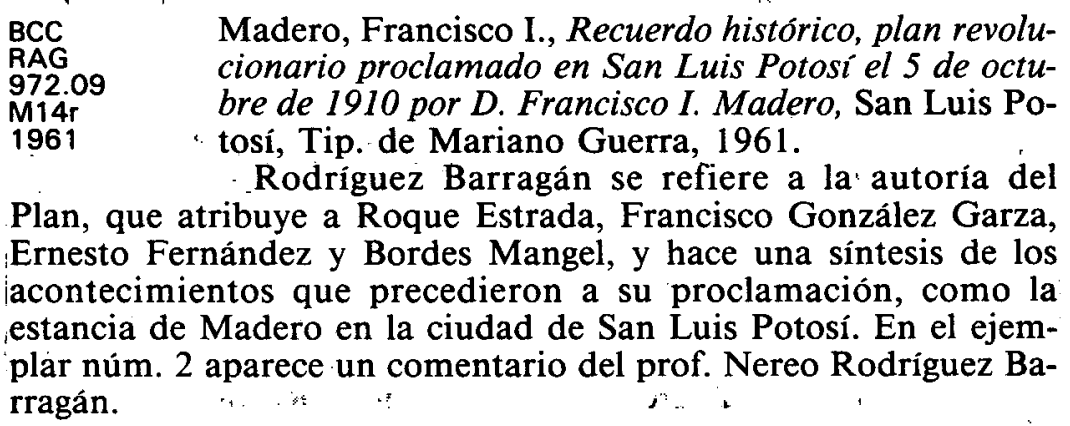


BP

92.19-21

M13j

1965 El autor reconstruye en esta obra el itinerario bio-

mártir de la Revolución Mexicana, México, Talleres Gráficos de la Nación, 1965, 251 p. gráfico-político de quien, junto con Camilo Arriaga, Librado Rivera, Antonio Diaz Soto y Gama, Filomeno Mata y otros, perteneció al grupo de los precursores ideológicos del movimiento de 1910.

BCC Martínez Núñez, Eugenio, La Revolución en el es-

RAG

972.09

$\mathrm{M} 23 \mathrm{r}$

1964

AHE

BP 972.0931

M1r

1964 tado de San Luis Potosi, México, Biblioteca del Instituto Nacional de Estudios Históricos de la Revolución Mexicana, 1964, 77 p.

Este trabajo describe sobre todo, y de una manera minuciosa, las acciones revolucionarias de los hermanos Cedillo en la región oriental potosina. Haciêndose eco del testimonio e interpretaciones de Gildardo Magaña, Martínez Núñez se refiere también a las relaciones que sostuvieron los Cedillo con el frente zapatista.

BCC Mata, Luis I., Filomeno Mata su vida y su labor, en-

RAG

92.13-25

M25f sayo biográfico, México, Secretaría de Educación Pública, $1945,95 \mathrm{p}$.

1945

Escrita por uno de sus descendientes, esta obra es una de las escasísimas biografias de quién fue, desde el periodismo, uno de los críticos más denodados del régimen porfírista. Escritor de El Hijo del Ahuizote y del Diario del Hogar, Filomeno Mata fue uno de los precursores intelectuales de la Revolución mexicana.

BCUASLP Mendoza Vargas, Eutiquio, Gotitas de placer y chubasBP 918

$\mathrm{M} 4 \mathrm{~g}$

1960 cos de amargura; memorias de la Revolución mexicana en las Huastecas, México, D.F., s.e., 1960, ils.

Granito de Oro", da un testimonio interesante del surgimiento revolucionario de 1910. El libro es también una excelente monografía, documentada y ágil, sobre los acontecimientos politicomilitares que durante esa época tuvieron lugar en la región de las Huastecas y, específicamente, en la hidalguense (colindante con la potosina).

BCC

RAG
$92.3-34$

N74C

1964

Noyola Barragán, Luis, Cómo murieron los generales Magdaleno y Saturnino Cedillo, San Luis Potosí, Ediciones Peritos, 1964,75 p.

Este fue uno de los primeros trabajos biograficos

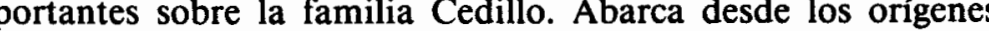
revolucionarios hasta el alzamiento de Saturnino (1938) contra el gobierno del Gral. Lázaro Cárdenas. El autor es particularmente prolijo en datos sobre este último acontecimiento.

BCC Prieto Laurens, Jorge, Lic. Antonio Diaz Soto y Ga-

GOH

92.4-51

L26a

1971 ma, México, Publicaciones del FPACM 1971, 35 p.

Síntesis biográfica y esbozo ideológico de uno de los precursores intelectuales de la Revolución mexicana. El autor, destacado político e ideólogo conservador, ofrece -a través de la reconstrucción mínima del derrotero 
de Diaz Soto y Gama- su testimonio como participante de las jornadas revolucionarias.

AHE Rojas, Beatriz, La pequeña guerra. Los Carrera ToBP 0912 rres y los Cedillo, Zamora, El Colegio de Michoacán, R18p. 1983, 155 p., ils.

1983 Producto de una investigación más amplia sobre el tema, en este libro se plantea el análisis del surgimiento y desarrollo revolucionario de quienes, durante las décadas de 1910 y 1920 , acaudillaron a grandes contingentes sociales de la región potosina de Ciudad del Maíz y de Tula, en Tamaulipas. La autora basa sus interpretaciones en documentos existentes en archivos como el Histórico de la Secretaría de la Defensa Nacional y el General de la Nación.

$\begin{array}{ll}\text { BCC } & \text { Velázquez, Primo Feliciano, La División del Nor- } \\ \text { BP } & \text { deste (capitulo de un libro inédito), Introducción, } \\ 972.008 & \text { transcripción e iconografía, Alberto Alcocer Anda- } \\ \text { A26b } & \text { lon, San Luis Potosí, Academia de Historia Potosina, } \\ 1969 & 1976,21 \text { p. } \\ 40 & \end{array}$

\section{La RatificaCion del PaCtó Federal}

AHE Constitución Politica del Estado Libre y Soberano de BP $\quad$ San Luis Potosi decretada el 5 de octubre de 1917 y 1917 sancionada el 8 del mismo mes y año, San Luis PoBCuAsLP tosí, Escuela Industrial Militar, 1917, 40 p.

$+1342.2$

1917

Texto original y completo de la Constitución suscrita cional del estado de San Luis Potosí y el secretario de gobierno José González, y que significó la ratificación potosina del Pacto Federal.

BCUASLP Prieto Laurens, Jorge, Cincuenta años de política mexiBP

92.16-8

P81c cana; memorias politicas... México, editado por Edi1968 tora Mexicana de Periódicos, Libros y Revistas, 1968,422 p., ils.

Autobiografía de quien fuera fundador del Partido Cooperatista Nacional, regidor del ayuntamiento del D.F. y líder de la Cámara de Diputados durante la presidencia del Gral. Alvaro Obregón y aspirante a la gubernatura potosina en 1923. Uno de los capítulos más destacados de esta obra es, precisamente, el que da cuenta de los enfrentamientos políticos que tuvieron lugar durante ese año entre las fuerzas del Gral. Cedillo y los seguidores del autor.

BCC Villegas Galván, José Alfredo, Biografía de Rafaél Nieto, San Luis Potosí, Universidad Autónoma de San Luis Potosí, 1982, 91 p., ils.

Esta obra, basada en fuentes de primera y segunda mano, y en periódicos de la época y la región, es la primera biografia que se hace de un modo extenso y acucioso sobre quien fue gobernador del estado (1920-23), subsecretario de Hacienda durante la ad- 
ministración carrancista, y un notable ideólogo y traductor de obras del pensamiento socialista de su época.

\section{Dos POTOSINOS PRESIDENTES DE LA REPÚBLICA}

\begin{tabular}{|c|c|}
\hline $\begin{array}{l}\text { BCC } \\
\text { RAG } \\
92.2-24 \\
\text { B24d } \\
1953\end{array}$ & $\begin{array}{l}\text { Barragán, Juan, Datos biográficos del Presidente de la } \\
\text { República y héroe de Ulúa General de División Don } \\
\text { Miguel Barragán, México, s.e., 1953, } 10 \text { p. } \\
\text { Originario de Ciudad del Maíz, S.L.P., el Gral. Ba- }\end{array}$ \\
\hline $\begin{array}{l}\text { BCUASLP } \\
+192.3-24 \\
824 d \\
1953\end{array}$ & $\begin{array}{l}\text { rragán }(1789-1836) \text { fue un destacado militar, minis- } \\
\text { tro de Guerra, y presidente de la República. Se le } \\
\text { atribuye la expedición de la Ley Constitucional de } \\
15 \text { de diciembre de } 1835 \text {, considerada por algunos }\end{array}$ \\
\hline \multicolumn{2}{|c|}{$\begin{array}{l}\text { autores como el antecedente del Amparo mexicano. } \\
\text { El autọ de este folleto, general de brigada y descendiente } \\
\text { del biografiado, incluye la bula del Santo Padre Gregorio P. XVI } \\
\text { del } 13 \text { de junio de } 1836 \text {, la que presenta sus condolencias por la } \\
\text { muerte de Barragán al sustituto presidente, José Justo Corro. }\end{array}$} \\
\hline
\end{tabular}

BCC Carbalho y Filos, Felipe, Lineas biográficas del GeneRAG ral de División Mariano Arista ex-Presidente de la C22e $e^{92}-$ República, trad. por Felipe de Carbalho y Filos., San 1934 Luis Potosi, Potosí Editores, 1934, 24 p., una lám.

La presente biografía -comentan Alcorta y Pedraza en su Bibliografía- fue publicada en Lisboa, en La Correspondencia de Portugal, diario de aquella ciudad, y traducida a su vez del Diccionario Enciclopédico Americano The New American Encyclopedia a raíz del traslado de los restos del Gral. Arista de Lisboa, ciudad donde murió el 9 de agosto de 1855, a su país.

BCC González Bustamante, J.J., Mariano de Arista, preRAG

92.1-82

G75m

1955 cursor del Plan de Ayutla, México, Editores e Impresores Beatriz de Silva, 1955, 47 p., una lám.

Notas sobre la actuación política del Gral. Arista que, originario de San Luis Potosí, fungió como presidente de la República de 1851 a 1853 , y que, junto con José Joaquín Herrera, hizo frente a las precarias condiciones en que quedó el país después de la invasión norteamericana de 1847 . Arista fue un defensor del sistema federal, a pesar de sus antecedentes conservadores y de su adhesión al Gral. Santa Anna.

González Bustamante presenta tambiên una descripción de las luchas entre liberales y conservadores que se libraron en los años anteriores a la promulgación de la Constitución de 1857.

\footnotetext{
AHE Rodríguez Barragán, Nereo, El general don Mariano BP 1-82 Arista (en el centenario de su muerte), San Luis Po92.1-82 tosí, Talleres Gráficos de la Editorial Universitaria, 1976 $1976,28 \mathrm{p}$.

Reedición de este folleto, escrito con motivo de la BNAL conmemoración que hizo el gobierno del estado de MIS.14. San Luis Potosí del primer centenario de la muerte del general Mariano Arista, militar potosino destacado, sobre todo en los años 1830. Fue secretario de Guerra y Màrina, fundador de colonias militares y presidente de la República (1853). La primera edición se hizo en 1955.
} 


$\begin{array}{ll}\text { BCC } & \text { Rodríguez Barragán, Nereo, Honores póstumos al Ge- } \\ \text { BP } & \text { neral Don Miguel Barragán, San Luis Potosí, Talle- } \\ 92.2-24 & \text { res Gráficos de la Editorial Universitaria, 1976, 38 p.' } \\ \text { R7h } & \text { Breve semblanza del insurgente oriundo de Ciudad } \\ 1976 & \text { del Maíz que alcanzó la presidencia de la República en } \\ \text { BNAL: } & \text { 1836 cuando el general Santa Anna se separó de ella } \\ 923.272 & \text { para afrontar la iniciación del conflicto con los nor- } \\ \text { BAR.r. } & \text { teamericanos. La primera edición se.hizo en } 1958 .\end{array}$

\section{GobernANTES}

$\begin{array}{ll}\text { BCC } & \text { Grimaldo, Isaac, Gobernantes potosinos 1590-1939, } \\ \text { RAG } & \text { San Luis Potosi, Tip. Escuela "Hijos del Ejército No. } \\ 972.0261 & \text { 10", } 1939,27 \text { p., ils. } \\ \text { G83g } & \text { Partiendo del error de considerar } 1590 \text { como la fe- } \\ 1939 & \text { cha de fundación de la ciudad de San Luis Potosi y no } \\ \text { BCUASLP } & \text { la de } 1592, \text { generalmente aceptada, Grimaldo hace } \\ +192 & \text { un listado amplio de quienes gobernaron-constitucio- } \\ \text { G83g } & \text { nal, interina po provisionalmente- al estado potosino }\end{array}$ hasta finales de la época cedillista (1925-1939).

BCC $\quad$ Mariano Éscobedo en el primer centenario dé su náci-

RAG $\quad$ miento, México, Imprenta Artística, 1927, 23 p. Rela-

1927 ción del homenaje a quien fuera gobernador potosino

$\therefore$ en 1874 , y jefe del Ejército Republicano, cuando. el sitio de Querétaro (1867).

BCC . Meade, Joaquín, El Nobilisimo y muy Ilustre Ayuntamiento de San Luis Potosi y Concejos que lo precedie353 ron 1592-1971, San Luis Potosí, Sociedad Potosina

1971 ,

BCUASLP

BP

912.9

M3n

1971 de Estudios Históricos, 1971, 310 p.

Esta obra, como muchas otras del autor, es una fuente para la investigación de la historia regional. Contiene una detallada y precisa relación de quienes, desde los albores de la vida estatal hasta la década de 1960, ocuparon cargos como presidentes municipales, alcaldes, regidores,: síndicos, procuradores, etc., en la capital del estado.

$\begin{array}{ll}\text { BCC } & \text { Purata Gómez, Carlos, Integrantes del Poder Legisla- } \\ \text { RAG } & \text { tivo de San Luis Potosi del Constituyente de } 1824 \text { a la } \\ 972.047 & \text { fecha, San Luis Potosí, Escuela de Jurisprudencia, } \\ \text { P93i } & 1965, \text { Bol. } 5,27 \text { p. }\end{array}$

Catálogo útil -aunque incompleto-' de la Diputación potosina durante algo más de un siglo de vida política y legislativa (18241965) en San Luis Potosi.

\section{Historia económica}

Sobre la historia de los procesos y regiones económicas del estado de San Luis Potosí, las monografías escritas a propósito de la vida de las haciendas y sus propietarios ocupan el lugar más destacado. Obras como la del académico Bazant o las de los hermanos Cabrera Ipiña -de recio origen terrateniente- muestran no sólo las complejas formas de constitución y desarrollo que experimentaron 
las haciendas, sino también, y de un modo evidente, el proceso profundo que les dio unidad y sentido histórico: la formación de la oligarquia regional potosina que sucumbiría con el advenimiento revolucionario.

Por otra parte, los estudios relativos a la explotación petrolera y minera en el estado -aunque esta última ha recibido poca atención por parte de los investigadores-y los dedicados a otros ramos de fomento, asi como los que José Francisco Pedraza ha escrito sobre numismática, complementan nuestra bibliografía histórica sobre temas económicos.

\section{FOMENTO, MINERIA Y PETROLEO} BCC Bustamante, Miguel, Ligero estudio sobre los pozos

B971 de "El Ebano", explotados por la Mexican Petroleum Co. 1913, s.1., Boletín de la Sociedad Geológica Mexi1913 cana, vol. II, 111-132 p.

Contiene un croquis de los terrenos petrolíferos del Ebano, S.L.P. El autor, ingeniero de minas, hace algunas consideraciones técnicas sobre estos pozos y su producción y estima la extensión de explotación industrial de combustibles líquidos, petróleos, alquitranes minerales y asfalto, concretándose a la costa del golfo, entre Soto la Marina y Tuxpan.

BCC Cabrera Ipiña, Octaviano, El Cerro de San Pedro, $\mathrm{BP}$ Nuevo León, sobretiro de Humanitas, núm. 20, Universidad de Nuevo León, 1979, 339-355 p.

Trata del descubrimiento de las minas del Cerro de San Pedro del Potosí en 1594-1596, localidad que más tarde fue erigida en municipio, y reproduce declaraciones como las de Gregorio de León ante el alcalde mayor Juan López del Riego (1594), Pedro Benito (1594) y (1596) y Pedro Gómez de Buitrón (1594).

$\mathrm{BCC}$

RAG

918.33

D73d 1906

Doheny, Edward L., A brief statement of the results accomplished by the Mexican Petroleum Company at Ebano, San Luis Potosi, México, México, Imprenta y Fototipia de la Secretaria de Fomento, 1906, 3 p.

Breve informe del desarrollo de las actividades exploradoras de petróleo durante cinco años (1901-1906), desde el punto de vista técnico, de producción y de mercado.

Doheny fue el primer explorador petrolero en México, y tuvo como escenario de sus actividades la región del Ebano, en el norte de la Huasteca potosina.

BCUASLP Menéndez, Gabriel Antonio, Doheny el cruel; episo918.3 dios de la sangrienta lucha por el petroleo mexicano, 1958 México, Ediciones Bolsa Mexicana del Libro, 1958, 309 p.

El autor, periodista yucateco, recuerda la forma en que el país fue despojado de una propiedad nacional, el petróleo. Para ello se remonta a los años del porfiriato, concretamente a 1885 , año en que don Angel Saénz Trápaga (introductor del uso del petróleo en la región de Tampico, Tamps.) decidió secundar la resolución de una compañia norteamericana de instalar dos refinerias: una en el 
puerto de Veracruz y otra en la ciudad de San Luis Potosí. En la obra se reviven los "crueles episodios" de las haciendas de El Tulillo, Hopoy, El Chach, Juan Casiano, Cerro Azul, Amatlán, etc. de los estados de Tamaulipas, San Luis Potosí y Veracruz. Edward L. Doheny fue el creador de la Huasteca Petroleum Company, que llegó a México hacia 1900.

BCC Prieto, Alejandro, Proyecto de ferrocarril de San Luis RAG Potosi al Puerto de Tampico, México, Tip. Escaleri080 llas, núm. 13, 1875, 34 p.

Propuesto debido a la enorme desventaja que acarreó para las regiones potosina y tampiqueña la apertura de la ruta ferroviaria México-Veracruz (1873), este proyecto se realizó, luego de no pocas gestiones y negociaciones, hacia finales de la década de 1890. Accionistas principales de la empresa constructora, fuera de los norteamericanos, fueron gente como los hermanos Carlos y Pedro Diez Gutiérrez.

BCUASLP Ramirez, Santiago, Informe sobre el Mineral de Gua+1916.1 dalcázar, en el estado de San Luis Potosí, presentado 1879 al señor Ministro de Fomento, México, Imprenta de José Vicente Villada, 1879, 90 p.

Contiene datos históricos y geológicos sobre Guadalcázar en cinco capítulos: noticias sobre la Mina de Guadalupe, Mina de San Pedro. el Alto, Mina de San Esteban, Mina del Carmen, Mina del Espiritu Santo, etc. Se citan también algunas minas de mercurio. Informe fechado en la ciudad de México, en julio 25 de 1878.

BCUASLP The Illustrated Mexican Developer, 1907, San Luis BP

Ex.

912.1 Potosí, Edición especial, 1907.

1907

Reportaje monográfico sobre el desarrollo económico e institucional del San Luis Potosí porfirista, esta edición especial apareció cuando los signos del derrumbe de esa época de auge eran ya ciertos y estaban cargados de premoniciones.

Gobernaba a San Luis por entonces (1907) el ingeniero José María Espinosa y Cuevas, cuya imagen fue muy cultivada en órganos de información empresarial norteamericanos -como el The Illustrated...- y aún europeos (como la Revue des Relations Internationales et Commerciales de París).

\section{HACIENDAS}

BCC Bazant, Jan, Cinco haciendas mexicanas; tres siglos

BP

913.1

B29c

1975

BCOLMEX 301.35 B362C de vida rural en San Luis Potosi, 1600-1910, México, El Colegio de México (Centro de Estudios Históricos, nueva serie 20),1975, 226 p., ils.

Basado principalmente en documentos de los archivos de la familia Cabrera Ipiña y de la exhacienda de Bocas, es una serie de monografías sobre la vida económica y social que se daba en esta hacienda y en otras como La Parada, Santa Teresa, Bledos y San Diego. El libro aborda, paralelamente, la historia de la oligarquía que fue propietaria de ellas, y que ejerció una influencia notable en los procesos políticos regionales durante largos años. 
BCC 'Bazant, Jan, Terratenientes, peones $y$ arrendatarios BP $\quad$ en San Luis Potosi, 1822-1910, San Luis Potosí, AcaA26b 1969 63 demia de Historia Potosina, 1978, 34 p., (Biblioteca: de Historia Potosina, serie cuadernos 63).

A partir de la información obtenida en los archivos privados de dos haciendas potosinas, San Diego y Bocas, y de la consulta de obras que analizan el sistema general de la hacienda y de estudios detallados sobre haciendas específicas, el autor nos ofrece un ensayo en el que mide, "por un lado, la relación entre haciendas, y por el otro, entre los peones, arrendatarios y aparceros".

El sistema de arrendamiento de terrenos de las haciendas a cam: pèsinos independientes tuvo vigencia en la hacienda potosina del siglo XIX.

\begin{tabular}{|c|c|}
\hline $\begin{array}{l}\text { BCC } \\
\text { Ex. } \\
\text { BP } \\
913 \\
\text { C1d } \\
1979\end{array}$ & $\begin{array}{l}\text { Cabrera Ipiña, Octaviano y Matilde Cabrera I, } 200 \\
\text { haciendas potosinas y su triste fin, San Luis Potosí, } \\
\text { s.e., } 1979,200 \text { p., ils. } \\
\text { Catálogo de datos básicos (ubicación geográfica, } \\
\text { propiedad, demografía, comunicaciones, climas, ac- }\end{array}$ \\
\hline $\begin{array}{l}\text { AHE } \\
\text { BP } \\
913.1 \\
\text { C3h }\end{array}$ & $\begin{array}{l}\text { tividad económica, extensión, sërvicios, estado j } \\
\text { dico) de } 200 \text { haciendas potosinas. Los autores ha } \\
\text { en el prólogo, una apasionada defensa de la hacie } \\
\text { porfiriana y de la propiedad privada en el camp }\end{array}$ \\
\hline
\end{tabular}
BCC Cabrera Ipiña, Octaviano, Historia de Bledos, Ble- RAG dos, s.e., 1958, 169 láms.
Basada en estudios geográficos, históricos, biográ- ficos sobre la hacienda de Bledos y sus propietarios: (ascendientes del autor), y en archivos particulares (archivos Ipiña-Verástegui), esta Historia comienza en la época prehispánica para concluir èn la primera mitad del siglo presente.
historia y escusa crita en forma de cuentos de estilo ligero.
Cabrera Ipiña de Corsi, Matilde, "Los Bledos" me-, morias y leyendas de una haciénda, Madrid, Indus- trias Gráficas Mil, 1946, 257 p.; ils.
Leyendas y tradiciones "bledeñas" basadas en la

BCC Cabrera Ipiña de Corsi, Matilde y Octaviano Cabrera Ipiña, Expropiación de haciendas de los Cabrera Ipiña, San Luis Potosí, s.p.i., 267 p., ils.

Inventario de las haciendas propiedad de la familia Ipiña: pequeñas monografías de doce haciendas en las que se incluyen cronologías, mapas, estadísticas, planos de obras hidraúlicas, descripciones de las actividades económicas, cálculos del valor de la tierra, fotografías de las tierras de labor, construcciones, de los habitantes, piezas arqueológicas encontradas, etcétera.

Obra en la que los autores pretenden hacer una crítica a la política agrariá de la Revolución de 1910. 
BP

913.36

C1s

1978

BINAH

LBS

F1336

C32

Francisco Javier de la Parada, San Luis Potosí, Ed. Universitaria, $1978,127 \mathrm{p}$.

El objeto del estudio, según los propios autores, es explicar "cómo evolucionó la propiedad rural en San Luis Potosí, tomando como ejemplo un predio tipo (hacienda de La Parada) del altiplano potosino". La cronología estudiada va del siglo XVI hasta el presente. La primera edición de esta obra se hizo en 1965.

\begin{tabular}{|c|c|}
\hline $\begin{array}{l}B C C \\
B P \\
917.65 \\
126 j \\
1984\end{array}$ & $\begin{array}{l}\text { Ibarra Grande, Jesús, Jaral de Berrio y su Marque- } \\
\text { sado. Monografia histórica, León, Talleres Linotipo- } \\
\text { gráficos Lumen, } 1984,195 \text { (2) p., ils. } \\
\text { El autor, presbitero originario del lugar, ofrece una }\end{array}$ \\
\hline $\begin{array}{l}\text { AHE } \\
\text { BP } \\
92.10-22 \\
19 j \\
1983\end{array}$ & $\begin{array}{l}\text { vasta información sobre la hacienda de Jaral de Be- } \\
\text { rrio, ubicada en el estado de Guanajuato, y que per- } \\
\text { teneció-en lo eclesiástico y por más de } 200 \text { años- a } \\
\text { la parroquia del Valle de San Francisco, hoy Villa de }\end{array}$ \\
\hline
\end{tabular}

$\mathrm{BCC}$

$\mathrm{BP}$

972.008

A26b

1969

83

AHE

BP

333.2
M13f

1981

pas del fraccionamiento sucesivo de las tierras de Barragán, y de la producción regional durante buena parte del siglo pasado. Contiene tambiên un cuadro genealógico de la descendencia barraganeña, que incluye a personajes politicos potosinos como Miguel Barragán, Carlos y Pedro Diez Gutiérrez, Manuel Escontria, etcétera.

BCC
BP
972.008
A26b
1969
52

Martínez Rosales, Alfonso, Las haciendas potosinas y el Regimiento Provincial de Dragones de San Luis 1796, San Luis Potosí, Academia de Historia Potosina, 1977, 24 p. (Biblioteca de Historia Potosina, serie cuadernos 52).

En este ensayo, el autor identifica las haciendas y los hacendados potosinos que tuvieron que ver con el establecimiento de ese cuerpo militar, a finales del siglo XVIII. Asimismo, estudia a quienes participaron activamente en él y qué lazos de parentesco existían entre ellos.

Util para el conocimiento de las familias de hacendados predominantes en la región en el siglo XIX.

BCUASLP . Mendoza, Salvador, La hacienda de Gogorrón frente BP*

917.4

M4h

1924 al espiritu revolucionario, México, s.e., 1924, 17 p.

Folleto escrito con motivo de la defensa que el autor, abogado, hizo de los intereses de los señores Felipe Muriedas y sucesores de San Luis Potosí, propietarios de la 
hacienda de Gogorrón y anexas, en conflicto con los propósitos agraristas del pueblo de Villa de Reyes, colindante de aquellas propiedades.

BCC Pozo Rosillo, Paulino del, La hacienda de la Pila, San 972.008 Luis Potosí, Academia de Historia Potosina, 1970, A26b $\quad 14 \mathrm{p}$.

1969

11

Monografía documentada de la que fue una importante hacienda mezcalera. Situada a menos de $30 \mathrm{ki}-$ lómetros de la ciudad de San Luis Potosí, fue propiedad, entre otros, del general Carlos Díez Gutierrez, gobernador del estado de 1876 a 1880 , y de 1884 a 1898.

BNAL Pozo Rosillo, Paulino del, coord., "Las haciendas poR 7205 tosinas" en Artes de México, año 22, núm. 189, 1975, ART.m.189 92 p. Fotos de Carlos Alcazar... et al.

En el escueto texto de esta obra gráfica, se consignan algunos datos sobre 19 haciendas potosinas: los nombres de sus dueños, su actividad económica, su arquitectura, etc. Las haciendas de referencia son: Santiago, Bledos Carranco, La Ventilla, Calderón, San Pedro de Gogorrón, La Pila, La Sauceda, Peñasco, El Corte, La Parada, Valleumbroso, Bocas, San Antonio de Rul, Guanamé, Peotillos, Corcovada, Pozo del Carmen, y San Diego del Rioverde.

BCC

913.2

V51h

1881

BCUASLP

$+1304$

V55j

1881

\section{Hacendados}

BCC

$\mathrm{BP}$

869

C1c
1975

AHE

BP

929.1

C3c

1975 Entre sus descendientes se encuentran personalidades notables en la vida política y económica de San Luis Potosí.

BCC

RAG

92.6-43

C1c

1956

AHE

BP

929.1

C3c

1956

Villaurrutia, Agustin, La hacienda de la Pila, San Luis Potosi, Imprenta Dávalos, $1881,15 \mathrm{p}$.

Información sobre los derechos del autor a la hacienda que perteneció en 1815 a Manuel Maria de Gorriño y Arduengo (primer rector del Colegio Guadalupano Josefino).

Cabrera Ipiña de Corsi, Matilde, La casa de Cabrera en San Luis Potosi, San Luis Potosí, Ed. Universitaria Potosina, 1975, 207 p., 1 h. pleg.

Basado en archivos nacionales y extranjeros, parroquiales, y en testimonios orales, este es un estudio histórico-genealógico de la familia Cabrera a partir de uno de sus miembros, don Francisco de Paula de Cabrera y Alderete, nacido a finales del siglo xvill. Cabrera Ipiña de Corsi, Matilde, Cuatro grandes dinastias mexicanas en los hermanos Fernández de Lima y Barragán, San Luis Potosi, Talleres Gráficos de la Editorial Universitaria, 1956, $181 \mathrm{p}$.

Estudio de una de las genealogias más extensas y de mayor importancia de la heráldica hispanomexicana, según la autora. Importante para el análisis de la formación de la oligarquia regional de San Luis Potosí durante el siglo XIX. 
BCC Cabrera Ipiña de Corsi, Matilde, De la Peña de San

Luis Potosi, San Luis Potosí, Editorial Universitaria,

$92 p$

C78p

1985

1985, 201 p. biográficos de los descendientes de cuatro hermanas cuyo apellido era De la Peña y Santacruz. Entre ellos se encuentran miembros de familias prominentes de la actividad política, económica y social del estado durante el siglo pasado y el presente.

La autora es bisnieta de Genoveva de la Peña y Santacruz, esposa de Pantaleón Ipiña, hacendado y político potosino que tuvo una importante presencia al inicio de la vida independiente en San Luis Potosí.

AHE Cabrera Ipiña de Corsi, Matilde, Don Paulo de Be-
BP
929.1
C3p rástegui y de la Vara, México, s.p.i., 1968, 39 p.,
$1968 \quad$ láms.
potosino del siglo XIX, propietario de la hacienda de San Diego y
de otras fincas en la región de Rioverde, S.L.P. La autora incluye
un artículo aparecido en 1935 en el periódico capitalino El Nacio-
nal Revolucionario titulado "Un hacendado excepcional", en el
que transcribe la invitación que Berástegui hizo a los arrendata-
rios de sus fincas y animales para que tomaran las armas junto con
él en defensa del territorio mexicano frente a la invasión nortea-
mericana en 1847, sufragando los gastos de campaña y de manu-
tención de las familias de los que a él se unieren.

BCC Cabrera Ipiña de Corsi, Matilde, La familia Hernández Soto de San Luis Potosi, San Luis Potosi, Ed.

92.8-45

C1f

1966

BCUASLP

BP

929.2

C1f Universitaria Potosina, 1966, 201 p., láms.

Estudio genealógico de una de las familias representantes de la oligarquía potosina. En él se descubre toda una serie de relaciones de parentesco entre los miembros de las familias que controlan la actividad económica y política de la capital potosina durante el los Hernández Soto. siglo XIX y el actual. La autora es bisnieta de uno de

AHE

BP 92.1

C3f

1962

Cabrera Ipiña de Corsi, Matilde, La familia Toranzo de San Luis Potosi, México, San Luis Potosí, s.p.i., 1962, 48 p., 1 h. pleg.

Estudio genealogico de una notable familia de hacendados potosinos que se arraigó en la región potosina hacia mediados del siglo xIX y que tuvo en Casimiro Toranzo a su más destacado representante. Una de las propiedades importantes de esta familia fue la hacienda de Cerro Prieto, en la zona del altiplano, y que poco después de la Revolución de 1910 era una de las principales productoras de mezcal en el estado.

BCC Cabrera Ipiña de Corsi, Matilde y Bárcena, Maria B. de, La Lonja de San Luis Potosi, un siglo de tradición, s.p.i., 418 p.

Microhistoria del centro social que durante el siglo pasado fue el espacio recreativo de las más connotac1179 das familias de la capital de San Luis Potosi. Incluye 
las memorias de una joven de la época, memorias que funcionan como coronación de la sensibilidad porfirista potosina.

\begin{tabular}{|c|c|}
\hline C & $\begin{array}{r}\text { Gamil } \\
\text { Gráfi } \\
\text { blanz }\end{array}$ \\
\hline \multicolumn{2}{|c|}{$\begin{array}{l}\text { Encarnación Ipiña. } \\
\text { La autora, sobrina de la biografiada, incluye importante infor- } \\
\text { mación sobre aquellos potosinos que, en la época, representaban } \\
\text { los intereses económicos más fuertes de la región. }\end{array}$} \\
\hline & \\
\hline
\end{tabular}

Manrique de Lara fue miembro de una de las familias más prominentes de mineros y hacendados de la región potosina durante el siglo XIX. En esta obra se refiere especialmente al cultivo del naranjo y de los bosques en territorio potosino.

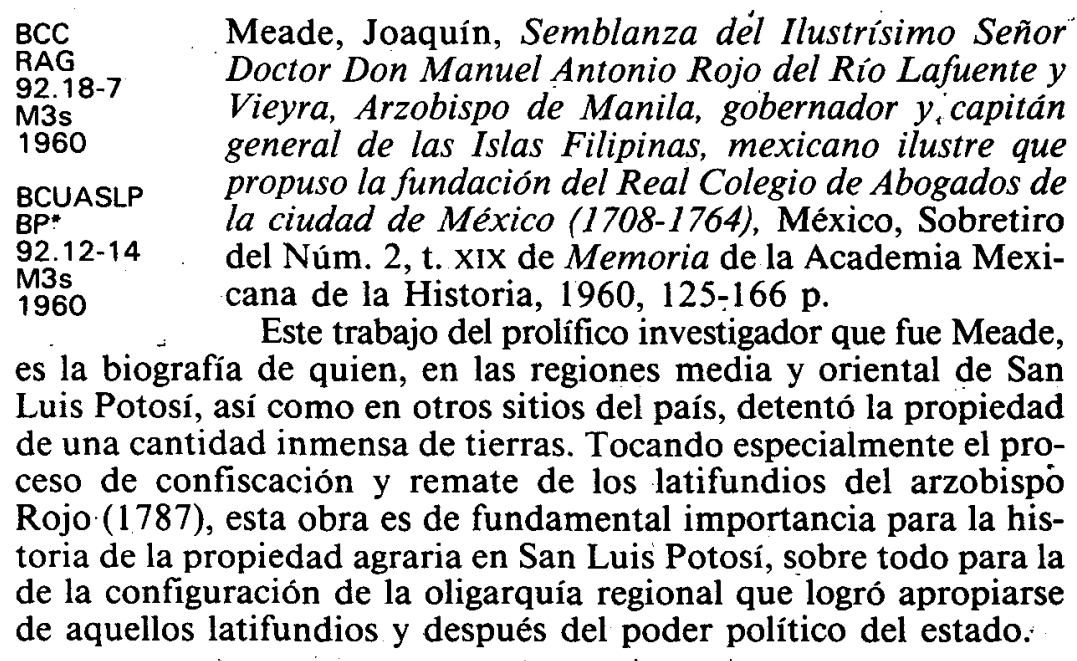

BCC Meade, Joaquin, Ipiña. Dos semblanzas, San Luis Po${ }_{92 y}^{\mathrm{BP}}$ tosí, Editorial Universitaria Potosina, 1956, 42 p., ils.

Estudio biográfico de Don Pantaleón de Ipiña y Eguía y de Don José Encarnación Ipiña, diputado éste y presidente municipal, gobernador del estado en 1910, además de propietario de grandes extensiones de tierra; aquél, padre de éste, fue regidor del ayuntamiento de la capital de S.L.P. el, 1821 , alcalde primero en 1824 al inicio de la vida constitucional, autor del primer reglamento sobre educación primaria en San Luis, y hacendado.

$\mathrm{BCC}$

RAG

92.13-7

R7u

1943
Rodriguez, Blas E., Una fiesta de Moctezumas, México, Tipografia El Nigromante, 1943, 27 p., ils.

Reseña de los actos religiosos, profanos y artísticos que se llevaron a cabo en la ciudad de Alaquines, con 


\begin{abstract}
AHE motivo de la celebración de los cien años de vida del BPE señor D. Severiano Moctezuma, vecino de esa ciu92.13-72 dad y miembro de una de las familias que detentaban

El autor, invitado a participar en las celebraciones, incluye además en este folleto datos genealógicos y biográficos de algunos otros miembros de la familia Moctezuma.
\end{abstract}

BCC Rodríguez Barragán, Nereo, Doña Isabel Moctezuma. RAG Moctezuma II el joven. Dos de los árboles genealógi92.13-72 cos derivados de esa fundadora de la estirpe católica 1955 de los Moctezuma, San Luis Potosi, ed. mimeografiada, $1955,18 \mathrm{p}$.

Estudio del Lic. Alfredo Flores, de México, con notas y declaraciones de Nereo Rodríguez Barragán. Es un trabajo histórico-genealógico de una de las más remotas ascendientes de las familias Moctezuma y Barragán, propietarias de grandes haciendas en el oriente potosino y que desempeñaron acciones políticas destacadas durante el siglo XIX en el estado.

\title{
MONEDA
}

BCC - Espinosa, Antonio Kalixto, Billetes del Imperio MexiBP 2.008 cano de D. Agustín de Iturbide en la intendencia de 972.008 San Luis Potosi, 1822, San Luis Potosi, Academia de Historia Potosina, 1971, 19 p. (Biblioteca de Historia Potosina, serie cuadernos 13).

Estudio sobre estos famosos documentos histórico-numismáticos autografiados por D. Manuel Jacinto de Acevedo y por el Lic. Ignacio Rayón, ültimos intendentes y jefes políticos que gobernaron la provincia de San Luis Potosí, asi como participante, este último, en la organización del primer gobierno nacional.

\footnotetext{
BCC . Espinosa, Antonio Kalixto, Papel moneda de la Re972.008 volución Mexicana que circuló en San Luis Potosí, A26b San Luis Potosí, Academia de Historia Potosina, 1969 1981, 17 p., láms. (Biblioteca de Historia Potosina, 76 serie cuadernos 76).

AHE Este folleto hace mención y describe el papel mo${ }_{008}$ neda emitido por varios estados de la República duA3b 1969 476 rante la Revolución de 1910 que circuló en San Luis Potosí. Intenta comprobar el autor que San Luis Potosí ostenta una variedad mayor de resellos y revalidaciones que la de otros estados en billetes de la época revolucionaria.

Incluye algunos datos interesantes sobre la función que tenía el papel moneda durante la Revolución (propagador de consignas), su aceptación, su valor, etcétera.

BCC León Dávalos, José Everardo, Acuñación en San Luis Potosi, por primera véz en México, de las monedas de 92.008 plata fraccionaria, con el sistema métrico decimal, 1969 1863, San Luis Potosí, Academia de Historia Poto26 sina, 1973, 32 p. (Biblioteca de Historia Potosina, serie cuadernos 26 ).
} 
Estudio histórico-jurídico sobre la introducción del sistema métrico decimal francés en las unidades monetarias y en las medidas de longitud, peso y volumen; sobre la acuñación de moneda en San Luis Potosí y su Casa de Moneda. Se incluyen los textos de varios decretos expedidos por Comonfort en 1857, Juárez en 1861 y 1863 , Lerdo de Tejada en 1873 y otros. También, láminas que muestran las monedas acuñadas en San Luis Potosí.

\begin{abstract}
BCC Pedraza, José Francisco, La moneda provincial de
737

P33c

1961 San Luis Potosi, 1807-1821, San Luis Potosí, Ed. Universitaria Potosina, 1961, 17 p., (Cuadernos de Numismática Potosina 1).

$1 \quad$ Estudio de numismática potosina que tiene el mérito de rescatar un dato importante para San Luis Potosí: en todo el territorio de la Nueva España, esta Intendencia fue la que obtuvo la primera autorización del virrey Iturrigaray, dada al Ilustre Ayuntamiento de San Luis Potosí, para que procediera a la construcción de Tlacos de Ciudad (primeras monedas potosinas y primeras monedas provinciales).
\end{abstract}

BCC Pedraza, José Francisco, La moneda realista de San $\mathrm{BP}$

737

P33c

1961

2

Luis Potosi (acuñaciones de Catorce y Sierra de Pinos), San Luis Potosí, Ed. Universitaria Potosina, 1971, (Cuadernos de Numismática Potosina 2).

Descripción y estudio histórico del origen de la moneda del Real de Catorce y de la de Sierra de Pinos, la primera de plata (1811) y la segunda de cobre, muy rara (1814).

BCC
BP
737
P33C
1961
7

Pedraza, José Francisco, Las "monedas de hacienda" del estado de San Luis Potosi, signos de cambio de las haciendas de "San Juan de Banegas", "Santiago", "Sierra Hermosa", y "Peñón Blanco", San Luis Potosí, Universidad Autónoma Potosina, 1963, 51 p.

(Cuadernos de Numismática Potosina 7).

Estudio histórico-numismático antecedido por algunas notas sobre las monedas de las haciendas en México, llamadas también "tlacos" o "cuartillas". El autor describe e ilustra cada una de las monedas de estas haciendas potosinas, además de incluir algunos datos históricos sobre ellas.

\title{
V. Historia del pensamiento político y social
}

La historia potosina del siglo XIX y de principios del presente ha sido también el concurso vital de las ideologias: modernismo, liberalismo moderado y social, conservadurismo, anarquismo y catolicismo social, y socialismo científico han sido las estaciones de nuestro largo transcurrir ideológico. Manuel María de Gorriño y Arduengo, Ponciano Arriaga y Jesús Silva Herzog, Ignacio Montes de Oca y Obregón, Mauricio Zavala y Rafael Nieto, en obras que desafortunadamente no son todavía del conocimiento público, plasmaron en una forma inteligente y apasionada los fundamentos ideológicos de su acción política o de su propuesta social. 


\section{LIBERALISMO}

BCC Arriaga, Ponciano, Las Procuradurias de Pobres, San BP 00.08 Luis Potosi, UASLP, Facultad de Derecho, 1983, 37 $\mathrm{U} 65 \mathrm{c}$ 1983 p., (Cultura Juridica Potosina núm. 1). 1

Precedida de un estudio introductorio de Enrique Márquez, ésta es una compilación de documentos que reproduce integramente la exposición de motivos y proyecto de ley de la institución de los Procuradores de Pobres que el distinguido liberal Ponciano Arriaga planteara ante el Congreso del estado en 1847.

Arriaga, que nació y murió en la capital potosina (1811-1865) se desempeñó notablemente en la política regional entre 1832 y 1848 , antes de trasladarse a la ciudad de México, donde participaría en acciones de repercusión nacional (como el Congreso Constituyente del 57).

BCC Cardiel Reyes, Raúl, Del modernismo al liberalismo,

RAG

100

C22d

1967

$\mathrm{BCC}$

$\mathrm{BP}$

92.6-76

$\mathrm{C} 22 \mathrm{~m}$

1967

la filosofía de Manuel Maria Gorriño, México, UNAM, 1967, 262 p., láms.

Originado en una tesis presentada por el autor en la Facultad de Filosofía y Letras de la UNAM, este libro es un análisis del desarrollo ideológico de uno de los hombres políticos más destacados de San Luis Potosí durante la transición del Estado colonial al nacional. Gorriño, entre otras cosas, fue el autor de un proyecto constitucional potosino y primer rector del Colegio Guadalupano Josefino. Existe una segunda edición de esta obra hecha en 1981.

BFE Cockcroft, James D., Precursores intelectuales de la UASLP

972.052 Revolución Mexicana (1900-1913), México, Ed. Siglo XXI, 1971, 290 p.

Dedicado al análisis del proceso que involucró a liberales y anarquistas desde la etapa prerrevolucionaria hasta el huertismo, la obra presenta en su primer capítulo una sugerente interpretación sobre la historia económica, política y social de San Luis Potosi durante el porfiriato.

BCC Díaz Soto y Gama, Antonio, Breves consideraciones sobre la importancia del municipio, (Ed. e Introd. de U65c $\quad$ Enrique Márquez), San Luis Potosí, UASLP, Facultad 1983 2 de Derecho, 1984, 21 p. (Cultura Jurídica Potosina 2).

Reproducción de la tesis profesional que el autor presentara en 1901 en la Escuela de Jurisprudencia, y que fue leída como uno de los discursos centrales de la Convención Liberal que en ese año se efectuó en la ciudad de San Luis. Soto y Gama, uno de los abogados que con ardor se adhirió al zapatismo, presidia la Asociación de Estudiantes del Instituto Científico y Literario durante la época de redacción de este documento.

BCC Díaz Soto y Gama, Antonio, Otro Holocausto, pról. de Nemesio Rivera Linares, México, Ed. Jus, 1980, 140 p., láms. 
1980

Colección de artículos escritos por el licenciado Antonio Díaz Soto y Gama en los que "previene a México y al mundo del peligro que encierra esa doctrina: el comunismo, hasta el grado de llevarlos a su propio holocausto: el sacrificio de su libertad".

En el prólogo se incluye una carta de Diaz Soto y Gama dirigida al oficial mayor de la Secretaria de Agricultura y Fomento en 1938 en la que se define a sí mismo como antifascista, anticomunista, agrarista, zapatista, obregonista y partidario de la propiedad privada en el campo (en esta carta renuncia como abogado consultor a dicha Secretaría).

$\begin{array}{lc}\text { BCC } & \text { Guillén, Fedro, Jesús Silva Herzog, Isidro Fabela, } \\ \text { BP } & \text { José Vasconcelos, México, UNAM, 1980, 228 p. } \\ 92.5 & \text { Publicado con motivo del cincuentenario de la au- } \\ \text { G91j } & \text { tonomia universitaria por la UNAM. El autor, amigo } \\ 1980 & \text { de las tres personalidades que analiza, nos ofrece un estudio bio- } \\ \text { gráfico de quienes, ligados a la Universidad Nacional, fueron } \\ \text { "dentro de la diversidad de pensamiento y de lucha al servicio de } \\ \text { México" divulgadores de cultura y hombres de acción política. }\end{array}$

BCUASLP Herrera Angeles, Manuel, El pensamiento de Ponciano Arriaga y la reforma agraria mexicana, Mé92.1-84 xico, SEP, 1966, $61 \mathrm{p}$.

1966

Biografia del liberal potosino que vivió entre 181.1 y 1865 y que se destacó por su actuación en el Congreso Constituyente de 1856-57. En San Luis Potosí fue jefe del Partido Liberal, regidor del ayuntamiento, diputado local, secretario general de Gobierno, dos veces diputado federal y miembro del gabinete del presidente Mariano Arista.

BCC Medina Romero, Jesús, Ponciano Arriaga, idéario, BP pról. y selección de Jesús Medina Romero, San Luis 1974 Potosí, Gobierno Constitucional del Estado, 1974, 2 $66 \mathrm{p}$.

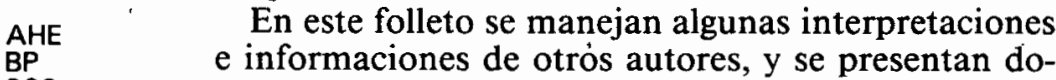
BP
920 G7p 1974

2

AHE

BP

92.1-82

M13c

1970 cumentos ilustrativos de las ideas sociales de Arriaga. paro. II. ¿Socialismo Democrático?, México, FPACM de divulgación histórica, orientación y propaganda, 1970, $21 \mathrm{p}$.

Se incluyen en el folleto un trabajo sobre Arriaga y su pensamiento político y social (Prieto Laurens) y un pequeño articulo titulado “Socialismo Democrático?” (Mier y Terán), en el que se intenta definir este concepto. nocido, México, Sociedad Mexicana de Geografía y Estadística, 1965, 540 p. 
1965

BCUASLP

BP

92.1-84

R19p

1965

BCC

92.1-82

R19p

1950

AHE

BP
$92.1-82$

R18p

1950

BCC

BP

864

$\mathrm{S} 5 \mathrm{i}$

1972

Aunque desordenado, impreciso y falto de documentación, éste es el único esbozo biográfico disponible sobre el destacado militante e ideólogo del liberalismo mexicano del siglo XIX.

Ramírez Arriaga, Manuel, Las Procuradurias de Pobres, México, s. e., 1950, 48 p.

A pesar de la falta de organización y ligereza que caracterizan la elaboración de este folleto, su autor tuvo el mérito indiscutible de dar a conocer por primera vez la iniciativa de Ponciano Arriaga para establecer las Procuradurias de Pobres. sobre problemas mundiales y Temas de carácter general.

Libro homenaje que en los ochenta años de Jesús Silva Herzog publicó el Colegio Nacional de Economistas y en el que se intenta transmitir los momentos culminantes de la labor y militancia política del autor. Incluye 18 ensayos.

BCC Silva Herzog, Jesús, Jesús Silva Herzog: la larga mar92.19-5 cha de un hombre de izquierda, México, Escuela Na-

S5j cional de Economía, 1972, 280 p.

Antología de textos publicada por la Escuela Nacional de Economía y seleccionada por una comisión especial del Consejo General de Estudiantes, Profesores y Trabajadores. Se excluye el tema del petróleo y se pretende reflejar el mensaje de Silva Herzog a las nuevas generaciones de mexicanos. Está dividida en seis partes: El economista, El educador, Contra el imperialismo, La lucha por la democracia y el progreso, La posición ideológica, y escritos varios.

BCC Silva Herzog, Jesús, Mis últımas andanzas 1947-

$\mathrm{BP}$

92.19-5

S5m

1972, México, Siglo XXI Editores, 1973, 350 p.

1973

Amena crónica de los 25 años de actividad polí-

tica, cultural y docente desarrollada por el autor en Mexico y en el extranjero. Estos son algunos de los capitulos que integran la obra: Actividad cultural; México y La Habana; Don Adolfo López Mateos en escena; La Universidad; La invasión a Cuba, otros sucesos menores y México 68.

BCC Silva Herzog, Jesús, El pensamiento económico, so$\mathrm{BP}$

330

S5p 1967 cial y político de México 1810-1964, México, Ed. Libros de México, S. A., 1967, 748 p., ils. Reimpreso por el Fondo de Cultura Económica en 1974.

Obra que tiene su antecedente en El Pensamiento Económico de México del mismo autor (1947). Esta, más extensa y completa, presenta un esbozo de 54 autores empezando con los grandes de la Independencia, Hidalgo y Morelos, pasando por Fray Servando, 
Lorenzo de Zavala, José María Luis Mora, Otero, Lucas Alamán, Ocampo, Zarco, Ignacio Ramirez, Prieto, Matías Romero, Adorno, Justo Sierra, Casasús, Bulnes, Rabasa, Madero, Carranza, González Roa, Luis Cabrera, Flores Magón, Bassols, Gamio, Alfonso Reyes e Isidro Fabela. Incluye al final las fotografias de cada uno de estos autores.

$\begin{array}{lc}\text { BCC } & \text { Silva Herzog, Jesús, Trayectoria ideológica de la Re- } \\ \mathrm{BP} & \text { volución Mexicana 1910-1917, y otros ensayos, Mé- } \\ 864 & \text { xico, Utopía Compañia Editorial, 1976, } 214 \mathrm{p} \text {. } \\ \mathrm{S5t} & \text { Son tres ensayos los que forman esta obra. En } \\ 1976 & \text { ellos, el autor desarrolla algunos temas fundamentales sobre la Re- } \\ \text { volución mexicana y sus consecuencias, como la trayectoria ideo- } \\ \text { lógica, la "Epopeya del petróleo" y "Meditaciones sobre México". }\end{array}$

BCC Silva Herzog, Jesús, Una vida en la vida de México,

$\mathrm{BP}$

92.19-5

1975

2a. Ed., México, Siglo XXI Editores, 1975, 347 p.

Esta es una obra autobiográfica: Silva Herzog describe su vida întima, su trayectoria política, diplomática, universitaria y cultural en México, en la provincia y en el extranjero.

Escrita a la edad de 77 años, comprende desde su nacimiento hasta la fecha en que está escrita.

$\begin{array}{lc}\mathrm{BCC} & \text { Silva Romero, Enrique, El pensamiento económico- } \\ \mathrm{BP} & \text { social de Jesüs Silva Herzog, San Luis Potosí, Ed. Vi- } \\ 330 & \text { sant, 1972, } 274 \mathrm{p} \text {. } \\ \mathrm{S} 5 \mathrm{p} & \text { Esta tesis presentada para obtener la licenciatura } \\ 1972 & \text { en Economía, es una semblanza de Silva Herzog, una exposición } \\ \text { de su pensamiento económico en siete capítulos y, finalmente, un } \\ \text { análisis sobre su pensamiento social, sobre la historia dé México, } \\ \text { la educación y la administración pública. }\end{array}$

BCC Zevada, Ricardo José, El pensamiento político de

RAG

92.1-38

Z48p

1968

Ponciano Arriaga, México, Editorial Nuestro Tiempo, S. A., 1968., 2 t.

BCUASLP

BP

92.1-84

$248 \mathrm{p}$

1968

|-II

A pesar de que esta obra es el intento de comprensión del pensamiento de Arriaga más importante, por su capacidad de sintesis analítica no incluye el periodo de gestación (1832-1847), y sólo hace énfasis en sus actividades e ideas durante el Constituyente de 1857.

\section{CONSERVADURISMO}

BCC Franco Ponce, José, Ipandro Acaico o. Monseñor $\mathrm{BP}$

MO

92.13-8

F8i

1921 Montes de Oca y Obregón, Arzobispo de Cesarea del Ponto, Obispo de San Luis Potosi, México, Agencia Eclesiástica Mexicana, 1921, 278 p.

Estudio biográfico escrito el mismo año en que murió Montes de Oca. Se presentan, también, notas sobre sus ideas proimperialistas, algunas de sus obras literarias, juicios que sobre él hicieron académicos, diplomáticos y funcionarios mexicanos y extranjeros, así como elogios de la prensa nacional y española. 
rista), subsecretario de Hacienda (1916), director de Ferrocarriles (1919), gobernador de S.L.P. (1920-1923), y ministro plenipotenciario en varios países de. Europa (1923-1926).

BCC Nieto, Rafael, Polémica Laborista. Más allá de la paBP $\quad$ tria (selección de textos), Pról. de Antonio Tenorio

1975

Adame, México, Gráficos Ers., 1975, 148 (5) p.

Los dos libros que sirvieron para elaborar esta antología de textos, tuvieron su primera edición en 1922 y 1926 y dan cuenta de un pensamiento avanzado, con notable influencia marxista, que quedó plasmado en la obra legislativa (voto a la mujer, servicio civil, reparto agrario, justicia laboral) de Nieto como gobernador del estado (1920-1923). El autor fue uno de esos mexicanos para los que la Revolución representó un momento propicio para reflexionar sobre el desarrollo y organización de las luchas proletarias del mundo.

BCC Zavala, Mauricio, Juárez y la Reforma. PensamienBP $20 s$ Reflexiones, 2a. ed., Mérida de Yucatán, Im$226 j$ prenta de la Ermita, 1896,75 p.

1896 En este folleto se transcriben los pensamientos emitidos por el presidente Diaz, por gobernadores y altos funcionarios de la época en torno a la persona y obra política del presidente Benito Juárez. El autor da su opinión sobre estos juicios "aplicándoles la lógica y la historia", como afirma él mismo. Incluye también su Contestación a los artículos que en contra de sus "Reflexiones" aparecieron entonces en los periódicos La Sombra de Cepeda y El Faro. En forma de artículos, Zavala elabora una severa crítica a la ideologia oficial y a los conceptos que sobre Juárez y el movimiento de Reforma prevalecian durante el porfiriato; su discurso, bien fundado, abriga una de las posturas ideológicas más radicales que tuvieron eco en el México de finales del siglo XIX.

\section{Historia de la iglesia}

La existencia de una Iglesia potosina, de una jurisdicción eclesiástica que abarcara la totalidad del territorio del estado (antes San Luis Potosí dependió eclesiásticamente del arzobispado de México y del de Michoacán) se inicia, como lo demuestran los estudios de Rafael Montejano y Aguiñaga y Francisco Peña López, a mediados de la década de 1850 .

Por otra parte, la historiografía de la Iglesia potosina ha tenido sus más logrados registros en las obras de Eduardo J. Correa, Montejano y Rodriguez Barragán, en las que se reconstruye el itinerario de los cinco obispos que hasta bien entrada la década de 1920 presidieron la diócesis, y de una manera destacada, en la que Alfonso Martínez Rosales dedicó a la historia de la orden carmelita potosina.

\section{OBISPADO}

AHE Montejano y Aguiñaga, Rafael, La erección de la dió${ }_{972}^{\mathrm{BP}} 057$ cesis de San Luis Potosi y sus diversas demarcaciones M15e geográficas, México, Sociedad Mexicana de Geogra- 
1947

BCUASLP $+1972.670$ M8c 1947

BCUASLP $+1972.670$ M8e 1954

fía y Estadística, Boletín t. LXIII, núm. 2, marzo-abril 1947, 580-604 p.

Documentado estudio del proceso de establecimiento de la diócesis potosina, proceso que culminó al promediar el siglo pasado.

Montejano y Aguiñaga, Rafael, Erección y Bula de Erección de la Diócesis de San Luis Potosi, San Luis Potosí, con el perfil de Estilo..., 1954.

Historia de los larguísimos trámites y de las razones para la erección de la diócesis de San Luis Potosí, y publicación anotada de la bula por la que se dispuso su establecimiento.

\begin{tabular}{|c|c|}
\hline $\begin{array}{l}B C C \\
B P \\
972.008 \\
A 26 b \\
1969 \\
501\end{array}$ & $\begin{array}{l}\text { Peña López, Francisco, Documentos para la historia } \\
\text { del obispado de San Luis Potosí, San Luis Potosí, } \\
\text { Academia de Historia Potosina, } 1969,70 \mathrm{p} \text {. } \\
\text { Esta compilación tiene un antecedente (1a. edi- } \\
\text { ción) en } 1887 \text {. Contiene datos sobre la erección del }\end{array}$ \\
\hline $\begin{array}{l}\text { BCUASLP } \\
\text { BP*AST } \\
972.08 \\
\text { A26b } \\
1969 \\
501\end{array}$ & $\begin{array}{l}\text { obispado en San Luis Potosí; sobre la formación de } \\
\text { la nueva diócesis y sobre el primer cabildo eclesiás- } \\
\text { tico; noticias sobre la construcción de la catedral, so- } \\
\text { bre la erección del Colegio Guadalupano Josefino en } \\
\text { 1826, y biografías de los cuatro primeros obispos po- }\end{array}$ \\
\hline
\end{tabular}

\section{OBISPOS}

BCC Correa, Eduardo J., Biografias. Miguel M. de la BP 13-82 Mora, Obispo de San Luis 14-VIII-1874, 14-VII-1930. C78d 1952 José de Jesús López, Obispo de Aguascalientes 16-X1872, 11-IX-1950, México, edición del autor, 1952, 252 p., láms.

Miguel M. de la Mora, $5^{\circ}$ obispo de San Luis Potosí, quien arribó a la diócesis potosina el 28 de junio de 1922, fue el sucesor de Ignacio Montes de Oca y Obregón, quien estuvo al frente de aquella durante 36 años. Entre ambos existían grandes analogías: conocedores de los clásicos, dominaban varios idiomas, poseian amplia cultura y eran oradores grandilocuentes; pero también tenían una gran diferencia con respecto a su conducción y personalidad: "mientras la de Montes de Oca era de tipo renacentista, la de De la Mora, era de tipo franciscano" (el autor). Estas son dos excelentes biografías, "cuya segunda edición se hizo en 1953.

BCUASLP Jiménez, Agustín, Elogio fúnebre de los tres primeros ${ }^{+192.2-22}$ obispos de San Luis Potosí que en la Catedral de la (58e 1913 misma pronunció el Dean Agustín Jiménez el 4 de marzo de 1913, San Luis Potosí, Imprenta de E. Ceballos Aramberri Sucr., 1913, 33 p.

Contiene datos biográficos de los obispos Dr. D. Pedro Barajas, Lic. D. Manuel del Conde y Lic. D. J. Nicanor Corona.

BCC . Montejano y Aguiñaga, Rafael, Don Pedro Barajas 92.2-22 primer obispo de San Luis Potosi (1795-1868), México, Editorial Jus, 1970, 190 p.

Biografía documentada de un personaje impor- 
BNAL

972.008 MEX.c.106 fue el primer obispo de San Luis
afrontó el conflictivo proceso de la Reforma.

tante para la historia de Jalisco y San Luis Potosí.

$\begin{array}{ll}\text { BCC } & \text { Peñalosa, Joaquín Antonio y Rafael Montejano y } \\ \text { BP } & \text { Aguiñaga, Miguel M. de la Mora, el obispo para to- } \\ 92.13-82 & \text { dos, México, Editorial Jus, 1963, 80 p. } \\ \text { P4m } & \text { Biografía de quien fuera obispo de Zacatecas y San } \\ 1963 & \text { Luis Potosí, extraordinario promotor de las obras so- } \\ \text { BNAL } & \text { ciales, y reproducción anotada de una parte de su } \\ 972.008 & \text { diario. A De la Mora correspondió dirigir la diócesis } \\ \text { MEX.c.19 } & \text { potosina durante el conflicto cristero. }\end{array}$

BCC Rodriguez Barragán, Nereo, Don Pedro Barajas, pri-

92.2-22 Mer obispo de San Luis Potosi (1795-1868), San Luis

R7d

1976

AHE

$\mathrm{BP}$

92.2-22

R18d

1976 Potosí, UASLP, 1976, $55 \mathrm{p}$.

Estudio biográfico incompleto de quien ocupó el obispado potosino entre 1854 y 1868. La primera edición se hizo en 1953.

\section{SEMINARIO Y ORDENES RELIGIOSAS}

BCC Anaya, Ricardo B., El Seminario Conciliar GuadaluRAG pano Josefino de San Luis Potosi, San Luis Potosí, A68s con el perfil de Estilo, 1956, 17 p.

1956 Sermón pronunciado en la catedral potosina el 18 de enero de 1856, en el centenario del Seminario Conciliar. Contiene noticias sobre la historia de la educación eclesiástica en San Luis Potosí y datos para la elaboración de biografias de potosinos distinguidos.

AHE Basalenque, Diego de, Los Agustinos, aquellos misioBP 0242 neros hacendados, historia..., Introd. selección y noB72.0242 tas de Heriberto Moreno, México, SEP, 1985, 278 p., 1985 ils.

Esta obra ofrece una selección de textos de Basalenque, extraidos de la Historia de la Provincia de San Nicolás de Tolentino de Michoacán del Orden de N.P.S. Agustín. Sólo en una de sus partes se refiere a la fundación del convento agustino en San Luis Potosí que tiene lugar a finales del siglo XVI.

\footnotetext{
AHE García López, Ricardo, La obra franciscana en San BP 1260 . Luis Potosí. Aspecto histórico y patrimonio cultural, 912.1260 ' San Luis Potosi, S.L.P., s.p.i., 1984, 59 p., 46 fotos. 1984 Semblanza histórica de la orden de religiosos que inició la penetración cultural y evangelizadora en San Luis Potosí. Este evento se verificó simultáneamente al descubrimiento, fundación y explotación del Mineral de San Pedro, antecedente de la fundación de la ciudad capital potosina, hacia el año de 1592 . El autor hace especial referencia a las obras escultóricas, pictóricas y arquitectónicas que ostenta el templo franciscano potosino.
} 


\begin{tabular}{|c|c|}
\hline $\begin{array}{l}\mathrm{BCC} \\
\mathrm{BP} \\
912.1209 \\
\mathrm{M} 23 \mathrm{~g} \\
1985\end{array}$ & $\begin{array}{l}\text { Martínez Rosales, Alfonso, El gran teatro de un pe- } \\
\text { queño mundo. El Carmen de San Luis Potosi, } 1732- \\
\text { 1859, México, El Colegio de México, 1985, } 369 \text { p., } \\
\text { ils. }\end{array}$ \\
\hline $\begin{array}{l}\text { BCOLMEX } \\
\text { M3856c } \\
1985\end{array}$ & $\begin{array}{l}\text { Apoyado en una vasta documentación de fuen } \\
\text { primarias, el autor reconstruye la vida de la or } \\
\text { carmelita potosina de los siglos XVIII y XIX en }\end{array}$ \\
\hline
\end{tabular}

\title{
ESTADISTICA Y FESTIVIDADES
}

BCC
RAG
252
M8e
1946
BCUASLP
BP*
+205.58
M8e
1946

Montejano y Aguiñaga, Rafael, Ensayo de estadística eclesiástica potosina, 2a. ed., San Luis Potosí, Imprenta Evolución, 1946, 33 p.

Estudio socioestadístico de la diócesis de San Luis Potosí del siglo XIX. Además de proporcionar algunos datos sobre el obispado de San Luis y sus obispos, presenta listas de los sacerdotes que ejercian en el estado en cada parroquia o iglesia, de los catedráticos del Seminario Conciliar Guadalupano Josefino, de las casas de religiosos y religiosas laicas y quienes las integraban, y de los asistentes eclesiásticos de la Acción Católica. Para terminar, incluye un elenco del clero diocesano por orden alfabético y por orden de antigüedad, según la fecha de ordenación.

La primera edición de este trabajo se hizo en 1945.

\begin{abstract}
BCC
RAG

912.1000

S9s

1941

BNAL

908

MIS.235

Sustaita, Francisco A., San Luis Potosi, sus fiestas titulares, San Luis Potosí, Talleres Acción, 1941, 40 p., ils. (monografías potosinas).

Basado en fuentes históricas locales, el autor narra en este folleto, con estilo muy sencillo, algunas de las festividades y costumbres de origen ancestral que calito, a las serenatas, las "bateas", el Callejón del Diablo, etcétera.
\end{abstract}

\section{Historia de la cultura}

El desarrollo de las artes, entendidas éstas como expresión de "alta" o "baja" cultura, ha merecido numerosos estudios sobre la arquitectura, las artes populares, la imprenta, la literatura, la música y la pintura que han cultivado los potosinos o quienes se avecindaron en el estado.

Entre los libros dedicados al análisis de la arquitectura potosina, sobresale el que Francisco de la Maza escribió sobre el arte colonial; entre los elaborados acerca de las tradiciones artesanales, está el de Gómez Gutiérrez. Atención especial ha merecido la introducción de la imprenta en San Luis Potosí (Alcorta, Montejano y Penilla), pero frente a la música y la pintura, la literatura ha sido objeto de importantísimos estudios que generalmente han tenido como tema central el quehacer literario de quien realizó con excelencia en la estética, los presupuestos políticos e ideológicos decimonónicos: el poeta modernista Manuel José Othón. 
La historia de la educación en San Luis Potosí y de las tradiciones y lenguas indígenas del estado, han sido objeto de escasos pero notables estudios (Muro, Montejano, Chemin Bassler, etc.). Del mismo modo, el análisis o recuento de la vida y obra de los historiadores potosinos ha sido un tema frecuentemente tratado.

\section{ARQUITECTURA}

BCC Cossío Lagarde, Francisco Javier, La investigación y ${ }_{972.008}^{\mathrm{BP}} \quad$ la historia del arte colonial en San Luis Potosi, San 972.008 A26b 1969 38 Luis Potosí, Academia de Historia Potosina, 1975, 20 p., láms. (Biblioteca de Historia Potosina, serie cuadernos 38 ).

Este folleto se refiere a algunos testimonios del arte colonial potosino, como pueblos, haciendas, arquitectura religiosa y civil, pintura, escultura y artes menores, existentes fuera de la capital.

El autor hace un recorrido por las principales fuentes documentales de consulta obligada para el estudio de la historia potosina de la Colonia.

BCC Espinosa Pitman, Alejandro, Las Cajas del Agua, BP
912.1700

E86C 1985 San Luis Potosí, Letras Potosinas, 1985, 36 p., ils.

- Basado en fuentes de primera y segunda máno, este breve trabajo ofrece alguna información sobre la existencia de varias cajas del agua en la ciudad de San Luis Potosi y no de una sola como se ha creido (la situada en el barrio de la Merced y llamada, a mediados del siglo pasado, Fuente de la Conservera). La caja del agua ha sido considerada como un símbolo de la ciudad y se trata de una obra arquitectónica de reconocida belleza e importancia. El autor de este estudio incluye además varios datos relativos a la construcción, utilización e historia de dichas cajas.

BCC Maza, Francisco de la, El arte colonial en San Luis 700 , Potosi, México, unam, 1969, 91 p., 103 láms.

M29a : Estudio histórico, ilustrado con muy buenas foto1969 . grafías, sobre la ciudad de San Luis Potosí y sus principales joyas arquitectónicas. El autor incluye noticias de algunos de los arquitectos que participaron en su.construcción. Está dividido en tres partes: la ciudad, la arquitectura civil y la arquitectura religiosa. Existe la segunda edición de 1985.

BCUASLP Montejano y Aguiñaga, Rafael, Santa Maria de Guadalupe en San Luis Potosí. Su culto, su Santuario, su calzada y sus santuarios, México, Ediciones Paulinas, 1982 S.A., 1982,481 p.

Documentada historia del culto guadalupano en el estado de San Luis Potosí y de los principales santuarios, especialmente del de la capital y de los edificios y lugares históricos a lo largo de la calzada de Guadalupe que empieza en el jardín Colón antes de la Merced.

BCC Morales Bocardo, Rafael, La sacristia franciscana de Morales Bocardo, Rafael, La sacristia franciscana de
San Luis Potosi. Una obra del barroco estipite, San Luis Potosí, UASLP, 1984, 63, 68 p., ils. 
1984

AHE

$\mathrm{BP}$

912.1260

M13s

1984

$\mathrm{BCC}$

$\mathrm{BP}$

912.1201

S9c

1943

Monografia de uno de los ejemplos de la arquitectura religiosa novohispana. Contiene los siguientes capítulos: Don José de Erreparáz (que participó en la realización de varias obras arquitectónicas, escultóricas y pictóricas), La Sacristía, Arquitectura, Escultura, y Pintura.

Sustaita, Francisco A., La Capilla de Aranzazú, San Luis Potosí, Imprenta "El Troquel", 1943, 18 p., láms.

Estudio histórico sobre esa joya arquitectónica, único ejemplo del barroco civil potosino.

\begin{abstract}
$\mathrm{BCC}$
RAG

912.1209

S9t

1949

BNAL

708

MIS.47

Sustaita, Francisco A., Templo del Carmen, San Luis Potosi, Alberto Macías, 1949, 32 p., ils.

Folleto en el que se ofrece amplia información sobre la fundación de la orden de los Carmelitas Descalzos en San Luis Potosí, sobre su templo que está considerado como una de las más notables joyas del estilo churrigueresco del país, sobre las fiestas titulares, sobre la devoción a la virgen del Carmen, etcétera.
\end{abstract}

BCC Sustaita, Francisco A., La Virgen de Guadalupe en 912.1289 San Luis Potosi. Reseña Histórica San Luis Potosí, s9v 1947 Gráficos Macias, 1947, 31 p., ils.

Basado en fuentes de segunda mano, este trabajo contiene información histórica sobre los templos dedicados al culto de la Virgen de Guadalupe en San Luis, sus constructores, sus moradores, su arquitectura, fiestas titulares, etcétera.

\begin{tabular}{|c|c|}
\hline $\begin{array}{l}\text { BCC } \\
\text { BP } \\
912.1209 \\
\text { V5C } \\
1964\end{array}$ & $\begin{array}{l}\text { Victoria Moreno, Dionisio, El Carmen de San Luis } \\
\text { Potosi, joya del barroco mexicano, México, s.e., } \\
1964,32 \text { p., láms, fotos. } \\
\text { Breve historia (siglo xvi al xx) sobre la fundación }\end{array}$ \\
\hline $\begin{array}{l}\text { AHE } \\
\text { BP } \\
912.1209 \\
\text { V22c } \\
1964\end{array}$ & $\begin{array}{l}\text { realizada por la orden de los Carmelitas Descalzos } \\
\text { durante la Colonia. Basada en un manuscrito de } \\
1786 \text { del P. Fr. José de Santo Domingo (prior enton- } \\
\text { ces del convento carmelita potosino), existente en el } \\
\text { Archivo Histórico de la Provincia Mexicana. Incluye }\end{array}$ \\
\hline
\end{tabular}

\title{
ARTESANIAS
}

$\mathrm{BCC}$

$\mathrm{BP}$

972.008

A26b

1969

606

Gómez Gutiérrez, Octaviano, Las artesanias en el estado de San Luis Potosi, San Luis Potosí, Academia de Historia Potosina, 1972, 74 p., 1 h. pleg. (Biblioteca de Historia Potosina, serie estudios 6).

Obra pionera en su género cuyos capítulos son: Notas sobre las artesanías en el Estado, Inventario de artesanias en el Estado por productos, Inventario de artesanías en el Estado por municipios donde se producen. y Mapa de artesanías. Monterrey, Fundidora Monterrey, S. A., 1977, 12 p., láms. 
1977

Este breve trabajo proporciona algunos datos sobre la geografía, paisaje, arquitectura, demografía y cultura de Santa María del Río, municipio potosino situado al sur de la ciudad de San Luis Potosí y en donde se elabora el rebozo, prenda femenina de uso nacional. Se incluyen también datos relativos al proceso de producción de esta pieza artesanal.

BCC Núñez y Domínguez, José de Jesús, El rebozo, MéxiBP 12 co, Departamento Editorial de la Dirección General

$\mathrm{Ngr}$

1917 de las Bellas Artes, 1917, 87 p.

Ensayo que aporta algunos datos sobre el origen del rebozo, su utilización durante el virreinato y después de éste, su significado en el proceso económico y social de México, su apogeo, su relación con las costumbres y su inclusión en las leyendas y en los libros. Al final, se ofrece una descripción de algunos detalles curiosos relacionados con el rebozo.

$\begin{array}{ll}\text { BCC } & \text { Reyes, Juan Carlos, La cerámica tradicional popular } \\ \text { BP } & \text { de San Luis Potosi, Colima, Universidad de Colima, } \\ 738 & 1983,40 \text { p., ils. } \\ \text { R47c } & \text { Primer trabajo serio sobre cerámica popular que, } \\ 1983 & \text {. }\end{array}$ frente a la cerámica arqueológica potosina, ha merecido menores e incompletos estudios. Basado en investigación realizada en el Museo Regional de Arte Popular de San Luis Potosí, el autor estudia la época prehispánica, la colonial y los siglos XIX y XX y contempla la producción actual en cuanto a las técnicas y materiales utilizados, los puntos del estado en que tiene lugar, los sistemas de organización y división del trabajo y los mercados.

BCC Sustaita, Francisco A., El rebozo de Santa Maria,

RAG

917.1

$\mathrm{S} 9 \mathrm{r}$

1932

AHE

BP

917.1

S19r

1932 San Luis Potosí, Imprenta Lozano y Caballero, 1932, $88 \mathrm{p}$.

Ensayo sobre esta prenda femenina, de origen antiguo, usada generalmente por las mujeres mexicanas, y cuya industria tradicional es típica de Santa María del Río, municipio potosino. Se ofrecen algunos datos históricos, etimológicos y anécdotas sobre el rebozo.

\section{IMPRENTA}

$\mathrm{BCC}$

BP 65.09

A64p

1969

BCC

RAG

655.09

1969

Alcorta Guerrero, Ramón, La primera imprenta potosina. Nuevas aportaciones para su historia y bibliografia, San Luis Potosí, Letras Potosinas, 1969, 48 p., 27 láms.

Notas y discusión sobre la fecha de establecimiento e historia de la primera imprenta potosina fundada por Alejo Infante a principios del siglo XIX en Armadillo, municipio situado a $60 \mathrm{k}$. al noreste de la capital del estado. El autor elaboró también un catálogo de los impresos incunables armadillenses.

BCC Montejano y Aguiñaga, Rafael, Los Infante; la im$\mathrm{BP}$ prenta y el grabado en San Luis Potosi, San Luis Po-

Estudio sobre la vida y obra de los integrantes de 
BNAL

608

la familia Infante, fundadores de la producción tipo-

MIS.41 gráfica en el estado de San Luis Potosí, a principios de la época independiente, y que empezaron a trabajar imprenta y grabado con instrumentos fabricados por ellos mismos.

BCC
RAG
$92.5-86$
P4d
1953

Penilla López, Salvador, El Dr. Francisco J. Estrada y la imprenta en San Luis y Zacatecas, San Luis Potosí, UASLP, 1953, $34 \mathrm{p}$.

1953

Basado en un manuscrito autobiográfico del Dr. Estrada, introductor de la imprenta en la capital potosina, este folleto proporciona una valiosa información sobre los orígenes y avances de la tipografía en las ciudades de San Luis Potosí y Zacatecas. Se proporcionan noticias sobre hallazgos documentales inéditos y parte del manuscrito "Recuerdos que hace de su vida Francisco J. Estrada" en el que éste puntualiza su participación en el ejercicio de las artes gráficas potosinas del siglo XIX.

\section{LITERATURA}

BCC Beltrán, Bernardino, Historia del Himno Nacional

RAG

92.7-75

B37h

1939 mexicano, y narraciones históricas de sus autores, $D$. Francisco González Bocanegra y D. Jaime Nunó, México, D. A. P. P., 1939, 182 p.

$\mathrm{El}$ autor incluye todos los antecedentes relacionados con quince tentativas realizadas para que México tuviera su propio himno. Al fín, y por concurso, resultó vencedor D. Jaime Nunó, español de origen y González Bocanegra, potosino.

\begin{tabular}{|c|c|}
\hline $\begin{array}{l}\text { BCC } \\
\text { RAG } \\
92.2-14 \\
\text { D51a } \\
1937\end{array}$ & $\begin{array}{l}\text { Diaz de León, Rafael, Los autores del Himno Nacio- } \\
\text { nal, San Luis Potosi, México, Editorial "Valores Hu- } \\
\text { manos", 1937, 61 p. } \\
\text { Contiene las biografías de Francisco González Bo- }\end{array}$ \\
\hline $\begin{array}{l}\text { BCC } \\
\text { BP } \\
92.7-76 \\
\text { D4a } \\
1937\end{array}$ & $\begin{array}{l}\text { canegra y Jaime Nunó; se relata el certamen musical } \\
\text { en el que triunfó Jaime Nunó; se reproducen el dicta- } \\
\text { men del músico potosino Juliân Carrillo, y una anéc- } \\
\text { dota de Nunó ocurrida en San Luis Potosí. }\end{array}$ \\
\hline $\begin{array}{l}\text { BCC } \\
\text { RAG } \\
\text { OT } \\
864 \\
\text { G75a } \\
1935\end{array}$ & $\begin{array}{l}\text { González, Manuel Pedro, Algunas influencias percep- } \\
\text { tibles en la obra de Manuel José Othón, Santiago de } \\
\text { Chile, Imp. Universitaria, } 1935,43 \text { p. } \\
\text { Para lograr mejor su objetivo, este estudio divide } \\
\text { la obra de Othón en tres manifestaciones o géneros: }\end{array}$ \\
\hline & $\begin{array}{l}\text { ial, "Poemas Rústicos" (1902); } \\
\text { narraciones descriptivas, etc.); y } \\
\text { onan al final algunas notas biográ }\end{array}$ \\
\hline
\end{tabular}

BCC

RAG

861

M33a

1953

$\mathrm{BCC}$
Medina Romero, Jesús, Antologia de poetas contemporáneos (1910-1953), San Luis Potosí, Universidad Autónoma, 1953, 254 p. (Biblioteca de Autores Potosinos núm. 1).

Con un estudio y notas de Medina, la selección incluye a los poetas nacidos en San Luis Potosi que salieron del estado y residen en la capital del pais, a 
la que llegaron plenamente formados; a los poetas potosinos por nacimiento que lograron su formación en otras partes y a los nacidos fuera de San Luis pero que en él se formaron. Contiene 24 muestras.

$\begin{array}{ll}\text { BCC } & \text { Millán, María del Carmen, 12 cuentistas potosinos } \\ \text { RAG } & \text { contemporáneos, San Luis Potosi, Letras Potosinas y } \\ 863 & \text { Asociación de Escritores, Artistas y Periodistas, } \\ \text { M57e } & 1959,148 \text { p. }\end{array}$

En esta obra se reunieron muestras de los trabajos de doce cuentistas, todos originarios de San Luis Potosí y cuya producción literaria se ubica entre 1930 y 1958 . Además de conocerse como cuentistas, los autores destacaron también en otras disciplinas, unos en la crítica, otros en la investigación o en la poesía. Sus nombres son Jorge Ferretis, Jesús R. Alderete, Jesús Goytortúa, Jesús C. Pérez, Miguel Alvarez Acosta, Rafael Montejano y Aguiñaga, María Ester Ortuño de Aguiñaga, Luis Reyes de la Maza, María Amparo Dávila de Coronel, Jesús Medina Romero, Gabriel Echenique y Raquel Banda Farfán. $\begin{array}{ll}\text { BCC } & \text { Millán, María del Carmen, El paisaje sinfónico, in- } \\ \text { RAG } & \text { troducción a la poesía de Manuel José Othón, San } \\ \text { OT } & \text { Luis Potosí, con el perfil de Estilo..., 1951, 5-19 p., } 1 \\ 864.15-81 & \text { h. pleg. } \\ \text { M57p } & \end{array}$

El análisis temático, y en especial, la identificación del sentido musical de la producción poética de Manuel José Othón, constituye el objeto de este sobretiro. La autora hace una revisión de los versos que evidencian las influencias que marcaron la obra del poeta (el ambiente musical potosino de la época porfiriana).

$\begin{array}{ll}\text { BCC } & \text { Montejano y Aguiñaga, Rafael, Ambiente cultural en } \\ \text { RAG } & \text { la juventud de Othón, San Luis Potosí, Instituto Po- } \\ 860.08 & \text { tosino de Bellas Artes, 1960, 22 p. } \\ 169 \mathrm{c} & \text { Estudio de la época 1850-1890 en que se forjaron } \\ 1959 & \text { el poeta potosino Manuel José Othón y los miembros } \\ 7 & \text { de su generación, con especial énfasis en las ciencias } \\ \text { BCC } & \text { y las artes, y, en general, en la cultura potosina deci- } \\ \text { BP } & \text { monónica. }\end{array}$

1959

7

$\begin{array}{ll}\text { BCC } & \text { Montejano y Aguinaga, Rafael, Manuel José Othón y } \\ \text { BP } & \text { su ambiente, San Luis Potosí, Academia de Historia } \\ 972.008 & \text { Potosina, 1984, 210 p. } \\ \text { A26b } & \text { Análisis de la formación literaria de Manuel José } \\ 1969 & \text { Othón y de sus primeras obras. }\end{array}$

AHE

$\mathrm{BP}$

008

A3b

1969

219 


\begin{abstract}
M8s
1978

BNAL

B

866

M8e

1952

$\mathrm{BCC}$

RAG

972

M96c

1908 artes y ciencias.

Muro, Manuel, Las ciencias, las letras y las artes potosinas en el siglo XIX; ligeros apuntes, San Luis Potosí, Tip. de la Escuela Industrial Militar, 1908, 49 p.

Contiene notas biográficas mínimas sobre quienes, desde sus de la historia de la literatura potosina desde sus orígenes virreinales hasta finales de la década de 1970.
\end{abstract}

Noyola Vázquez, Luis, Los cauces poéticos de $\dot{M a}$ nuel José Othón, Nota preliminar de Mauricio Magdaleno, México, Las Letras Potosinas, 1958, 46 p.

Ensayo de crítica en el que se analizan las influencias y la temática presentes en la obra de Othón. También pueden leerse algunas notas sobre el momento histórico que vivió al poeta.

BCC Othón, Manuel José, Manuel José Othón, poesia, teaRAG tro, prosa, epistolario, Ed., pról. y notas de Jesús Za860oc vala, México, D. F., Impreso por Librería Madero, $1954 \quad 1954,101 \mathrm{p}$.

Esta obra recoge los resultados de una investigación colectiva llevada a cabo por los "othonistas" Joaquín Antonio Peñalosa, Alfonso Mendez Plancarte, Francisco González Guerrero, Alfonso Junco, Luis Noyola Vázquez, Rafael del Río y Berenice Udick. Contiene 19 poemas, dos composiciones en prosa, cinco cartas y una comedia escritas por Othón durante el último cuarto del siglo XIX.

BCC. Othón, Manuel José, Paisaje, Prol. y selec. de MaRAG

$861 \mathrm{p}$ nuel Calvillo, México, Ediciones de la UNAM, 1944, 1944 XXXVII, 1969 (Biblioteca del Estudiante Universitario 50 ).

Esta obra se orienta fundamentalmente -según Calvillo- a tratar de situar la poesía de Othón, con un ensayo para descubrir el sentido íntimo de ella. Se hacen, en el prólogo, algunas observaciones sobre la vida, la actividad literaria, las relaciones culturales y la obra del escritor. En la segunda parte, se ofrece una selección de poemas othonianos.

$\mathrm{BCC}$

RAG

OT

92.15-83

P33a

1959 .

Pedraza, José Francisco, El ambiente literario que vivió Manuel José Othón, San Luis Potosí, UASLP, 1959, 28 p., (Sobretiro de Cuadrante No. 2, año VI).

Publicado por la Universidad potosina en el centenario del nacimiento del poeta y como reconocimiento a uno de sus "más preclaros hijos". El autor presenta este folleto como la "oportunidad de evocar la figura de Manuel José Othón en el marco romántico de la segunda mitad del siglo XIX potosino". El tema es pues, el ambiente literario que vivió el poeta en la ciudad de San Luis Potosí. 


$\begin{array}{ll}\text { BCC } & \text { Peñalosa, Joaquín Antonio, Francisco González Bo- } \\ \text { RAG } & \text { canegra, su vida y su obra, México, Imprenta Univer- } \\ 861 & \text { sitaria, 1954, 485 p. } \\ \text { P4f } & \text { Ensayo biográfico en el que, después de recorrer la } \\ 1954 & \text { vida de González Bocanegra y analizar su labor lite- } \\ \text { BCC } & \text { raria, se presentan sus poemas, dramas, crítica tea- } \\ \text { BP } & \text { tral y discursos. Basado en libros, periódicos, revistas } \\ 861 & \text { y documentos proporcionados por los familiares del } \\ \text { P4f } & \text { poeta potosino y autor de la letra del Himno Nacio- } \\ 1954 & \end{array}$

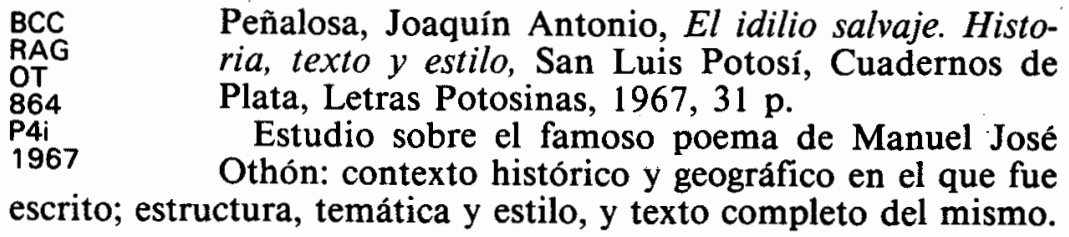

BCC Peñalosa, Joaquín Antonio, Manuel José Othón, novelista olvidado, San Luis Potosí, Estilo, 1952, 13 p.

Conferencia pronunciada con motivo de la dedicación de una sala al poeta en el Palacio de Gobierno de San Luis Potosí, el 28 de noviembre de 1950. Peñalosa rescata a Othón como autor de varias novelas y analiza algunos elementos temáticos presentes en ellas, además de hacer comentarios sobre sus cuentos y prosa en general.

BCC Perea, Socorro, Valonas y décimas potosinas de los BPares de Francia, s.p.i., 1980, 145-166 p. Sobretiro 398 P42v 1980 de Cuadernos Americanos, nov.-dic. de 1980, año XXXIX, vol. CCXXXIII.

La autora de este artículo presenta una colección de composiciones potosinas (valonas y poesias populares) sobre un mismo tema: los Doce Pares de Francia, asunto medieval muy llamativo. A manera de introducción, da una idea general del cancionero potosino, poniendo el énfasis en algunas indicaciones métricas; analiza también la existencia de los poesilleros en la región y su medio natural que es la fiesta. Asimismo, incluye una reflexión en torno a la temática de dicha forma de creación literaria popular en el estado.

\footnotetext{
BCC Ramirez Ambrosio, Ambrosio Ramirez, traductor de

864.18-19

R19a

1954 .

$\mathrm{BCC}$

RAG

864.18-19

R19a

1954 Horacio, Introd., transcripción y notas de Joaquín Antonio Peñalosa, San Luis Potosi, Editorial Universitaria Potosina, 1954, 300 p., retr.

Basada en fuentes de primera y segunda mano, esta obra incluye una biografía de Ramírez y una caracterización de él como traductor y estudioso de Horacio, como poeta, orador y crítico. En su parte central, se ofrece una transcripción de la obra poética del mismo autor para finalizar con unas notas sobre ella. Ambrosio Ramírez nació en Villa de Reyes, S.L.P., el 2 de diciembre de 1856, amigo de Manuel José Othón, maestro de humanidades, Ministro del Foro y la Judicatura, además de notable literato.
} 


\begin{tabular}{ll} 
BCC & Ramirez Arriaga, Manuel, Las elegias de Manuel \\
RAG & José Othón, San Luis Potosi, México, Cuadernos de \\
OT & Plata, Letras Potosinas, 1967, 30 p. \\
864 & Inventario de las elegías escritas por Othón y aná- \\
R19e & lisis de sus poemas líricos que, no siendo formal- \\
1967 & \multicolumn{2}{l}{. } \\
mente elegías, ofrecen el tinte propio de ellas.
\end{tabular}

$\begin{array}{ll}\text { BCC } & \text { Ruiz, Rodolfo Diódoro, Del lírico vergel potosino, } \\ \text { RAG } & \text { semblanzas y pergenios, San Luis Potosí, Imprenta } \\ 864 & \text { de la Escuela Industrial "Benito Juárez", 1919, } 207 \\ \text { R9d } & \text { p. }\end{array}$

Compuesto por una serie de breves artículos en los que el autor caracteriza la personalidad, temperamento literario y producción de cincuenta poetas potosinos en forma separada, incluyendo una muestra de la obra de cada uno de ellos.

\begin{tabular}{|c|c|}
\hline $\begin{array}{l}B C C \\
B P \\
972.008 \\
A 26 b \\
1969\end{array}$ & $\begin{array}{l}\text { Schneider, Luis Mario, La Ilustración potosina } \\
\text { (1869-1870), San Luis Potosí, Academia de Historia } \\
\text { Potosina, 1975, } 93 \text { p. (Biblioteca de Historia Poto- } \\
\text { sina, serie estudios 13). } \\
\text { Ensayo sobre una de las revistas literarias potosi- }\end{array}$ \\
\hline $\begin{array}{l}\text { OLMEX } \\
60.5 \\
59 i\end{array}$ & $\begin{array}{l}\text { nas más importantes del siglo XIX. Contiene un estu- } \\
\text { dio preliminar, el índice analítico de la revista y "La } \\
\text { Literatura Nacional", artículo escrito por José T. de } \\
\text { Cuellar para La Ilustración. }\end{array}$ \\
\hline $\begin{array}{l}\text { BCC } \\
\text { RAG } \\
\text { OT } \\
864 \\
\text { S720 } \\
1958\end{array}$ & $\begin{array}{l}\text { athón cuentista, San, } \\
\text { ate, } 195813 \mathrm{p} \text {. } \\
\text { tica sobre el Othón pro- } \\
\text { colocando al escritor en } \\
\text { ugar que ocupa en la lite- }\end{array}$ \\
\hline \multicolumn{2}{|c|}{$\begin{array}{l}\text { ratura mexicana, y precisando sus aciertos y desaciertos, descubre } \\
\text { en Othón una "empeñosa actitud de reaccionario en literatura". }\end{array}$} \\
\hline $\begin{array}{l}\mathrm{BCC} \\
\mathrm{BP}\end{array}$ & $\begin{array}{l}\text { Valle-Arizpe, A } \\
\text { José Othón, 2a. } \\
148 \text { (1) p. }\end{array}$ \\
\hline \multicolumn{2}{|c|}{$\begin{array}{l}\text { cidos poetas potosinos de finales del siglo XIX y principios del xx. } \\
\text { Escrita en } 1924 \text {, guardada por el autor hasta la fecha en que se } \\
\text { publicó con motivo del centenario del nacimiento de Othón, en } \\
\text { 1958. En ella se muestran las tendencias y aficiones del poeta en } \\
\text { su cotidianidad. }\end{array}$} \\
\hline
\end{tabular}

Musica

BCUASLP Carrillo Julián, Rectificación básica al sistema musi+192.3-23 cal clásico; análisis físico muisico pre-sonido 13, San 1930 Luis Potosí, Talleres Gráficos de la Escuela Industrial Militar, 1930, 62 p.

Este libro es presentado por el propio autor como "una rectificación general a la cultura musical del mundo, como la condena. ción de cuantas falsedades existen en el sistema musical clásico" desarrollado a partir del siglo XVI. Contiene una serie de notas sobre teoria musical, física y matemática. 
$\begin{array}{ll}\text { BCC } & \text { Flores Delgado, Manuel, Verdadera historia del so- } \\ \text { BP } & \text { nido } 13 \text { en San Luis Potosi, San Luis Potosí, s.p.i., } \\ 92 \mathrm{c} & 1984,72 \mathrm{p} \text {. } \\ \text { F68v } & \\ 1984 & \text { Obra que critica fuertemente al maestro Julián Ca- } \\ \text { rrillo y sus teorías. En la segunda parte, el autor alude al libro } \\ \text { titulado Juliân Carrillo, su vida y su obra, editado por el "Grupo } \\ 13 \text { Metropolitano", en 1945, y lo califica de autoelogio. Carrillo } \\ \text { murió en 1967, 17 años antes de la fecha de publicación de este } \\ \text { folleto. }\end{array}$

Se presentan algunas anécdotas sobre gobernantes potosinos del siglo $\mathrm{XX}$.

$\begin{array}{ll}\text { BCC } & \text { Velasco Urda, José, Juliân Carrillo, su vida y su obra, } \\ \text { RAG } & \text { México, Edición del Grupo } 13 \text { Metropolitano, 1945, } \\ 92.3-22 & 423 \text { p., láms. }\end{array}$ 1945 Biografía de quien fuera autor de la teoría musical del Sonido'13, nacido en Ahualulco, S.L.P. en 1875. Obra elaborada a base de entrevistas que Velasco Urda hizo a Carrillo en 1942; consta de 43 partes breves en las que el músico relata su vida, el contexto de sus descubrimientos y sus relaciones con altos funcionarios y personalidades del mundo musical de México y el extranjero.

El "Grupo 13 Metropolitano" fue fundado en la ciudad de México con el fin de difundir las teorías y descubrimientos musicales de Julián Carrillo.

\section{PINTURA}

BCUASLP Cravioto, Alfonso, Germán Gedovius, México, s.e., 92.7-32 + 1916, fotos.

1916 Pequeña monografía sobre el pintor. Cravioto fue el primer biógrafo de Gedovius. El texto está ilustrado con 25 reproducciones fotográficas.

BCC : Germân Gedovius. Una generación entre dos siglos: $92 \mathrm{~g}$ 1984 del porfiriato a la posrevolución 1867-1937, Museo Nacional de Arte Sala Exposiciones Temporales México, julio-octubre, 1984, México, INB, 1984, 83 p., ils.

Libro editado con motivo de la primera exposición de la obra de Gedovius, 47 años después de su muerte. Presenta una biografía del pintor, una muestra de su obra y algunos artículos sobre su persona, su producción pictórica y una útil cronología en la que corren paralelos los eventos de la vida de Gedovius y los de la cultura y la política del pais.

El pintor nació en México, D. F.; a los pocos meses de edad fue trasladado a San Luis Potosí, donde vivió sus primeros 15 años.

$\begin{array}{ll}\text { BCC } & \text { Pedraza, José Francisco, La pintura en San Luis Po- } \\ \text { RAG } & \text { tosi durante el siglo XIX, San Luis Potosí, Academia } \\ 972.008 & \text { de Historia Potosina, 1969, } 29 \text { p. (Biblioteca de His- } \\ \text { A26b } & \text { toria Potosina 1). } \\ 1969 & \text { Breve relación del arte pictórico en la provincia } \\ 1 & \end{array}$ 
prende también datos biográficos de los pintores potosinos de la época y algunos comentarios críticos sobre su obra.

\section{EDUCACION}

BCUASLP $+1972.500$ C26a 1890

Castillo Rafael del, Algunos apuntes sobre la instrucción primaria en el Estado, San Luis Potosi, Tip. de la Escuela de Artes y Oficios para señoritas, 1890, $46 \mathrm{p}$.

Segundo inspector del ramo, Castillo hace una interesante reseña sobre el desarrollo de la instrucción pública en el estado de San Luis Potosí, a partir del año de 1842, en que la Junta Lancasteriana estableció las primeras escuelas en la capital del estado hasta 1890.

\footnotetext{
BCC Compañia Editora "FIAT LUX", La Instrucción pública 351.850 en San Luis Potosi, México, Tallères Gráficos, 1910, $1910 \quad 34 \mathrm{p}$.

Reseña el estado de la instrucción pública en San Luis Potosí durante la administración porfirista del gobernador Ing. José María Espinosa y Cuevas, de quien se incluye un retrato y una semblanza extremadamente laudatoria.
}

BCC Erección de una Casa de Estudios en la capital del RAG Estado de San Luis Potosi, para su juventud, debida a $\begin{array}{ll}378.500 & \text { los extraordinarios esfuerzos de su Exmo. Gobernador }\end{array}$ 1826 el Sr. D. José Ildefonso Díaz de León, México, ImAHE prenta del Aguila, San Luis Potosí, Ed. Junio, 1826, $378 \quad 15 \mathrm{p}$.

G7e Contiene una corta e interesante relación sobre la 1826 apertura de los cursos del Colegio Guadalupano Josefino de San Luis Potosi, acto que se llevó a cabo el día 2 de junio de 1826 .

BCC Montejano y Aguiñaga, Rafael, Semblanza histórica 972.008 del Colegio Guadalupano Josefino, San Luis Potosí, A26b Academia de Historia Potosina, 1977, 15 p.

1969

1969

Reseña histórica del benemérito Colegio fundado en 1826 por el filántropo, educador, sacerdote, politico y filósofo Dr. Manuel María de Gorriño y Arduengo. Esta institución es conocida ahora como Seminario Conciliar Guadalupano Josefino. Entre 1826 y 1861 era la única institución que impartía estudios superiores en San Luis; de 1855 a la fecha, elevado a la categoría de seminario, sirvió para la formación del clero potosino. El autor aclara que la actual Universidad Autónoma de S.L.P. no es la continuación del Antiguo Colegio, sino que fue inaugurada en 1871 en oposición al Seminario Conciliar.

BCC Montejano y Aguiñaga, Rafael, Sintesis histórica de 972.008 la educación en el estado de San Luis Potosi, San $17 \mathrm{p}$.

Historia sintetizada de la educación pública y privada, a partir de la fundación de la ciudad de San Luis Potosí (1592). 


\begin{abstract}
$\mathrm{BCC}$
$\mathrm{BP}$

351.850

M96h

1899

BCUSLP

351.850 .9

M96h

1899

Muro, Manuel, Historia de la instrucción pública en

San Luis Potosi escrita por acuerdo del Sr. gobernador del estado Ing. Don Blas Escontria, San Luis Potosí, Imprenta, litografía, encuadernación y librería de M. Esquivel y Cía., 1899, 282 p.

Escrita por acuerdo del Sr. gobernador del estado, Ing. Blas Escontría, la obra es de carácter general y abarca desde los primeros tiempos de la Colonia, cuando fray Diego de la Magdalena, uno de los fundadores de San Luis Potosí, inició la enseñanza entre los indígenas, hasta la época contemporánea a esta publicación.
\end{abstract}

BCC Pedraza, José Francisco, Apuntes Históricos de la

$\mathrm{BP}$

378

P33a

1986

Universidad Autónoma de San Luis Potosi, San Luis Potosí, Ed. Universitaria Potosina, 1986, 38 p., 34 láms.

El índice de este trabajo es el siguiente: I. El Viejo Colegio de los Jesuitas (1624-1767); II. El Colegio Guadalupano Josefino (18261853); III. El Instituto Científico y Literario (1859-1922); IV. La Universidad de San Luis Potosí; llustraciones y Galería de Rectores de la UASLP.

BCC Rodríguez Barragán, Nereo, Apuntes para la historia RAG de la Universidad de San Luis Potosi en cien años de 378.500 vida (1826-1926) con algunos datos históricos y esta1936 disticos, San Luis Potosí, Ediciones de la Revista

BCUASLP $+378.590$ 1936

"Centro", Asociación de Estudiantes Potosinos, UASLP, 1936, $36 \mathrm{p}$.

La presente obra no es una historia completa de la institución, pero contiene abundante material no publicado anteriormente.

\title{
LINGÜISTICA Y TRADICIONES INDIGENAS
}

BCC Chemin Bassler, Heidi, Sobrevivencias precortesianas BP 92.008

A26b

1969

54 en las creencias de los Pames del norte, estado de San Luis Potosi, México, San Luis Potosí, Academia de Historia Potosina, 1977, 13 p. (Biblioteca de Historia Potosina, serie cuadernos 54.)

Contiene algunas notas sobre la presencia de ese grupo indigena en la parte oriental del estado de San Luis Potosí, en las regiones montañosas y semidesérticas, desde la época de la Conquista. Se estudian, en seguida, las costumbres y rasgos más importantes que conservan los indígenas que viven actualmente en las regiones más inhóspitas e inaccesibles de la Sierra Madre Oriental potosina.

BCC Gutiérrez de Sánchez, Oralia, Rituales y ofrendas BP huastecos, San Luis Potosí, Sociedad de Estudios G972.013 Históricos, A. C., 1980, 55 p. 1980

Este cuaderno es un testimonio de las ceremonias y rituales huastecos en los que la autora ha participado como observadora. Se divide en cinco partes: Del matrimonio, De la danza, De la muerte, De las ofrendas, y Del ideario. 
BCC

$\mathrm{BP}$

918

L27d

1985

Lavalle, Josefina et al., Danza de las Varitas. Tzineja, Huehuetlàn, S.L.P. Antecedentes históricos, constantes prehispánicas y estado actual de la danza, San

Estudio sobre una de las danzas más representativas de los grupos huastecos y mexicas que es una de las más bailadas en San Luis Potosí. Se analizan constantes de la época prehispánica a la actual, simbolismos, ideas estéticas, argumento, tema de la danza, y se da cuenta de cuál es su estado actual por medio de la notación coreográfica, el vestuario y utilería, el análisis musical, así como de los aspectos socio-económicos de las comunidades donde se ejecuta.

BCC Lorenzana, Serapio D., Un intérprete huasteco, RAG ayuda valiosa para los que quieran hablar este 972.013 idioma, México, Oficina Tip. de la Sría. de Fomento, 1896 $1896,43 \mathrm{p}$.

Pequeño diccionario o guía práctica de palabras y frases de uso común de la lengua huasteca.

$\begin{array}{ll}\text { BCC } & \text { Rodriguez, Blas E., Cultura Huasteca y Olmeca, Mé- } \\ \text { BP } & \text { xico, D. F., Editora Intercontinental, A. C., 1943, } \\ 972.013 & 98 \text { p. } \\ \text { R7c } & \text { Estudio histórico referente a la cultura que se desa- } \\ 1943 & \text { rrolló en la región; abarca desde las tierras contiguas } \\ \text { BCUASLP } & \text { a la desembocadura del río Pánuco en el golfo de } \\ +918 & \text { México, hasta las faldas de la sierra Madre Oriental } \\ \text { R7c } & \text { (Huasteca). Se estudian los movimientos migratorios } \\ 1945 & \text { de los huastecos, su idioma como vehículo de la cultura huasteca } \\ \text { de lo hula } & \\ \text { y su importancia como antecedente de otros idiomas (maya). Asi- } \\ \text { mismo, el autor se ocupa en esta obra de la implantación y desa- } \\ \text { rrollo de la cultura "olmeca" ("huaxteca") desde Tamoanchán a } \\ \text { Centroamérica. }\end{array}$

BCC Tapia Zenteno, Carlos de, Paradigma Apologético y BP Noticia de la Lengua Huasteca, Estudio bibliográfico Ms $497.45 \quad y$ notas de Rafael Montejano y Aguiñaga, México, T21p - UNAM, Edición de René Acuña, 1985, 61, 169, 128, 1985 63-73, p.

Este volumen contiene vocabulario, catecismo y administración de sacramentos y dos versiones de la misma Noticia de la Lengua Huasteca, de las cuales una se quedó inédita y la otra se publicó en 1767. Incluye también el Paradigma Apologético que es una descripción de la Huasteca, y al principio, un valiosísimo estudio bibliográfico en el que se describen y evalúan los esfuerzos o trabajos de los lingüistas anteriores a Tapia Zenteno. Finalmente, se presenta un índice analítico y una casi exhaustiva bibliografía lingüistica huasteca.

\section{Historiografia} riador y crítico del arte, México, Ediciones de la Aca- 


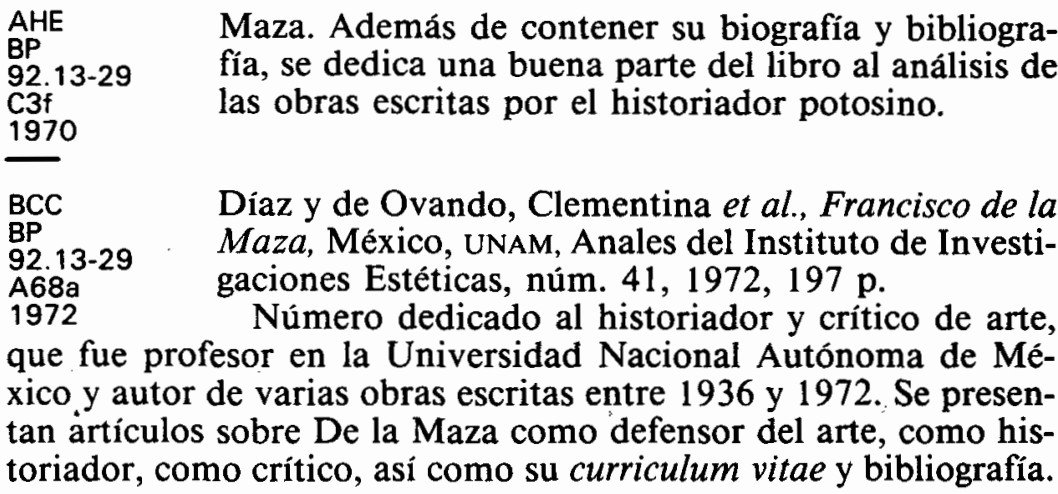

BCC Meade, Joaquin, Datos biográficos del Lic. D. Primo

RAg Feliciano Velázquez, México, Academia Mexicana de

M3d

1954

BCUASLP

BP*

92.22-38

M3d

1954

la Historia, 1954, 55 p.

Biobibliografía del historiador potosino, autor de la Historia de San Luis Potosi en cuatro volúmenes publicada entre 1946 y 1948, que fundó, con Francisco de P. Cossío, la publicación semanal La Voz de San Luis, y el periódico El Estandarte (1885) opuesto al gobierno del Estado.

BCC Meade de Angulo; Mercedes, Don Joaquin Meade BP

A26b

1969

14

(1896-1970), San Luis Potosî, Academia de Historia Potosina, 1972, $47 \mathrm{p}$.

Escrito por su hija, este opúsculo es una síntesis biográfica de quien fue un notable historiador de la vida potosina $y$, sobre todo, de la correspondiente a la región huasteca. AHE Meade de Angulo, Mercedes, Joaquín Meade, su vida

92.13-7

M13j y su obra, San Luis Potosí, s.p.i., 1980, 79 h. 1980 una de las primeras figuras de la historiografía poto-

Estudio genealógico, biografía y bibliografía de sina. La autora, su hija, se basa en fuentes familiares y de segunda mano. Meade pasó cerca de treinta años realizando investigaciones sobre historia y arqueología en el Archivo General de la Nación; fue miembro de la Academia Mexicana de la Historia, de la Sociedad Mexicana de Geografia y Estadística, de la Academia de Genealogía y Heráldica "Mota Padilla" de Guadalajara, de la Sociedad Potosina de Estudios Históricos, de la Academia de Historia Potosina y de otras más.

$\begin{array}{ll}\text { BCC } & \text { Montejano y Aguiñaga, Rafael, Elogio in memoriam } \\ \text { RAG } & \text { del Sr. Lic. D. Primo Feliciano Velázquez, San Luis } \\ 92.22-38 & \text { Potosi, Taller Linotipográfico "Evolución", 1966, } \\ \text { M8e } & \text { 11 p. } \\ 1966 & \text { Pronunciado en la traslación de los restos de este } \\ \text { BCUASLP } & \text { ilustre potosino a la catedral de San Luis Potosí. El } \\ \text { BP* } & \text { escritor, originario de Santa María del Rio, S.L.P., se } \\ 92.22-38 & \text { distinguió como abogado, periodista, luchó contra el } \\ \text { M8e } & \text { cacicazgo diezgutierrista, como diputado maderista, } \\ 1966 & \text { caciono mo }\end{array}$ humanista y traductor de los clásicos. Fue ante todo un acucioso historiador. 
BCC Montejano y Aguiñaga, Rafael, La historiografia poBP 008 tosina, San Luis Potosi, Academia de Historia Poto-

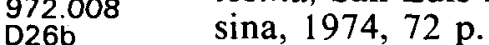

1969

35

Análisis exhaustivo de los principales historiadores potosinos y de su obra. Trabajo de ingreso como

BCOLMEX

907.2

M775h miembro de número a la Academia Mexicana de la Historia correspondiente de la Real de Madrid.

BCC
BP
972.008
A26b
1969
39

Montejano y Aguiñaga, Rafael, El historiógrafo $D$. Manuel Muro 1838-1911, semblanza biobibliográfica, San Luis Potosi, Academia de Historia Potosina, 1976, 45 p.

Estudio crítico y exhaustivo del político e historiógrafo potosino Manuel Muro.

BCC Montejano y Aguiñaga, Rafael, El humanismo de BP 13-11 Francisco de la Maza, sobretiro de Retablo Barroco a M8h la memoria de Francisco de la Maza, 343-349 p., 1974 láms.

Contiene algunas notas sobre el humanismo potosino de los siglos XVI al XIX; sobre el ambiente que vivió De la Maza (1913-1972), en la primera mitad de este siglo; sobre su vocación humanista y su profesión de historiador y crítico de arte, especialmente del colonial. Se incluyen fotografias del templo de San Agustín, joya del arte potosino. $\begin{array}{ll}\text { BCC } & \text { Montejano y Aguiñaga, Rafael et al., Ramón Alcorta } \\ \text { BP } & \text { Guerrero 1910-1970 in memoriam, San Luis Potosí, } \\ 972.008 & \text { Academia de Historia Potosina, 1970, 24 p. (Biblio- } \\ \text { A26b } & \text { teca de Historia Potosina, serie cuadernos 6). } \\ 1969 & \text { Semblanza, bibliografía y curriculum vitae del po- } \\ 6 & \\ \text { tosino que fue geógrafo de profesión, historiador y bibliógrafo por } \\ \text { afición, y catedrático e investigador en la UNAM, así como funda- } \\ \text { dor de la Facultad de Humanidades de la Universidad Autónoma } \\ \text { de San Luis Potosí en 1955. }\end{array}$

\begin{tabular}{|c|c|}
\hline $\begin{array}{l}\text { BCC } \\
\text { BP } \\
972.008 \\
\text { A26b } \\
1969 \\
12\end{array}$ & $\begin{array}{l}\text { Pedraza, José Francisco, Nereo Rodriguez Barragán } \\
\text { y su obra, San Luis Potosí, Academia de Historia Po- } \\
\text { tosina, } 1971,9 \text { p. (Biblioteca de Historia Potosina, } \\
\text { serie cuadernos 12). } \\
\text { Discurso pronunciado por el autor en la velada li- }\end{array}$ \\
\hline \multicolumn{2}{|c|}{$\begin{array}{l}\text { terario-musical organizada por la Academia Potosina de Ciencias } \\
\text { y Artes en la que el gobernador del estado entregó medallas de oro } \\
\text { al Mérito en la Cultura a los historiadores potosinos Nereo Rodrí- } \\
\text { guez Barragán y Francisco de la Maza. Se incluyen comentarios a } \\
\text { las obras publicadas por Rodríguez Barragán. }\end{array}$} \\
\hline $\begin{array}{l}\text { BCC } \\
\text { RAG } \\
92.13-96 \\
\text { R7r } \\
1965\end{array}$ & $\begin{array}{l}\text { Rodriguez Barragán, Nereo, Rasgos biográficos del } \\
\text { historiador potosino Don Manuel Muro, San Luis Po- } \\
\text { tosi, UASLP, } 1965,33 \text { p., ils. (Letras Potosinas núm. } \\
154 \text {, separata). }\end{array}$ \\
\hline & $\begin{array}{l}\text { Biobibliografia del historiador potosino nacid } \\
1839 \text { en la capital del estado. Muro fungió com } \\
\text { bernador constitucional sustituto entre } 1873 \text { y }\end{array}$ \\
\hline
\end{tabular}


Autor de la Historia de San Luis Potosi publicada en 1910 en tres tomos.

\section{Bibliografias y hemerografias}

A Ramón Alcorta Guerrero como a José Francisco Pedraza, Joaquín Meade y Rafael Montejano y Aguiñaga, corresponde el gran mérito de haber facilitado y de seguir facilitando la consulta que los estudiosos de la historia regional han hecho y hacen de los innumerables documentos y trabajos consignados en sus bibliografías y hemerografías. Rafael Montejano y Aguiñaga, finalmente, ha sido no sólo un investigador denodado, sino el bibliógrafo incansable que ha organizado, para beneficio de la investigación histórica regional, las tres colecciones de Bibliografía Potosina que existen en el estado, así como el vastísimo acervo documental del Archivo Histórico Potosino, que siguen todavía a la espera de quien decida aprovechar sus excelencias.

\begin{tabular}{|c|c|}
\hline $\begin{array}{l}B C C \\
B P \\
972.008 \\
A 26 b \\
1969 \\
27\end{array}$ & $\begin{array}{l}\text { Alcocer Andalón, Alberto, El Dr. Miguel Otero y Arce } \\
\text { (1854-1915), bibliografia, San Luis Potosí, Academia } \\
\text { de Historia Potosina, 1973, } 24 \text { p. } \\
\text { Nacido en la ciudad de México en } 1850 \text {, hijo de } \\
\text { Mariano Otero, Miguel Otero y Arce fue un desta- }\end{array}$ \\
\hline $\begin{array}{l}\text { AHE } \\
B P \\
O 08 \\
A 3 b \\
1969 \\
427\end{array}$ & $\begin{array}{l}\text { cado médico que desarrolló en San Luis Potosí lo } \\
\text { mejor de su obra y en donde se convirtió en un inno- } \\
\text { vador de la medicina de su tiempo. Murió en su lu- } \\
\text { gar de origen en } 1915 \text {, contagiado de tifo cuando in- } \\
\text { tentaba combatirlo. }\end{array}$ \\
\hline & \\
\hline
\end{tabular}

BCC Alcorta Guerrero, Ramón y José Francisco Pedraza, $\mathrm{BP}$

015.913

A65b Bibliografía Histórica y Geográfica del Estado de 1941 San Luis Potosi, México, Instituto Panamericano de Geografía y Estadística, publicación núm. 60, 1941, $655 \mathrm{p}$.

COLMEX

016.9724

A354b

Contiene 1321 fichas bibliográficas referentes a la historia y geografía de San Luis Potosí. Los autores pretenden en esta obra "presentar un índice de la cultura potosina". La Bibliografí... formó parte de un programa que incluia otras secciones: a) Derecho y Legislación del Estado, b) Literatura general, c) Ciencias, d) Cartografía del Estado, e) Periódicos y revistas, $f$ ) Volantes y Hojas sueltas, g) Manuscritos y documentos inéditos (Guía de Archivos), y h) Apéndices. Se incluyen materiales especialmente relacionados con la historia y geografia locales. Sin embargo, como señalan los autores, no todos los materiales son de la misma importancia respecto a la historia y la geografía del estado, y esta desproporción resalta todavía más para los que, en cierto modo, no están familiarizados con asuntos potosinos.

Se presentan también impresos que sin ser precisamente obras de historia y geografía sirven para constituirlas, tales como sermones, alegatos, informes sobre educación, minas y empresas comerciales. Esta obra constituyó el primer intento serio de recopilación de la bibliografía potosina pues anteriormente sólo existía la "Bi- 
bliografía Científica Potosina" del Lic. Primo F. Velázquez (1899), presentada ante la Junta Local de Bibliografía (S.L.P.).

BCC Alcorta Guerrero, Ramón, Bibliografia de D. Manuel RAG María de Gorriño y Arduengo, primer rector del Cole-

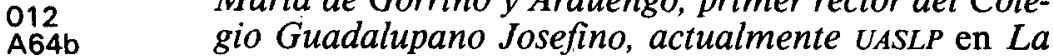
$1941 V o z$ Guadalupana, México, enero de 1941, Año VII, núm. 10, 9-10 p.

Don Manuel María de Gorriño y Arduengo (1767-1830), originario de San Luis Potosí, fue uno de los principales representantes del humanismo potosino como filósofo, escritor y orador. En este artículo se ofrece una semblanza y las referencias bibliográficas de sus obras, y se hace mención de aquéllas que dejó inéditas, así como de los autores que han escrito sobre el filósofo.

BCC Alcorta Guerrero Ramón, Documentos para la histo-

RAG

92.3-25

A64d

1956 ria de la bibliografia en San Luis Potosi. El Dr. Don Francisco de Asís Castro (1860-1933), precursor de la

BNAL

B En este folleto se transcribe el artículo publicado 010.8 por el Dr. Francisco de Asís Castro en el periódico MIS.8 potosino El Correo de San Luis, el 23 de agosto de 1891, titulado "Bibliografía Potosina". Para complementar o perfeccionar este trabajo, de quien es considerado como el iniciador de los estudios bibliográficos potosinos, se incluyen aquí algunas notas que identifican mejor la mayor parte de las obras que en aquél se mencionan, añadiendo también reproducciones en facsímil de algunas portadas de impresos raros y, en especial, de las correspondientes a las obras de Manuel Josê Othón.

BCC Alcorta Guerrero, Ramón y José Francisco Pedraza, RAG

015

A65b

1947

BCOLMEX 016.9724 A354b Primeras Adiciones a la Bibliografía Histórica y Geográfica del Estado de San Luis Potosi, México, s.e., 1947, $91 \mathrm{p}$.

Obra publicada con el objeto de "aminorar las deficiencias" que se proyectaban en su Bibliografia Histórica y Geográfica del Estado de San Luis Potosí.

Se publican 150 fichas más, ordenadas en forma progresiva, continuándose la numeración iniciada en la obra anterior, y conservando las mismas caracteristicas de redacción y presentación.

$\mathrm{BCC}$

$\mathrm{BP}$

972.008

A26b

1969

502

BCOLMEX 016.9724 A3543s

BCC

RAG

050

CH47i

1950
Alcorta Guerrero, Ramón, Segundas y Terceras Adiciones a la Bibliografía Histórica y Geográfica del Estado de San Luis Potosi, Introd. de Rafael Montejano y Aguiñaga, San Luis Potosí, S. L. P., Academia de Historia Potosina, 1972, 106 p.

En 1950 Alcorta Guerrero concluyó las Segundas Adiciones... con un total de 104 títulos; las Terceras, en 1962, con un total de 215 títulos.

Chessal, Luis, Indice de la Revista de Cultura Letras Potosinas, años 1947-1958, San Luis Potosí, Talleres Gráficos de la Editorial Universitaria, 1959, 45 p.

Se publicó este índice con motivo del XVI aniversa- 
rio de la revista, y por el fin de su segunda época. Esta revista, de contenido artístico y cultural, ha recogido la obra de escritores potosinos y de otras partes del país.

BCC. Macías Valadez, Francisco Jr., Lic. Francisco Macias 972.008 Valadez 1833-1890. Bibliografía, notas de Rafael 972.008 1969 33 Montejano y Aguiñaga, San Luis Potosí, Academia de Historia Potosina, 1974, 16 p., (Biblioteca de Historia Potosina, serie cuadernos 33).

Semblanza y bibliografía de Macias Valadez, potosino, liberal, abogado, diputado en 1860 a la Legislatura del Estado y magistrado del Supremo Tribunal de Justicia. Como periodista, sostuvo el periódico El Liberal con sus propios recursos y con artículos políticos y literarios de combate; fue redactor del Periódico Oficial. Fungió como jefe político en el estado por poco tiempo, como secretario general de gobierno cuando Juárez se instaló en la capital potosina en 1867 , y como administrador principal de rentas. Una de sus obras más importantes es el "Cuadro Sinóptico sobre el Estado de San Luis Potosi”, publicado en 1867.

$\begin{array}{ll}\text { BCC } & \text { Meade, Joaquín, Hemerografia potosina. Historia del } \\ \mathrm{BP} & \text { periodismo en San Luis Potosi 1828-1956, San Luis } \\ 070 & \text { Potosi, bajo el ángulo de Letras Potosinas, 1956, } \\ \text { M3h } & 199 \text { p. }\end{array}$

BCUASLP Pionero en su género, este trabajo de Meade sería +015 retomado y complementado en 1978 por los historiaM3h dores locales Rafael Montejano y Aguiñaga, Alberto Alcocer y otros.

BCC
RAG
972.008
A26b
1969
3

Montejano y Aguiñaga, Rafael, Bibliografia de Don Ignacio Montes de Oca, San Luis Potosí, Academia de Historia Potosina, 1969, 51 p.

Descripción de los escritos del célebre obispo, orador y traductor de los clásicos, y de los artículos y libros referentes a él.

$\begin{array}{lc}\text { BCC } & \text { Montejano y Aguiñaga, Rafael, Bibliografia del Ilmo. } \\ \text { BP } & \text { Sr. Dr. D. Pedro Barajas, primer obispo de San Luis } \\ 012.222 & \text { Potosi, México, UNAM, núm. 4, julio-diciembre de } \\ \text { M8b } & \text { 1970, 289-297 p. (sobretiro del Boletín del Instituto } \\ 1970 & \text { de Investigaciones Bibliográficas). } \\ \text { BNAL } & \text { Don Pedro Barajas fue además periodista en su } \\ \text { 027.572 } & \text { natal Guadalajara, diputado por Jalisco en dos oca- } \\ \text { Bib.bis4 } & \text { y } \\ \text { siones y obispo de San Luis Potosi entre 1854 y } 1869 .\end{array}$

BCC Montejano y Aguiñaga, Rafael, Bibliografia del Sr. RAG Pbro. D. Ricardo B. Anaya, San Luis Potosí, Imp. M8b Evolución, 1946, 9 p.

1946 Contiene los títulos de los libros, folletos y artículos escritos por Anaya durante los 25 años de su sacerdocio, cuya celebración dio motivo a la publicación de esta bibliografía. Se incluyen también referencias de las conferencias, discursos y sermones pronunciados por el que entonces fuera asistente eclesiástico de la Acción Católica en San Luis Potosi. 
BCC Montejano y Aguiñaga, Rafael, Bibliografia de los $438 \mathrm{p}$. de elaboración de esta bibliografía.

$\begin{array}{ll}\text { BCC } & \text { Montejano y Aguiñaga, Rafael, IV Ciclo de dias médi- } \\ \text { RAG } & \text { cos; la. Exposición de bibliografía médica potosina, } \\ \text { O16.619 } & \text { San Luis Potosí, Talleres Gráficos de la Ed. Univer- } \\ \text { M8c } & \text { sitaria, 1950, 56 p. } \\ 1950 & \text { Descripción de los principales impresos, hojas vo- } \\ \text { BCUASLP } & \text { lantes, folletos, tesis, revistas, libros, etc., relaciona- } \\ \text { BP* } & \text { dos con la medicina potosina. }\end{array}$

M8c

1950

$\mathrm{BCC}$

RAG

012.1582

M8e

1959

Montejano y Aguiñaga, Rafael, Lo que escribió Manuel José Othón. Bibliografía esencial, San Luis Potosí, Universidad Autónoma, 1959, 46 p.

registra tanto la obra impresa como la inédita del poeta.

BCC Montejano y Aguinaga, Rafael, Manuscritos y Obras RAG de Manuel José Othón. V Exposición bibliogrâfica po-

OT

012

M8m

1956 tosina, San Luis Potosí, UASLP, 1956, 15 p.

Guía de la Exposición en la que se exhibió una ria Potosina y del Año Othoniano por la Biblioteca de la Universidad Autónoma de San Luis Potosí.

BNAL Montejano y Aguiñaga, Rafael, Notas de bibliografia B lingüistica huasteca y el paradigma apologético del MON.n $B r$. Tapia Centeno, San Luis Potosí, Universidad Autónoma, 1961, 66 p., ils.

Descripción y análisis de la producción lingüistica huasteca de los siglos XVI al XX, tanto inédita como publicada. Además se da a conocer la obra (inédita) del bachiller y lingüista Tapia Zenteno titulada "Paradigma Apologético".

$\begin{array}{ll}\text { BCC } & \text { Montejano y Aguiñaga, Rafael, Nueva Hemerografia } \\ \text { BP } & \text { Potosina, 1828-1978, México, UNAM, 1982, 373 p. } \\ \text { O25.173 } & \text { Descripción bibliográfica y analítica de las publi- } \\ \text { MBn } & \text { caciones periódicas aparecidas en el estado de San } \\ 1982 & \text { Luis Potosí en el periodo que se indica, y que apa- } \\ \text { AHE } & \text { rece como continuación de la Hemerografía Potosina } \\ \text { BP } & \text { de Meade, de 1956. }\end{array}$

Montejano y Aguiñaga, Rafael, Primera exposición de bibliografía juridica potosina presentada en la Facultad de Derecho, San Luis Potosi, Talleres Gráficos de la Ed. Universitaria, 1953, 183 p.

Catálogo descriptivo de los más importantes impresos y manuscritos de la jurisprudencia potosina. 


\begin{abstract}
BCC Montejano y Aguiñaga, Rafael, Primera exposición 015.913 bibliográfica potosina, 2-18 - VI - 1949, San Luis PoM8p tosí, Talleres Gráficos de la Editorial Universitaria, $1949 \quad 1949,48 \mathrm{p}$.

BCUASLP Catálogo descriptivo de la selección de impresos y BP*

015

M8p

1949 manuscritos referentes a la cultura potosina exhibidos en esa ocasión y provenientes de distintos propietarios.
\end{abstract}

BCC
$B P$
920
1978
6

Noyola, Juan Francisco et al., Ing. Don Valentín Gama y Cruz. Antologia Biobibliográfica, San Luis Potosi, Gobierno del Estado, 1978, 52 p., Potosinos Eméritos núm. 6.

Compilación de siete escritos que se refieren a la AHE BP

920

G7p

1974 6 vida y obra del ilustre matemático potosino, nacido en 1868 en la capital del estado y muerto en 1942 en la ciudad de México. Gama y Cruz fue miembro de numerosas sociedades científicas, catedrático, director del Observatorio Astronómico de Tacubaya en donde elaboró trabajos de investigación muy importantes para la ciencia universal, impulsor de los trabajos cartográficos en la República y encargado en 1920 del levantamiento de la Carta del Valle de México.

BCC Padilla Carreño, Gloria Yolanda, Bibliografia de JeBP 12.195 sús Silva Herzog, México, Edición-de Cuadernos P13b 1973 Americanos, 1973, $121 \mathrm{p}$.

Esta bibliografia se refiere a la vasta obra del potosino Jesús Silva Herzog, a partir de la época revolucionaria y durante este siglo $\mathrm{Xx}$. Está dividida de la siguiente manera: Ensayos, artículos y notas; Poemas; Discursos; Conferencias; En el Colegio Nacional; Entrevistas; Notas bibliográficas; y, Opiniones.

$\begin{array}{ll}\text { BCC } & \text { Pedraza, José Francisco, El Mexicano Libre Potosi- } \\ \text { BP } & \text { nense (primer periódico potosino) y la ciudad de San } \\ 972.008 & \text { Luis Potosi en 1828, San Luis Potosí, Academia de } \\ \text { A6b } & \text { Historia Potosina, 1978, 23 p. } \\ 1969 & \text { Monografia del primer periódico potosino, apare- } \\ 56 & \text { cido cuatro años después de constituirse el estado de } \\ \text { AHE } & \text { San Luis Potosí. } \\ \text { BP } & \\ \text { O08 } & \\ \text { A3b } & \\ 1969 & \\ 456 & \\ \text { BCC } & \text { Peñalosa, Joaquín Antonio, Indice del Humanismo } \\ \text { RAG } & \text { en San Luis Potosi, Sobretiro de Humanitas Monte- } \\ 864 & \text { rrey, N. L., Anuario del Centro de Estudios Huma- } \\ \text { P4i } & \\ 1965 & \text { nisticos de la Universidad de Nuevo León, núm. 6, } \\ \text { BNAL } & \text { 1965, 251-275. p. } \\ \text { 308 } & \text { Este folleto contiene una noticia sobre los princi- } \\ \text { MIS.249 } & \text { pales representantes del humanismo potosino de los } \\ \text { siglos XVI al XX. Además, incluye una bibliografía de estudios ge- } \\ \text { nerales escritos por potosinos, de estudios sobre humanistas poto- } \\ \text { sinos, de estudios sobre la Compañía de Jesús, sobre el Colegio } \\ \text { Guadalupano Josefino y sobre el Seminario Conciliar. }\end{array}$


$\begin{array}{ll}\text { BCC } & \text { Rodriguez Barragán, Nereo, Biografias potosinas, In- } \\ \text { BP } & \text { trod. biobibliográfica y notas de Rafael Montejano y } \\ 972.008 & \text { Aguiñaga, San Luis Potosi, Academia de Historia } \\ \text { A26b } & \text { Potosina, 1976, 294 p. } \\ 1969 & \text { Incluyendo semblanzas de personajes potosinos } \\ 615 & \text { del siglo pasado, en su mayoria, en este ameno y do- } \\ \text { BCOLMEX } & \text { cumentado libro se hacen esbozos biográficos de Ca- } \\ \text { R6961b } & \begin{array}{l}\text { lleja, Blas Escontria, Carlos Diez Gutiérrez, Manuel } \\ \text { José Othón y otros. }\end{array}\end{array}$

BCC Ruiz de Larrinaga, Juan y Rafael Montejano y Agui972.008 ñaga, P. Fr. José de Arlegui, rasgos bio-bibliográficos, A26 A26b 30 San Luis Potosí, Academia de Historia Potosina, 1974, 28 p., (Biblioteca de Historia Potosina, serie cuadernos 30 ).

Semblanza y bibliografía del Padre Arlegui, franciscano, eminente orador y cronista de la provincia de Zacatecas en el siglo XVIII, que ocupó un destacado lugar como provincial en San Luis Potosí. Arlegui nació hacia 1686 y murió en San Luis Potosí por el año de 1750.

\section{BIBLIOTECAS CONSULTADAS}

BCC BP: Biblioteca de la Casa de la Cultura. Bibliografia Potosina.

(S.L.P.)

BCC RAG: Biblioteca de la Casa de la Cultura. Ramón Alcorta Guerrero. (S.L.P.)

AHE BP: $\quad$ Archivo Histórico del Estado. Bibliografia Potosina. (S.L.P.)

BCUASLP BP: Biblioteca Central de la Universidad Autónoma de San Luis Potosí. (S.L.P.)

BFE UASLP: Biblioteca de la Facultad de Economia de la Universidad

Autónoma de San Luis Potosi. (S.L.P.)

BCOLMEX: Biblioteca de El Colegio de México (D. F.)

BINAH: Biblioteca del Instituto Nacional de Antropología e Historia (D. F.)

BNAL: $\quad$ Biblioteca Nacional (D. F.) 